\title{
Investigation of Pressurized Entrained-Flow Kraft Black Liquor Gasification in an Industrially Relevant Environment
}

\author{
Final Technical Report \\ Reporting Period Start Date: $\quad$ 09/30/2004 \\ Reporting Period End Date: $\quad$ 06/30/2007
}

\author{
Kevin Whitty \\ University of Utah \\ Issue Date: September 2007
}

DOE Cooperative Agreement DE-FC26-04NT42261
Prime (submitting) Organization: University of Utah
1471 East Federal Way
Salt Lake City, UT 84102
PI: Kevin Whitty

Project Subcontractors: Brigham Young University

A-261 ASB

Provo, UT 84602

PI's: Larry Baxter, Dale Tree

Simulent, Inc.

203 College Street, Suite 302

Toronto, ON M5T 1P9, Canada

$\mathrm{PI}$ : Nasser Ashgriz 


\section{DISCLAIMER}

This report was prepared as an account of work sponsored by an agency of the United States Government. Neither the United States Government nor any agency thereof, nor any of their employees, makes any warranty, express or implied, or assumes any legal liability or responsibility for the accuracy, completeness, or usefulness of any information, apparatus, product, or process disclosed, or represents that its use would not infringe privately owned rights. Reference herein to any specific commercial product, process, or service by trade name, trademark, manufacturer, or otherwise does not necessarily constitute or imply its endorsement, recommendation, or favoring by the United States Government or any agency thereof. The views and opinions of authors expressed herein do not necessarily state or reflect those of the United States Government or any agency thereof. 


\section{EXECUTIVE SUMMARY (ABSTRACT)}

The University of Utah's project "Investigation of Pressurized Entrained-Flow Kraft Black Liquor Gasification in an Industrially Relevant Environment" (U.S. DOE Cooperative Agreement DE-FC2604NT42261) was a response to U.S. DOE/NETL solicitation DE-PS36-04GO94002, "Biomass Research and Development Initiative" Topical Area 4 - Kraft Black Liquor Gasification. The project began September 30, 2004. The objective of the project was to improve the understanding of black liquor conversion in high pressure, high temperature reactors that gasify liquor through partial oxidation with either air or oxygen. The physical and chemical characteristics of both the gas and condensed phase were to be studied over the entire range of liquor conversion, and the rates and mechanisms of processes responsible for converting the liquor to its final smelt and syngas products were to be investigated. This would be accomplished by combining fundamental, lab-scale experiments with measurements taken using a new semi-pilot scale pressurized entrained-flow gasifier.

As a result of insufficient availability of funds and changes in priority within the Office of Biomass Programs of the U.S. Department of Energy, the research program was terminated in its second year. In total, only half of the budgeted funding was made available for the program, and most of this was used during the first year for construction of the experimental systems to be used in the program. This had a severe impact on the program. As a consequence, most of the planned research was unable to be performed. Only studies that relied on computational modeling or existing experimental facilities started early enough to deliver useful results by the time to program was terminated.

Over the course of the program, small scale (approx. 1 ton/day) entrained-flow gasifier was designed and installed at the University of Utah's off-campus Industrial Combustion and Gasification Research Facility. The system is designed to operate at pressures as high as 32 atmospheres, and at temperatures as high as $1500^{\circ} \mathrm{C}\left(2730^{\circ} \mathrm{F}\right)$. Total black liquor processing capacity under pressurized, oxygen-blown conditions should be in excess of 1 ton black liquor solids per day. Many sampling ports along the conversion section of the system will allow detailed analysis of the environment in the gasifier under industriallyrepresentative conditions. Construction was mostly completed before the program was terminated, but resources were insufficient to operate the system.

A system for characterizing black liquor sprays in hot environments was designed and constructed. Silhouettes of black liquor sprays formed by injection of black liquor through a twin fluid (liquor and atomizing air) nozzle were videoed with a high-speed camera, and the resulting images were analyzed to identify overall characteristics of the spray and droplet formation mechanisms. The efficiency of liquor atomization was better when the liquor was injected through the center channel of the nozzle, with atomizing air being introduced in the annulus around the center channel, than when the liquor and air feed channels were reversed. Atomizing efficiency and spray angle increased with atomizing air pressure up to a point, beyond which additional atomizing air pressure had little effect. Analysis of the spray patterns indicates that two classifications of droplets are present, a finely dispersed "mist" of very small droplets and much larger ligaments of liquor that form at the injector tip and form one or more relatively large droplets. This ligament and subsequent large droplet formation suggests that it will be challenging to obtain a narrow distribution of droplet sizes when using an injector of this design.

A model for simulating liquor spray and droplet formation was developed by Simulent, Inc. of Tornoto. The model was able to predict performance when spraying water that closely matched the vendor specifications. Simulation of liquor spray indicates that droplets on the order 200-300 microns can be expected, and that higher liquor flow will result in better distribution of liquor in the reactor. 


\section{TABLE OF CONTENTS}

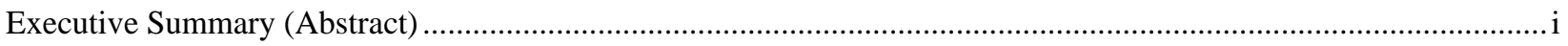

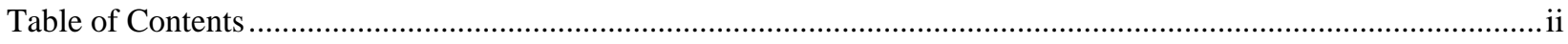

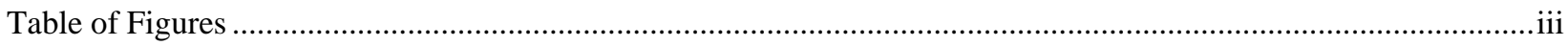

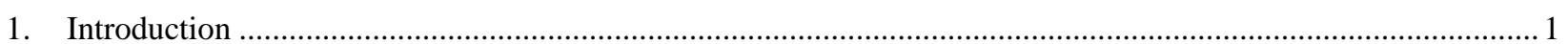

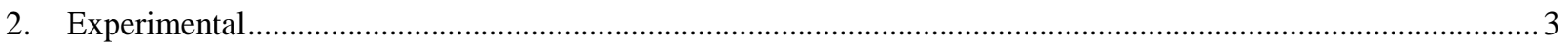

$2.1 \quad$ Entrained-Flow Gasifier.................................................................................................................

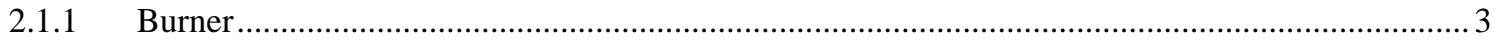

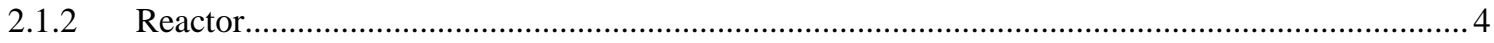

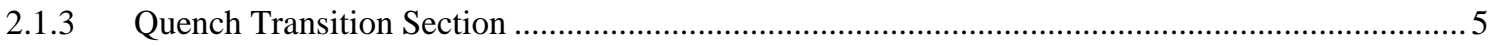

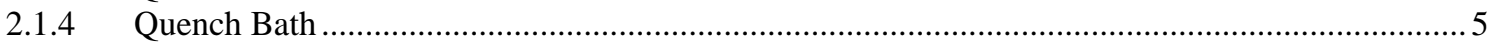

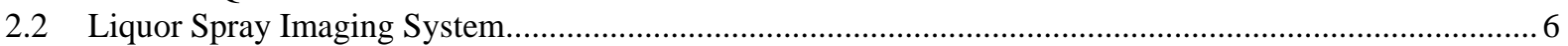

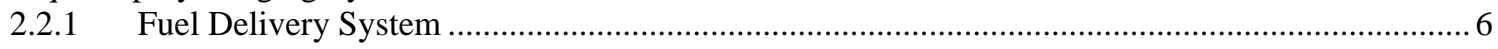

2.2.2 Backlit Imaging System........................................................................................................... 7

2.2.3 Heated Spray Chamber ....................................................................................................... 8

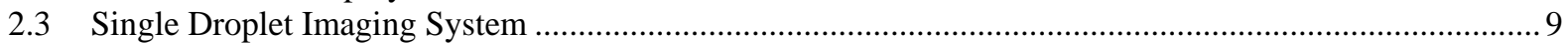

2.4 Smelt Radiative Properties Measurement System...................................................................................... 10

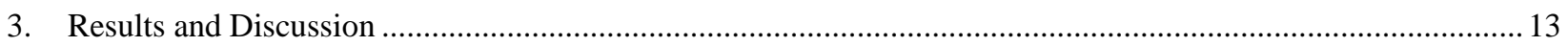

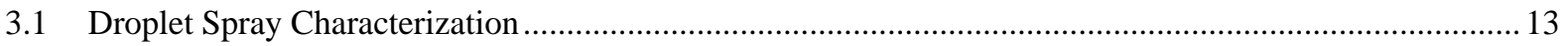

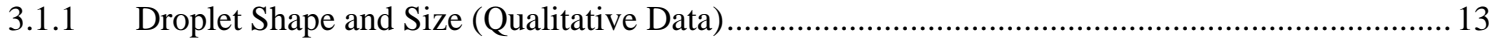

3.1.2 Spray Shape ............................................................................................................................. 15

3.1.3 Approximate Radial Mass Distribution in the Spray ……..........................................................17

3.1.4 Development of Ligaments into Droplets.................................................................................. 18

3.1.5 Comparison of Black Liquor and Water Sprays ............................................................................... 20

3.1.6 Comparison of Liquor Sprays in Hot and Cold Surroundings.......................................................2 24

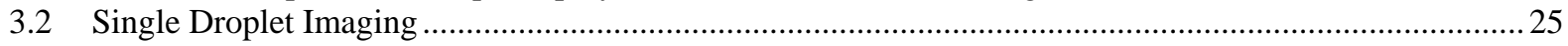

3.3 Computational Modeling of Black Liquor Spray Formation ....................................................................2 26

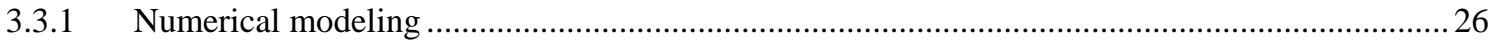

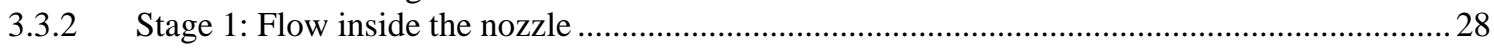

3.3.3 Stage 2: Spray modeling at the exit of nozzle ............................................................................... 36

3.3.4 Stage 3: Estimating the Droplet size at the exit of nozzle ......................................................... 40

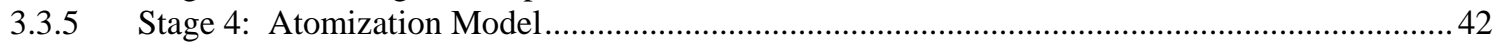

3.3.6 Experimental study of Fulljet nozzle ........................................................................................... 45

3.3.7 Comparison of the developed code by Simulent with the experimental data ................................ 50

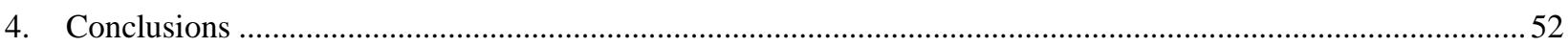

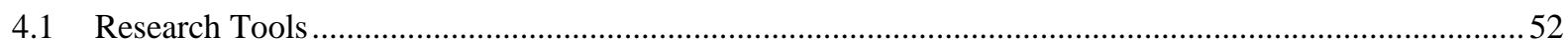

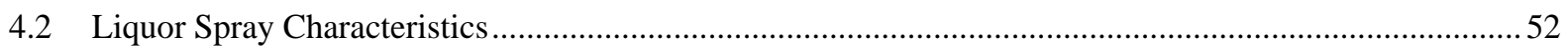

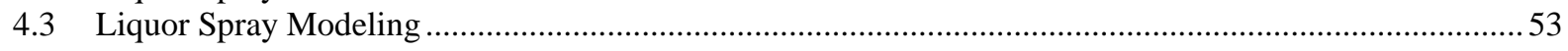

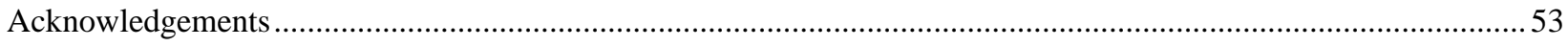

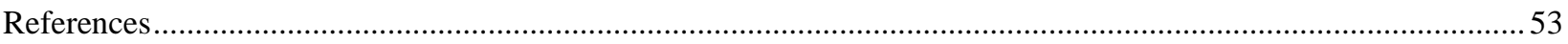




\section{TABLE OF FIGURES}

Figure 1. Rendering of the entrained-flow gasifier and split view of same.............................................................. 4

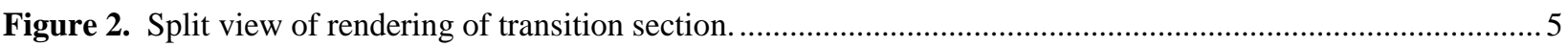

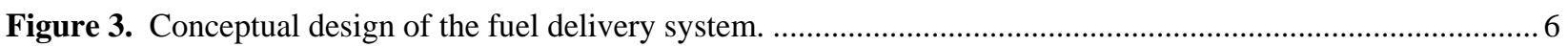

Figure 4. Cutaway view of an internal mix, air atomizing nozzle. (Source: Spraying Systems Co.).......................... 7

Figure 5. Experimental setup for backlit images of the liquid spray.................................................................. 7

Figure 6. Diagram of the electrically heated spray chamber. Multiple chambers may be stacked to form an entrained

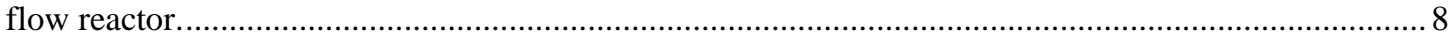

Figure 7. View of the fuel delivery system at the pressure side of the pump........................................................ 9

Figure 8. Liquor feed system installed above the heated reactor. .....................................................................

Figure 9. Single droplet generator head. Overall diameter ca. 0.7 inch. ...................................................................10

Figure 10. Schematic diagrams of measurement systems for viscosity and emissivity. .......................................... 11

Figure 11. Furnace used for smelt properties testing............................................................................................ 11

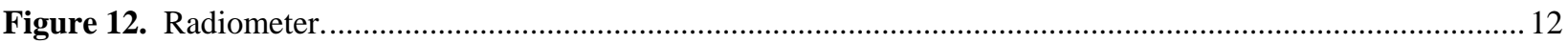

Figure 13. A sample image of a water spray taken at $16 \mu$ s exposure. Nozzle conditions: $5 \mathrm{~kg} / \mathrm{hr}$ water, $0.95 \mathrm{~kg} / \mathrm{hr}$ air at 18 psig.

Figure 14. Cutaway view of the steam-atomized New Bern gasifier nozzle. (Source: Weyerhaeuser, fluid labels added)

Figure 15. A sample image of a water spray taken at $16 \mu$ s exposure with the fluid and air connections reversed. Nozzle conditions: $5 \mathrm{~kg} / \mathrm{hr}$ water, $0.44 \mathrm{~kg} / \mathrm{hr}$ air at $40 \mathrm{psig}$.

Figure 16. The independence of spray shape and mass distribution on atomizing air pressure is demonstrated by results of backlight extinction analysis of the water spray images. Data for a single liquid mass flow rate (5 kg/hr) over a wide range of atomizing air pressures (22-58 psig and selected lower pressures) $2 \mathrm{~mm}$ downstream from nozzle is shown.

Figure 17. The edges of the spray (indicated by the dashed lines) are found by locating the departure of the smoothed derivative of extinction data from the neighborhood around zero.

Figure 18. Relative spray density calculated from backlight extinction data for the maximum liquid flow rate $(5 \mathrm{~kg} / \mathrm{hr})$.

Figure 19. A sequence of images taken at 17900 fps showing the development of ligaments into smaller structures.

Figure 20. Comparison of water and black liquor sprays in the membrane breakup regime. Water (left): $\mathrm{Re}_{\mathrm{L}}=1982$, $\mathrm{We}=49$; Black Liquor (right): $\mathrm{Re}_{\mathrm{L}}=17$, We $=242$.

Figure 21. Comparison of water and black liquor sprays $15 \mathrm{~mm}$ downstream from nozzle. (Water: $\mathrm{Re}_{\mathrm{L}}=1982$, We=49; Black Liquor: $\operatorname{Re}_{\mathrm{L}}=17$, $\mathrm{We}=242$ ).

Figure 22. Comparison of water (left) and black liquor (right) droplet asphericity as a function of droplet size. ....22

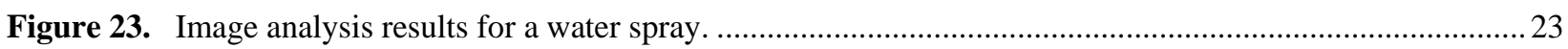

Figure 24. Image analysis results for a black liquor spray.

Figure 25. Summary of results of image analysis on black liquor sprays in hot and cold chambers. The Student's ttest results show that the claim that the hot environment produced larger droplets is statistically significant. 
Figure 26. Tip of the prototype droplet injector and resulting droplet stream.........................................................26

Figure 27. The Full Jet 1/8G3 nozzle. (Spraying System Co.)............................................................................27

Figure 28. The CAD design of the nozzle, shown in Figure 27 ……................................................................

Figure 29. Schematic presentation of the simulations steps for modeling the atomization.......................................28

Figure 30. Simulation domain, flow boundary location, and mesh generated for simulating the flow inside the

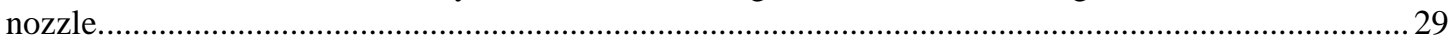

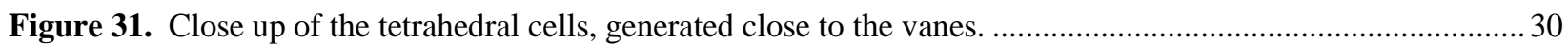

Figure 32. Pressure contours inside the nozzle at two different flow rates. The unit for pressure is Pascal............... 31

Figure 33. Velocity contours and velocity vectors of liquid at a cross section of nozzle, at the middle of the nozzle.

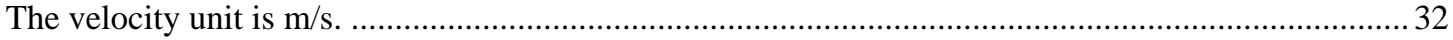

Figure 34. Flow stream lines inside the nozzle, colored based on the velocity magnitude .........................................33

Figure 35. Velocity vectors at 4 different cross sections of the nozzle, along the axis............................................... 34

Figure 36. Velocity vectors at the cross section used as the inlet boundary for stage two of simulations..................35

Figure 37. Average values of the axial, radial, and tangential components of the velocity at the exit of the nozzle. 35

Figure 38. Schematic of the 2-D axi-symmetric simulation domain for stage two..................................................37

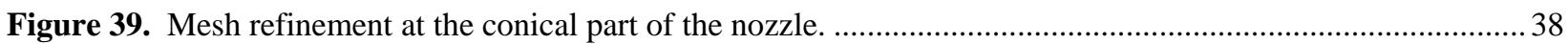

Figure 40. Snapshots of the 2D modeling of the flow at the exit of nozzle for flow rate of 2 liters/min. Time interval between snapshots is $10 \mathrm{~ms}$. The horizontal lines indicate the location of the nozzle tip.

Figure 41. Snapshots of the 2D modeling of the flow at the exit of nozzle for flow rate of 3 liters/min. Time interval between snapshots is $10 \mathrm{~ms}$. The horizontal lines indicate the location of the nozzle tip........................ 40

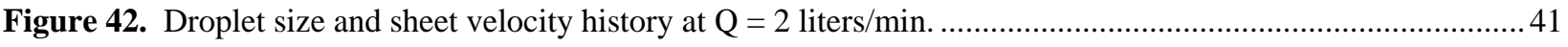

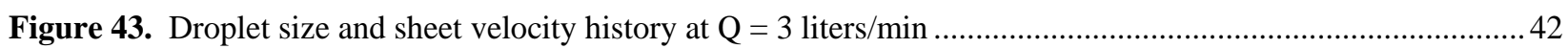

Figure 44. Droplet size distribution at $10 \mathrm{~cm}$ below the nozzle, simulation results. Flow rate is 2 liters/min. ...........43

Figure 45. Velocity histogram at $10 \mathrm{Cm}$ below the nozzle, simulation results. Flow rate is 2 liters/min. ................ 44

Figure 46. A snap shot of the simulation results for spray distribution and spray angle outside the nozzle. Colors represent the size of each particle, blue being smaller size and yellow larger sizes. ............................... 45

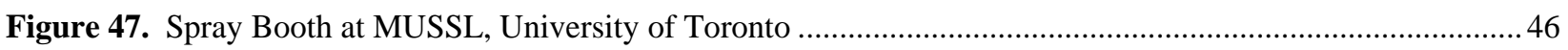

Figure 48. PDPA system (top) and measurement process (below) ........................................................................ 46

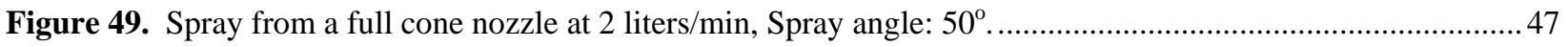

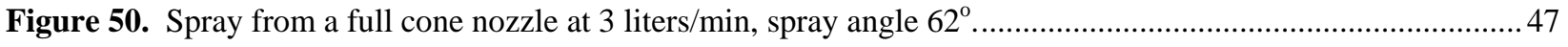

Figure 51. Typical measured information for spray, at 10 centimeter below the nozzle, for flow rate of 2 liters/min

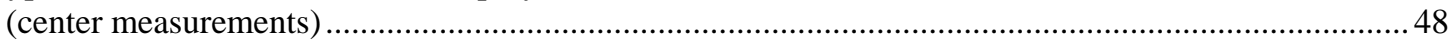

Figure 52. Typical measured information for spray, at 10 centimeter below the nozzle, for flow rate of 3 liters/min (center measurements).

Figure 53. Typical measured information for spray, at 10 centimeter below the nozzle, for flow rate of 3 liters/min (edge measurements) 


\section{Investigation of Pressurized Entrained-Flow Kraft Black Liquor Gasification in an Industrially Relevant Environment}

\section{INTRODUCTION}

Black liquor gasification has been identified as a promising alternative to the conventional black liquor processing technology; namely, the recovery boiler. In addition to improvements in environmental performance and safety, a black liquor gasification system has the potential to double the electrical output from a mill while maintaining steam output. Alternately, a gasification system can be used to produce syngas that can be catalytically converted to biofuels (e.g., dimethyl ether or Fischer-Tropsch fuels).

Entrained-flow black liquor gasification is one of the most developed approaches, and shows promise of becoming a commercial success. Two development lines are being pursued, an atmospheric pressure, airblown "booster" version aimed at providing incremental black liquor processing capacity for a mill and more advanced pressurized, oxygen blown version intended to be a replacement technology for recovery boilers.

The University of Utah's project entitled "Investigation of Pressurized Entrained-Flow Kraft Black Liquor Gasification in an Industrially Relevant Environment" (DOE Cooperative Agreement DE-FC2604NT42261) was developed in response to a joint U.S. Department of Energy and Department of Agriculture solicitation released in December 2003, addressing research, development, and demonstration of biomass based products, bioenergy, biofuels, biopower, and related processes. The particular technical area addressed by this project was "Thermochemical conversion - Kraft black liquor gasification."

The overall goal of this project was to acquire data to support commercialization of entrained-flow black liquor gasification through a combination of laboratory-scale experiments and operation of a small-scale gasifier operating under conditions representative of those in a commercial system. The project focused on the gasifier reactor itself, and took into consideration the entire range of conversion. The project had the following four technical objectives: (1) to characterize black liquor droplet formation in a pressurized, high temperature environment, (2) to generate data on the chemical and physical aspects of black liquor conversion, (3) to characterize major and minor components in the synthesis gas, and (4) to develop tools useful for design, optimization and troubleshooting of entrained-flow back liquor gasifiers. The project aimed to achieve these goals through the following technical tasks:

1. Design and construction of an entrained-flow gasifier

2. Evaluation of droplet formation and burner performance

2.1 Spray and droplet formation characterization

2.2 Computational modeling of black liquor droplet formation

2.3 Computational model validation

3. Detailed analysis of black liquor conversion

3.1 Physical characterization of black liquor during conversion

3.2 Chemistry of black liquor conversion

4. Transport and radiative properties of black liquor smelt

5. Characterization of synthesis gas from a black liquor gasifier. 
The project included two subcontracts to groups that possess expertise in technical areas relevant to the project. These subcontractors and their corresponding roles within the project were:

1. Brigham Young University (Prof. Larry Baxter): Liquor injector spray characterization

2. Simulent, Inc. (Dr. Nasser Ashgriz): Computational modeling of black liquor droplet formation

In addition to these official project members, the University of Utah received technical input from Chemrec, developers of entrained-flow black liquor gasification technology, and Weyerhaeuser Corporation.

Due to limited funding availability and a shift in research priorities within the Office of Biomass Programs of the U.S. Department of Energy, this program was terminated in its second year. Overall, only half of the scheduled funding became available, and much of this had been spent in the first year constructing a gasifier described in this report. This seriously impacted the success of the program. This report describes the technical achievements of the project, describes the experimental equipment and computational models developed under this project and presents results and conclusions of the work. 


\section{EXPERIMENTAL}

Several experimental devices, ranging from lab-scale systems focusing on individual liquor droplets to semi-pilot scale systems, were constructed for this project. These are described in the following sections.

\subsection{Entrained-Flow Gasifier}

A new pressurized, oxygen-blown entrained-flow gasifier for black liquor was designed and built under this project. This reactor was designed to reproduce conditions in a full-scale system, and to produce a syngas representative of that produced by a full-scale system. The entrained-flow gasifier was installed into the University of Utah's existing gasification research facility at it's off-campus Industrial Combustion and Gasification Research Facility. This facility already had the infrastructure and many of the necessary sub-systems, such as the black liquor storage and feed system, syngas handling and combustion system, cooling water system and control system backbone.

The entrained-flow gasification system was designed with flexibility in mind. The base design is for operation at $12 \mathrm{~atm}, 1000^{\circ} \mathrm{C}\left(1830^{\circ} \mathrm{F}\right)$, processing 1 ton/day of kraft black liquor solids in pressurized, oxygen-blown mode. The pressure vessel shell is rated to $450 \mathrm{psig}$ (32 atm total pressure), and the materials used will allow operation at temperatures as high as $1500^{\circ} \mathrm{C}\left(2730^{\circ} \mathrm{F}\right)$. Independent air and oxygen lines join together to feed the burner, which allows the oxygen concentration to be adjusted from $21 \%$ to $95 \%$ (or whatever the purity of the oxygen used). In theory, it should be possible to operate the gasifier as an air-blown, low pressure system representative of Chemrec's booster gasifier, although cofiring of natural gas may be necessary to maintain heat load.

A rendering of the entrained-flow gasifier is presented in Figure 1. The gasifier comprises four different sections, which are described below.

\subsubsection{Burner}

The burner for the gasifier is a combination burner capable of simultaneously burning black liquor and natural gas. The burner comprises three concentric channels. The innermost channel is the liquor channel. An off-the-shelf burner tip (injection nozzle) from a nozzle supplier (e.g. Bete Nozzles or Spraying Systems) is installed at the bottom of this channel, and dictates the spray pattern of the liquor. A full cone spray, in which the liquor is evenly distributed, may be used. Alternately, a hollow cone spray nozzle can be installed, which will feed the liquor in a ring, with few or no droplets in the middle. Different spray angles can be chosen, as well. If, for instance, the testing focuses on liquor behavior as it contacts the walls of the gasifier, a wide angle hollow cone nozzle can be used.

The second channel is for natural gas. The reactor will be heated using natural gas, and will be kept on hot standby during weekends and at night using natural gas. If necessary, it will be possible to co-fire natural gas with the black liquor to maintain the flame and provide the heat required for the reactions. This may be necessary when running low liquor loads (required at low pressure) or when running low solids liquor.

The outer channel is for the oxidant, air, oxygen or a mixture of the two. A swirl ring can be installed at the exit from this channel to provide some swirl for the oxidant. This swirl cannot be adjusted, although different rings with different degrees of swirl can be installed if the burner is removed. 
The whole burner assembly is mounted inside a sleeve that fits into a nozzle in the "lid" of the gasifier. Refractory cast around this sleeve fills the gap between the outer pipe of the burner and the inside of the burner nozzle. A small air purge around this refractory provides a bit of cooling and keeps the narrow channel between the sleeve and nozzle clean. It is possible that the high temperatures and environment in the near-burner region will lead to unacceptable corrosion and burner refractory wear in this section. If this is the case, a new water-cooled burner housing can be built and installed.

Two ultraviolet sensing "peepers" are installed in angled nozzles in the lid of the gasifier and aim towards the region downstream of the burner. These peepers indicate whether or not the gasifier has a flame.
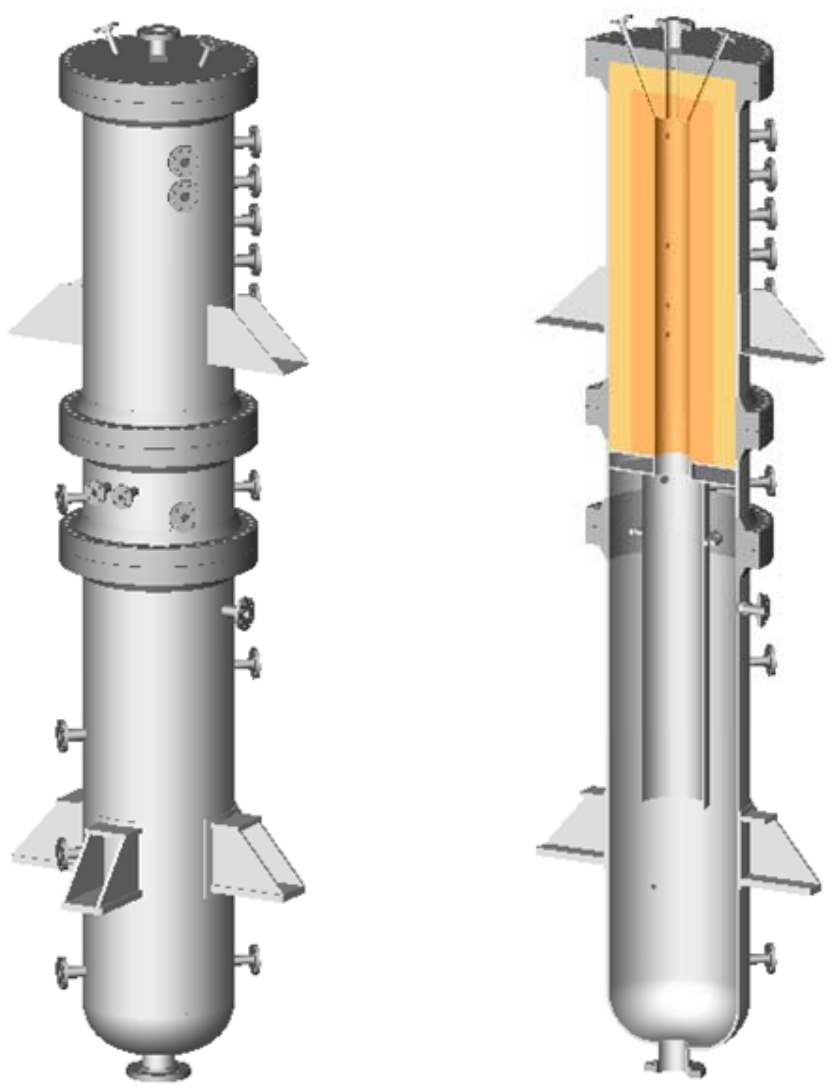

Figure 1. Rendering of the entrained-flow gasifier and split view of same.

\subsubsection{Reactor}

The gasifier reactor is the heart of the system, and is where the gasification reactions take place. The reactor vessel is 30 inches OD, lined with two layers of refractory to create a reactor chamber that is 8 inches diameter, 64 inches long. Six 2-inch sampling ports, spaced 8 inches from one another, run down the length of the reactor. These are blocked with a refractory plug when not being used. Two additional ports near the burner can be configured to allow inspection and imaging of the burner region. Four additional, smaller ports down the side of the reactor are used for measurement of temperature and system pressure.

Typical commercial gasifiers have height-to-diameter ratios of 2 to 3, similar in geometry to a can of soda. The University of Utah gasifier has a much higher height-to-diameter ratio of roughly 8. The idea behind 
this is to "stretch out" the gasification environment. This is a research reactor, and the focus is to follow changes in physical and chemical properties of the fuel as it is converted. Particular attention is paid to the near-burner region. By having a relatively tall, slender reactor with many sampling ports down its length, gas and condensed-phase samples can be taken at short residence time increments.

\subsubsection{Quench Transition Section}

The transition section (Figure 2) can be considered to have three parts. The upper part is actually the bottom eight inches of the reactor chamber, and is cast in refractory. The refractory tapers slightly in this section, so that the exit to the reactor is roughly six inches in diameter. This refractory sits upon a watercooled ring, four inches tall, having an inner diameter of 8 inches. A 14-inch diameter dip tube is located beneath this, effecting a diameter expansion of six inches. Four water spray nozzles protrude through the top of this dip tube, two inches below the cooled ring and three inches back from the edge of that ring so as to avoid water splashing upwards toward the reactor.

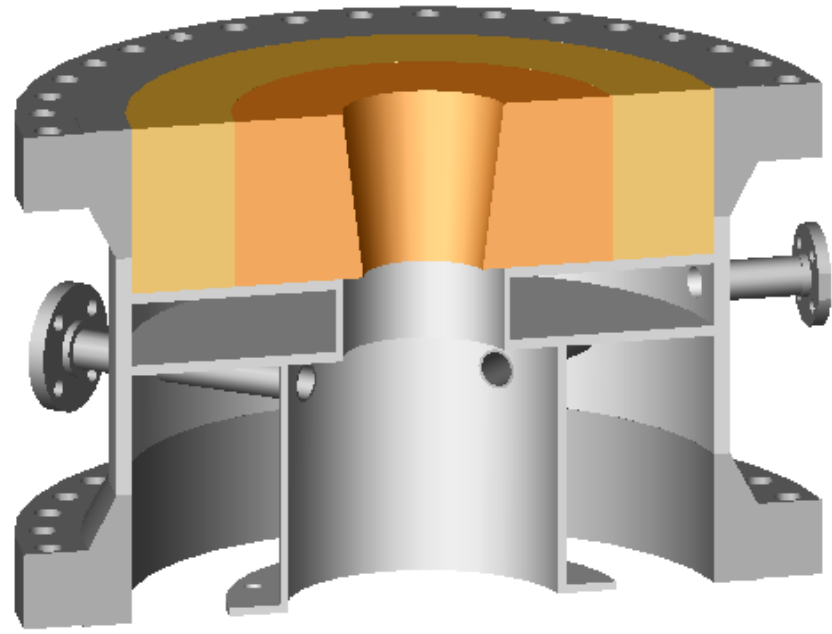

Figure 2. Split view of rendering of transition section.

The focus of this program was the gasification reactor itself; downstream quenching of the gasification products will not be studied. Therefore, the quench system is relatively crude, and is designed to safely and effectively cool the gas and smelt from the reactor.

\subsubsection{Quench Bath}

The bottom section of the gasifier is a deep quench bath. That portion of the vessel is 8.5 feet long, and is lined with 2205 duplex steel. The dipleg from the transition section extends approximately halfway down the length of this section. The product gas bubbles around the end of this diptube, providing additional cooling, and the smelt product from the gasifier falls into the bath to form green liquor. The liquid in the bath is recirculated to keep it mixed, and passes through a heat exchanger to keep it cool.

The quench bath section has a nozzle near the top to exhaust the gasifier product gas. Two additional nozzles are connected to an external level measuring system to control the quench bath level. There are also three nozzles for measurement of temperature in the quench bath. 
The product gas from the reactor flows through a pressure control valve and into the gasification research facility's natural gas-fired afterburner to burn the combustible gases. The liquid in the quench bath is drained as necessary to maintain the desired level.

The entrained-flow gasifier is tied into the overall gasification research facility, and has its own dedicated control subsystem and modules for process control and measurement of flows, temperatures and pressures. The control system is designed to safely shut down the system in case of problems such as a power outage or loss of cooling water.

\subsection{Liquor Spray Imaging System}

A novel system to analyze droplet formation and injector spray patterns for black liquor in hot environments was developed under this program. This system comprises two main components, the fuel delivery system and the heated spray chamber.

\subsubsection{Fuel Delivery System}

The fuel delivery system is shown conceptually in Figure 3. The pump is a Seepex, progressive cavity, positive displacement pump that allows precise and repeatable control of the fuel flow rate. The injector is a twin fluid (liquor and air) nozzle (Figure 4), and is capable of producing fine sprays of black liquor.

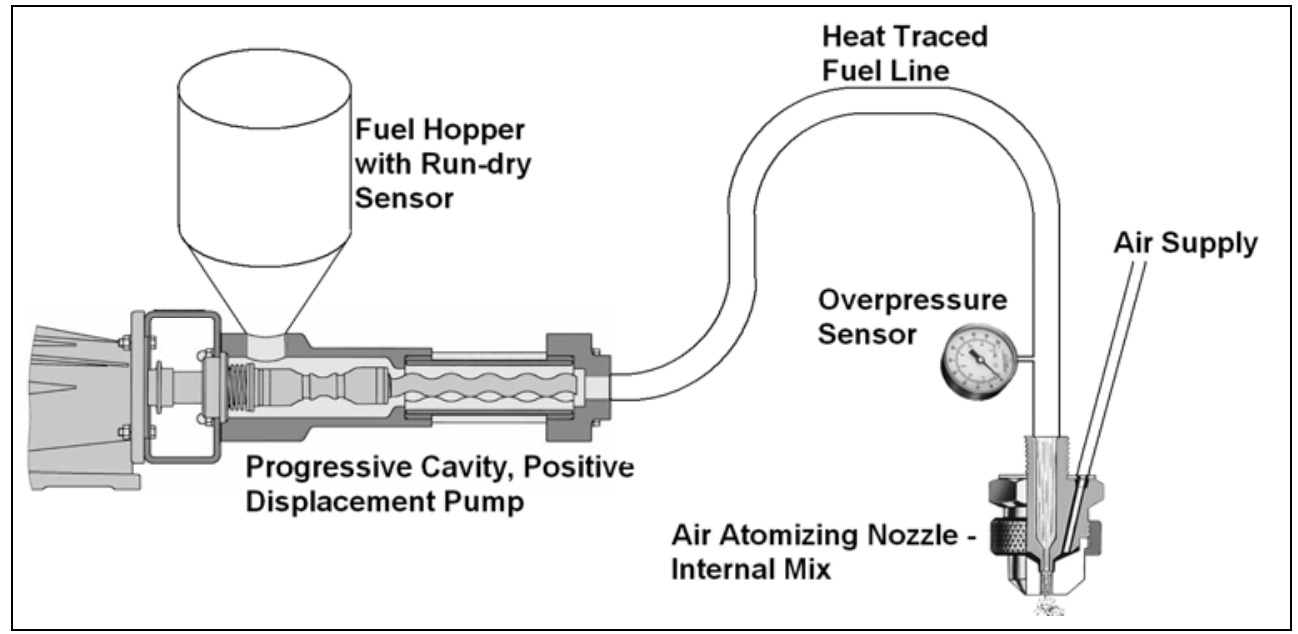

Figure 3. Conceptual design of the fuel delivery system. 


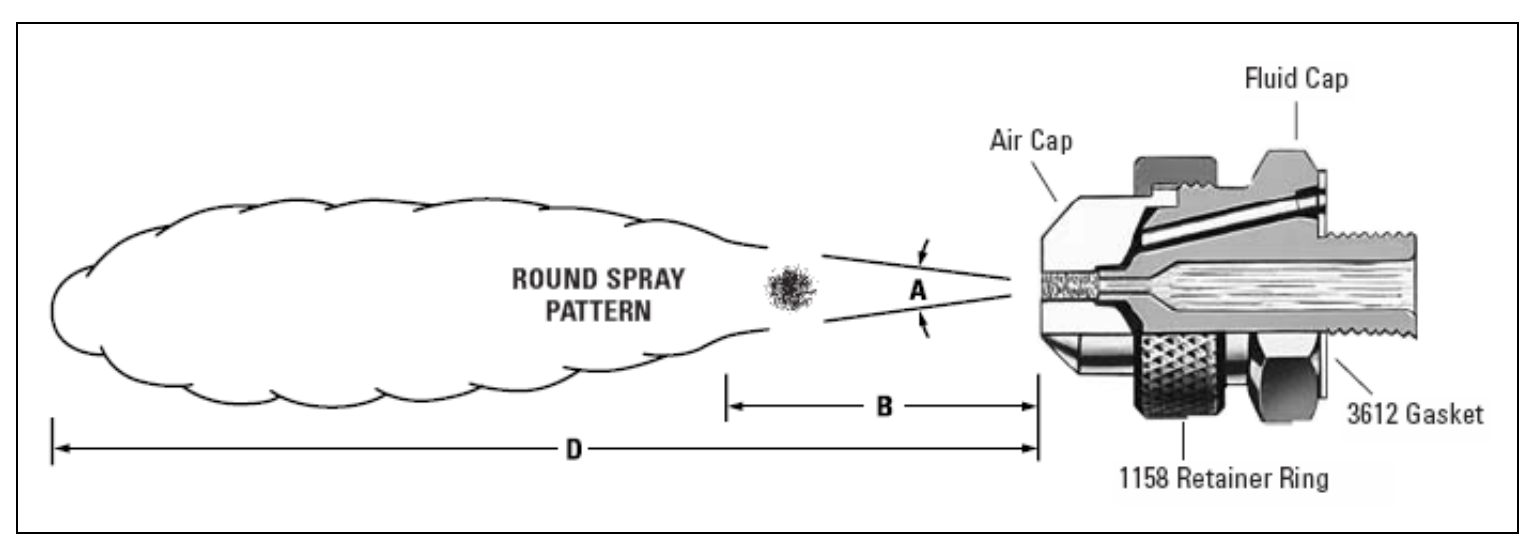

Figure 4. Cutaway view of an internal mix, air atomizing nozzle. (Source: Spraying Systems Co.)

The fuel delivery system was used in two types of experiments. In one type, the spray nozzle was placed against a bright light so that the liquor droplets showed up as shadows on the imaging system. In the other type, the injector was placed inside a heated chamber to study droplet formation in a hot environment.

\subsubsection{Backlit Imaging System}

This system combines high speed photography with a liquor injection nozzle in front of a very bright light source, and allows identification of individual droplets in the liquid spray. A photograph of the backlit imaging system is shown in Figure 5. Optics in this system magnify the liquor spray.

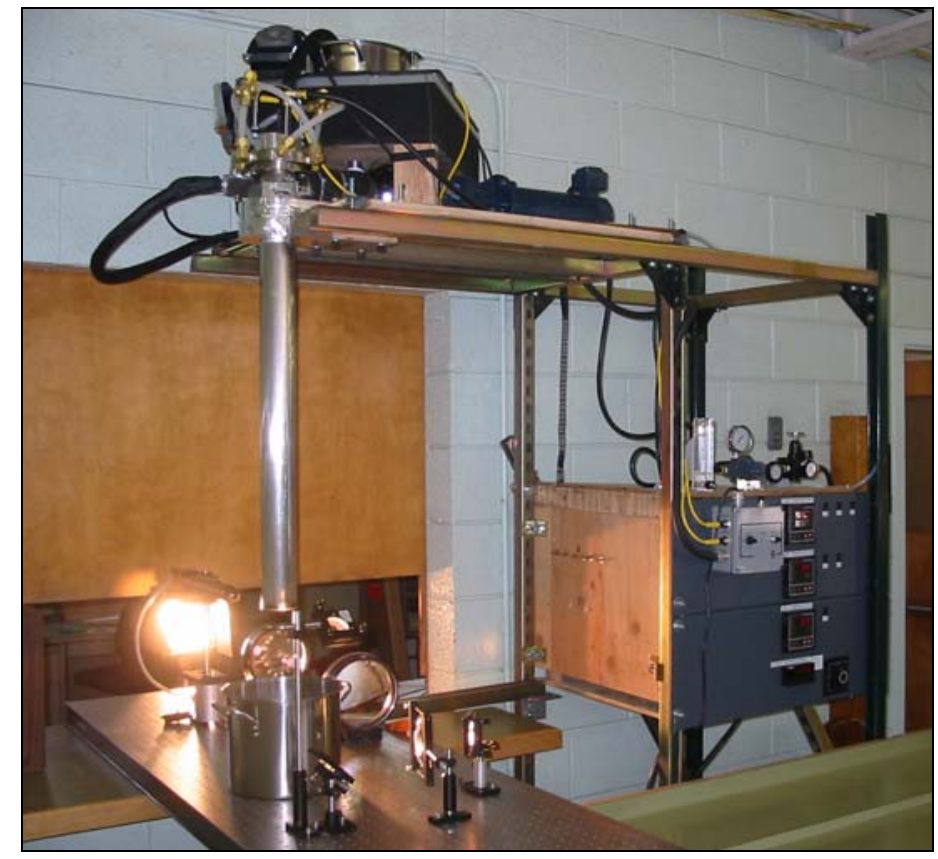

Figure 5. Experimental setup for backlit images of the liquid spray. 


\subsubsection{Heated Spray Chamber}

An electrically heated, atmospheric spray chamber (Figure 6) was designed, constructed and tested to $1000^{\circ} \mathrm{C}$. The heated section of the chamber is a $0.610 \mathrm{~m}$ long $0.152 \mathrm{~m}$ inside diameter Silicon Carbide tube. The tube is surrounded by four resistance heaters, and insulated with refractory material. Optical access to the spray is obtained by moving the spray nozzle to different heights inside the tube and imaging the spray as it exits the bottom end of the tube into an induced draft exhaust duct. Unburned material and particulate is collected in the exhaust system.
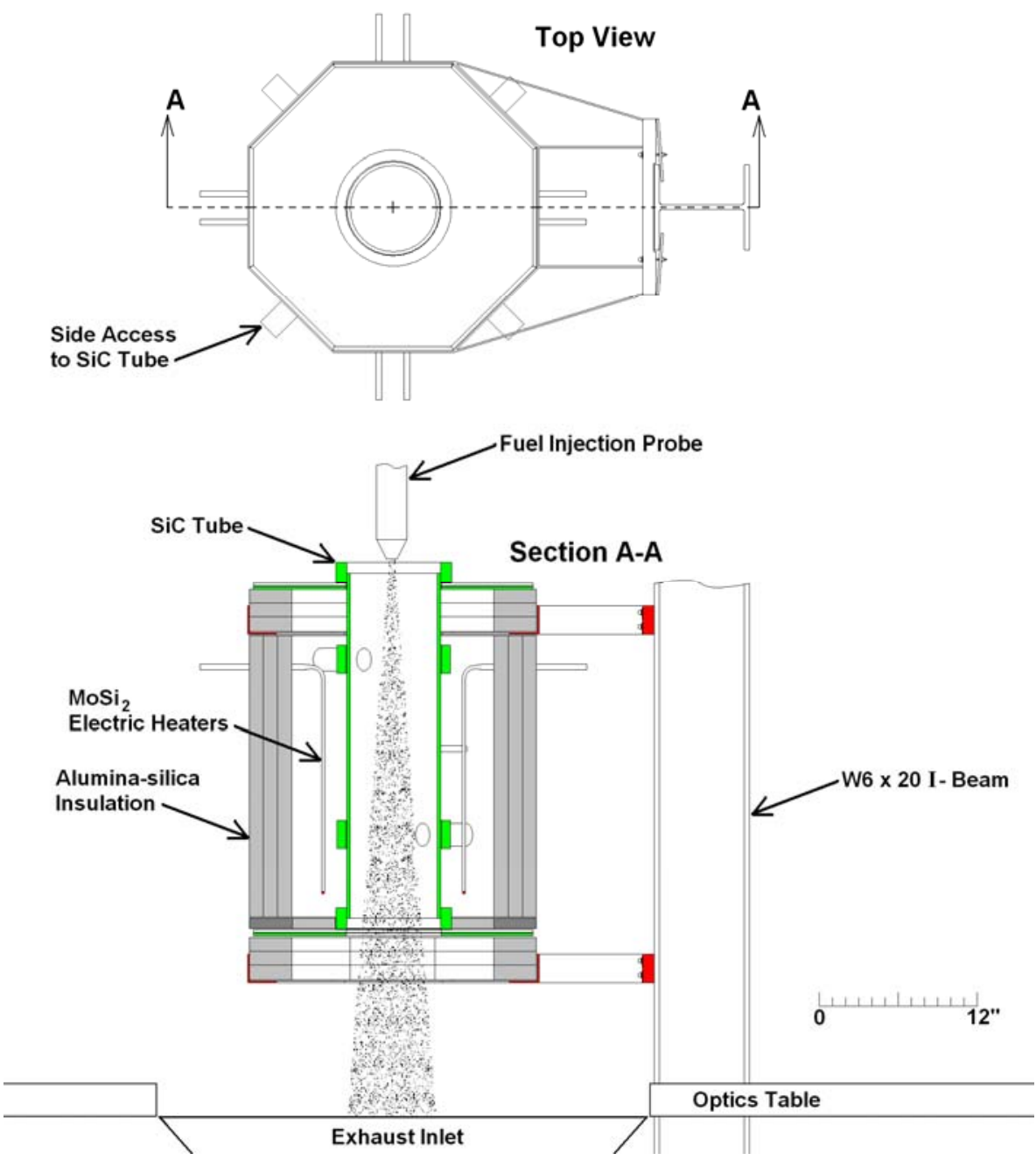

Figure 6. Diagram of the electrically heated spray chamber. Multiple chambers may be stacked to form an entrained flow reactor.

For operation in the heated environment, the fuel delivery system is modified. The fuel and air lines enter the heated reactor through a water jacketed probe (Figure 7). The probe has sufficient cooling capacity to be inserted fully into the reactor at $1000^{\circ} \mathrm{C}$. Figure 8 shows the fuel delivery system mounted atop the heated reactor. 


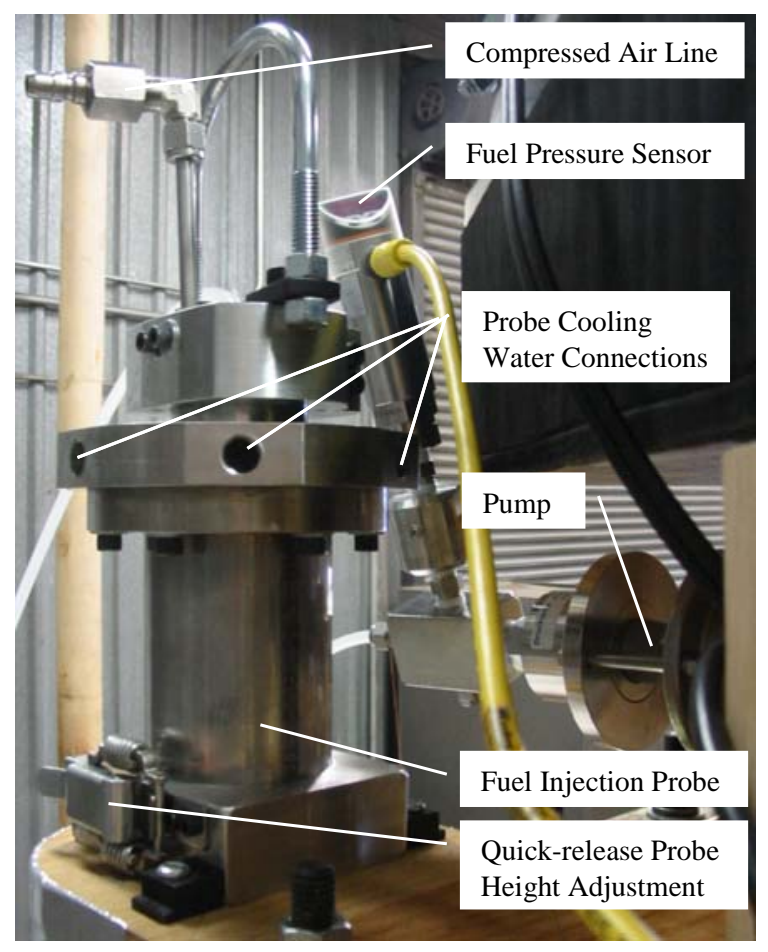

Figure 7. View of the fuel delivery system at the pressure side of the pump.

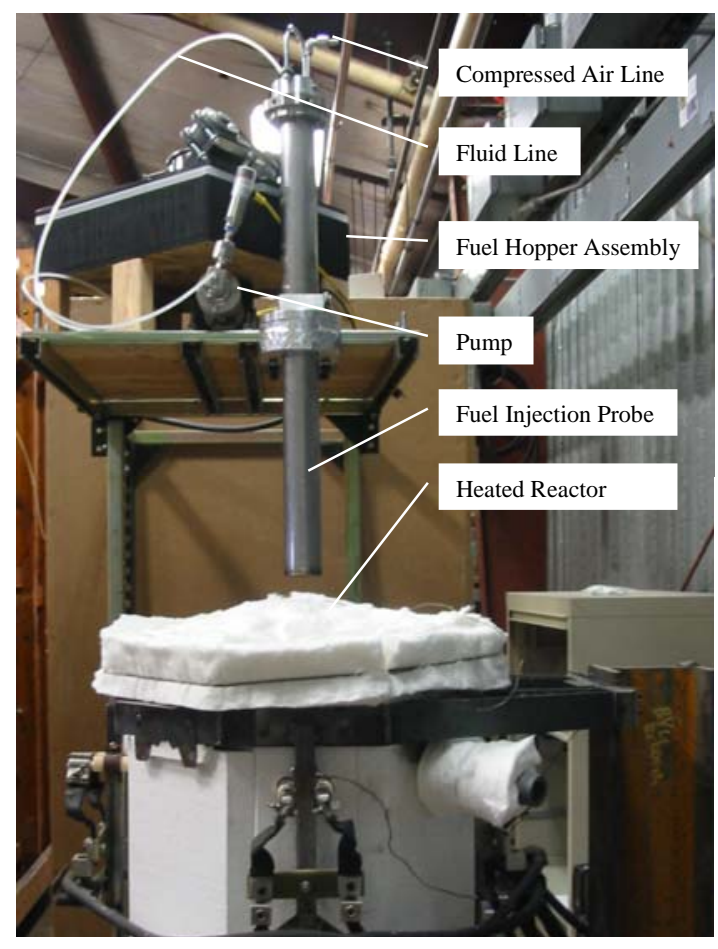

Figure 8. Liquor feed system installed above the heated reactor.

\subsection{Single Droplet Imaging System}

The University of Utah developed a system to study the behavior and characteristics of very small droplets of black liquor as they pyrolyze in-flight in a hot environment. Creating very small, single droplets of a very viscous fluid such as black liquor poses a significant challenge. The single droplet generator for the project uses shear force to create individual droplets. A rendering of the droplet generator head is shown in Figure 9. Hot black liquor is forced through the 1/16" tubing, which has a small length of hypodermic tubing glued inside the end. The liquor flows through this hypodermic tubing and a droplet begins to form at the end. Air is fed into a chamber around the tubing, and exits in the annulus between the hypodermic tubing and an adjustment plate at the bottom of the injector. The air is fed at such a rate as to create a high velocity flow past the hypodermic tubing. As the droplet diameter grows at the end of the hypodermic tubing, the combination of the shearing effect of the air and the pressure difference created between the inner chamber and outside of the injector causes the droplet to "tear" off. In this manner, a stream of uniform sized droplets can be created. It is critical that the hole in the adjustment plate and the hypodermic tubing are perfectly centered. Once the hypodermic tubing assembly has been installed and is held in place by the set screw, the adjustment plate can be shifted around slightly so as to center the hold and the tubing. 


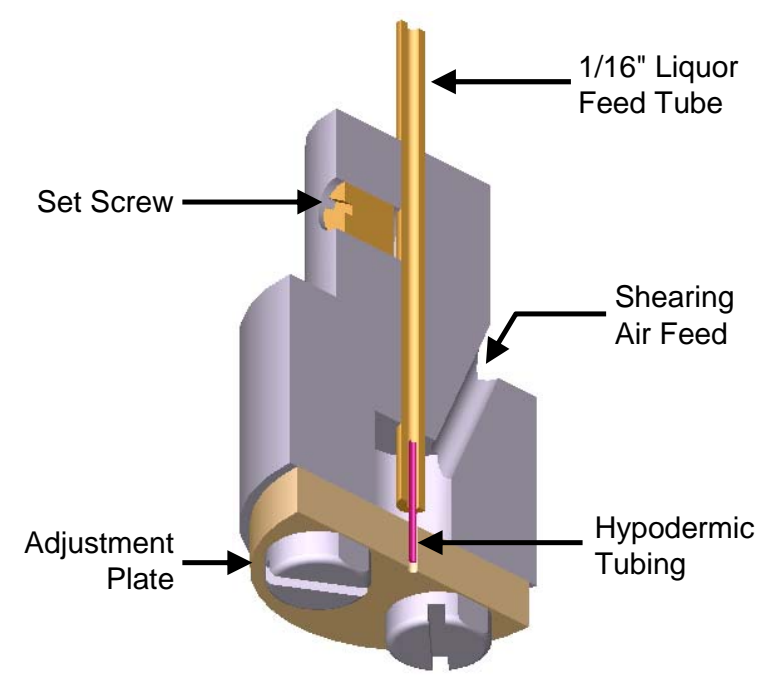

Figure 9. Single droplet generator head. Overall diameter ca. 0.7 inch.

The single droplet generator can be placed inside a water-cooled probe which extends into an existing optical-access drop tube furnace at the University of Utah. An electrical heating tape is placed around the liquor injection line within the cooled sample probe to keep the liquor hot so it does not plug.

\subsection{Smelt Radiative Properties Measurement System}

In a high temperature gasifier, black liquor pyrolyzes to form char, which is subsequently converted to molten smelt that exits the vessel in liquid form. Typically there is a small amount of unconverted carbon remaining in this material. Even small concentrations of carbon can dramatically affect smelt emissivity and corresponding heat transfer. Flow of smelt on reactor walls will also impact heat transfer and the residence time of the condensed phase material, so it is important to understand rheological properties of the molten smelt as a function of temperature and carbon content.

The University of Utah designed a new system suitable for measurement of both viscosity and emissivity of smelt and partly-converted char. Schematic diagrams of the systems for measurement of smelt viscosity and smelt emissivity are shown in Figure 10a and b, respectively. The furnace chamber for both systems is the same: a Thermolyne F48015 muffle furnace (Figure 11) capable of achieving a temperature of $1200^{\circ} \mathrm{C}$, having a 1.25 -inch hole through the top to allow either the viscometer spindle or to allow optical access for measurement of emissivity. 


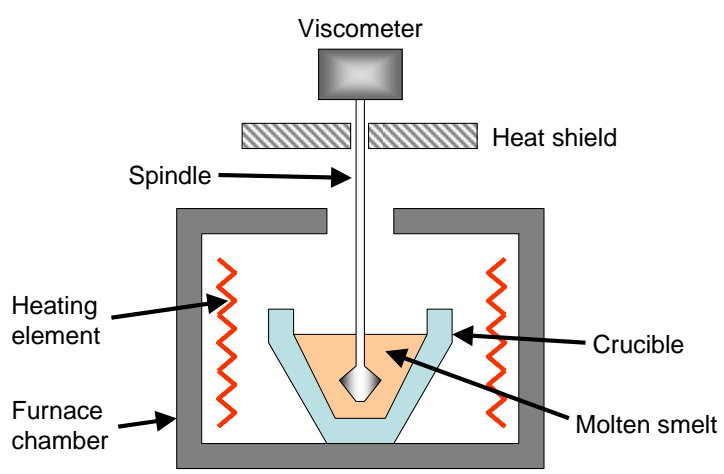

(a) Viscosity

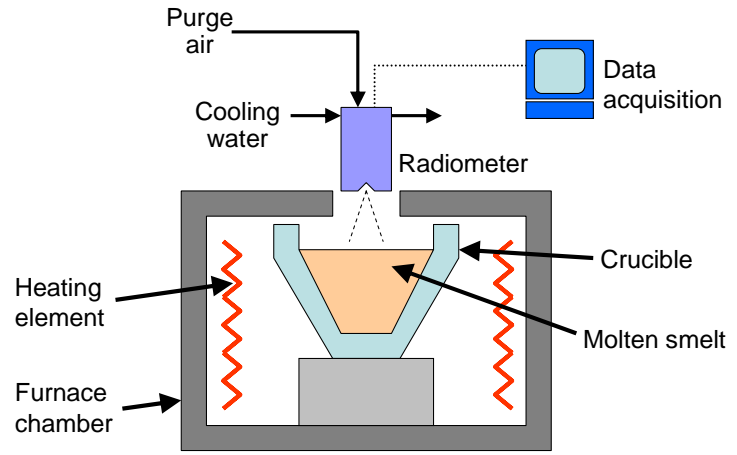

(b) Emissivity

Figure 10. Schematic diagrams of measurement systems for viscosity and emissivity.

Viscosity measurements. To measure the viscosity of the smelt, a modified viscometer is placed above the furnace chamber such that the measurement spindle passes through the hole in the furnace. The viscometer is an off-the-shelf Brookfield DV series viscometer. It is necessary to have a few modifications to the viscometer. First, the spindle needs to be longer than normal in order to reach into the crucible inside the furnace. Second, due to the corrosive nature of the material the spindle needs to be made of a high temperature material such as 310 stainless steel. Finally, a water-cooled heat shield with a hole in the middle needs to be placed around the spindle to protect the viscometer electronics from the heat of the furnace.

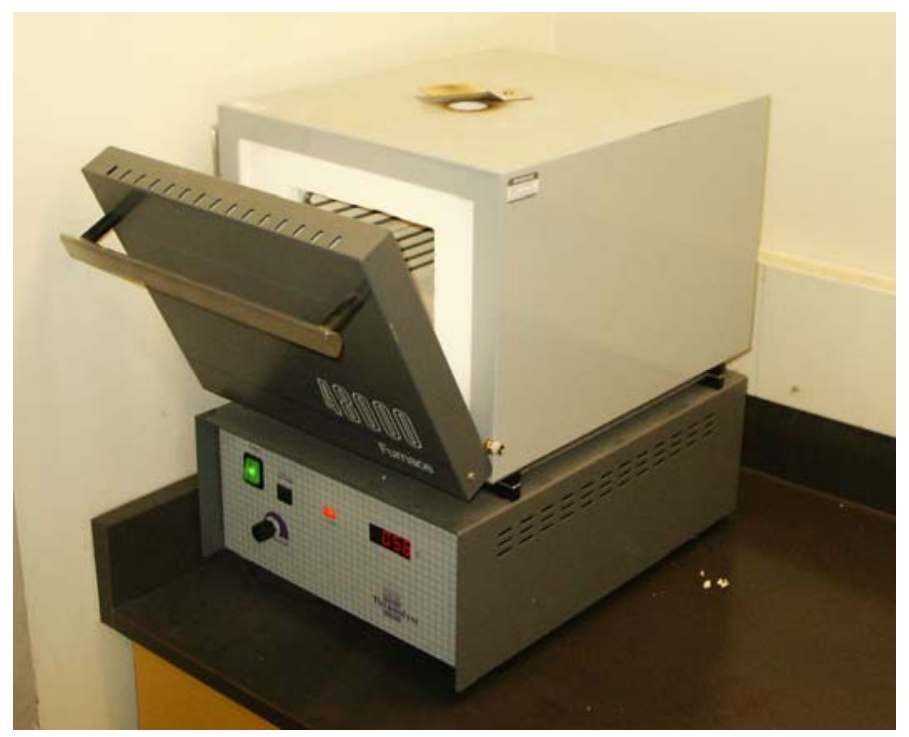

Figure 11. Furnace used for smelt properties testing.

The viscometer is calibrated using standards of known viscosity. These fluids are poured into the crucible, which is inserted into the (cold) furnace to simulate the environment as closely as possible. Once calibrated on these fluids, a crucible with the desired smelt or salt mixture is placed into the preheated 
furnace. Once the smelt or salts are molten, the spindle of the viscometer is carefully lowered into the molten material and the viscosity is measured.

Emissivity measurements. Total emissivity of molten smelt samples will be measured initially by a radiometer. The radiometer (Figure 12) is produced by Vatell Corporation, and comprises a total heat flux transducer containing an air-purged window over the transducer to eliminate convective heat transfer. The transducer is a differential thermocouple measuring the temperature difference between the center and the circumference of a thin circular foil disk. The disk is bonded to a circular opening in a cylindrical heat sink. The standard foil is made of Constantan and the heat sink is copper. These materials produce an output which is directly proportional to the absorbed heat flux. The radiometer is water-cooled to protect it from the heat of the furnace. Radiometers can be ordered with different viewing angles. The radiometer chosen for this study has a narrow viewing angle $\left(\sim 20^{\circ}\right)$ to avoid interference from the furnace chamber or sides of the crucible.

To measure emissivity, smelt or salt mixtures are placed into the crucible and heated in a manner similar to the viscosity experiments. The radiometer is placed a small distance into the hole in the top of the furnace and positioned such that it views only the surface of the sample in the crucible. The signal from the radiometer is recorded and compared to the signal received when the radiometer is calibrated using a blackbody source. The emissivity of the sample can thusly be determined.

Carbon present in the smelt, before the liquor is fully converted, is very black and has a correspondingly high emissivity. The emissivity of smelt is therefore very sensitive to the presence of carbon. Experiments with differing concentrations of carbon will help identify how the presence of unburned carbon impacts the emissivity of the smelt. At higher temperatures, the change in emissivity as carbon reacts with the sodium carbonate will be investigated.

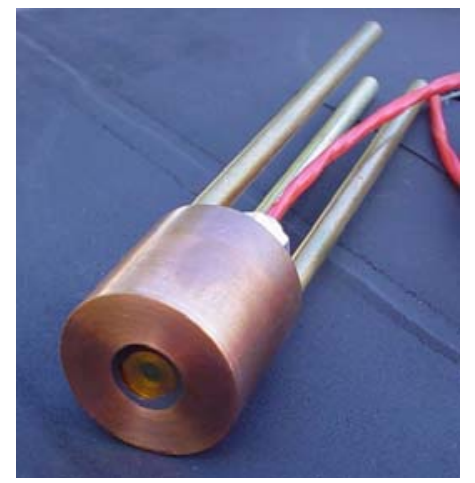

Figure 12. Radiometer.

In addition to overall emissivity measured by the radiometer, spectral emissivity can be measured using a Fourier transform infrared (FTIR) spectrophotometer. Setting up for this type of experiment is somewhat more challenging, since the light from the smelt must be fed to the FTIR. Measurement of spectral emissivity is considered a second phase to the emissivity measurements. 


\section{RESULTS AND DISCUSSION}

The initial phase of the project was dominated by design and construction of experimental facilities. Construction of the entrained-flow gasifier was nearly complete by the time the program was ended, but was not ready for operation. So, no results from that system are available. Most results are from the droplet imaging and computational modeling studies, and are described below.

\subsection{Droplet Spray Characterization}

A series of tests was conducted using the backlit imaging system described in Section 2.2.2. Resulting droplet sizes and shapes as well as the overall shape of the liquor spray were identified.

\subsubsection{Droplet Shape and Size (Qualitative Data)}

Backlit images of water sprays were taken at three different pump speed settings over a range of atomizing air pressures. The pump speed settings corresponded to 1.3, 2.7 and $5.0 \mathrm{~kg}$ liquid per hour (without air flow). Air pressures used ranged from 4-58 psig in 2 psi increments. Images were also taken at 0,3 and 70 psig to obtain data at operating extremes. 25 images were obtained at each operating point. The data indicate that the nozzle becomes choked (with respect to air flow) between 4 and 8 psig, depending on the liquid flow rate.

A sample backlit image of a water spray taken with an exposure time of $16 \mu$ s is shown in Figure 13 . The image shown covers an area of 5.5 x $7.3 \mathrm{~mm}$. One pixel corresponds to $11 \mu \mathrm{m}$. Droplet sizes observed range from $11 \mu \mathrm{m}$ to $150 \mu \mathrm{m}$ and most appear spherical. Generally speaking, the larger droplets appear slower, and smaller droplets are too fast to be frozen by the camera. Determining droplet size distributions was beyond the capability of this equipment, but it was generally observed that higher atomizing air pressures produced smaller droplets. Larger structures of fluid are seen attached to the perimeter of the nozzle. The development of these ligaments into droplets is shown later.

It was of interest to switch the fluid and air connections of the nozzle (refer to Figure 4) to obtain an interior geometry closer to that used in an atmospheric, air-blown black liquor gasifier at Weyerhaeuser's New Bern mill (Figure 14). That nozzle has the liquor flow radially outward in the nozzle through a passage and steam is blown perpendicular to and through the flow of liquor (see right side of Figure 14). With the flow reversed in our nozzle, the liquor flowed from around the outer radius inward and the air flowed through the liquor along the centerline. The result was a greater occurrence of the ligament formation at the nozzle perimeter, as seen in Figure 15, with generally poorer atomization. 


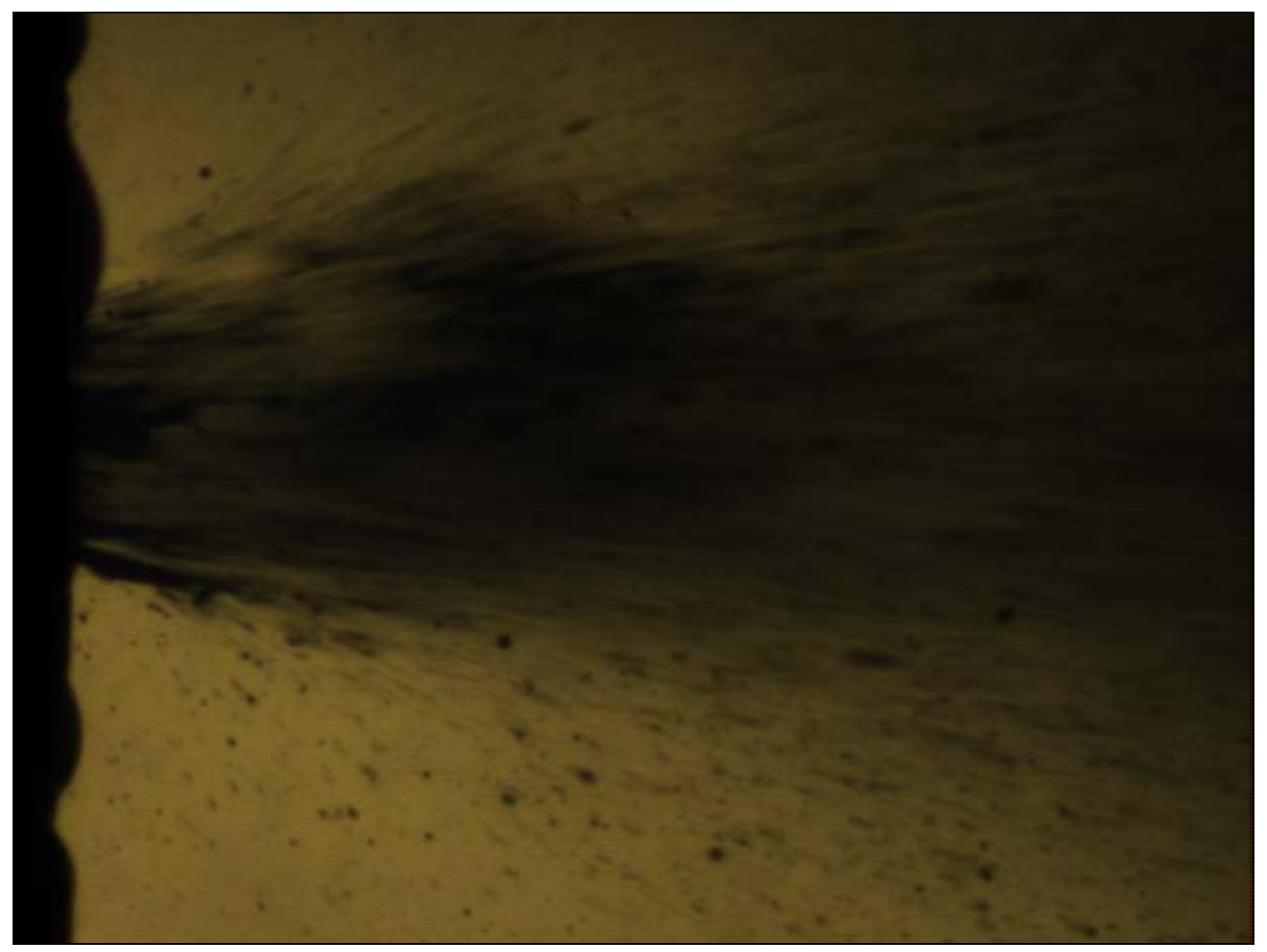

Figure 13. A sample image of a water spray taken at $16 \mu$ s exposure. Nozzle conditions: $5 \mathrm{~kg} / \mathrm{hr}$ water, $0.95 \mathrm{~kg} / \mathrm{hr}$ air at $18 \mathrm{psig}$.

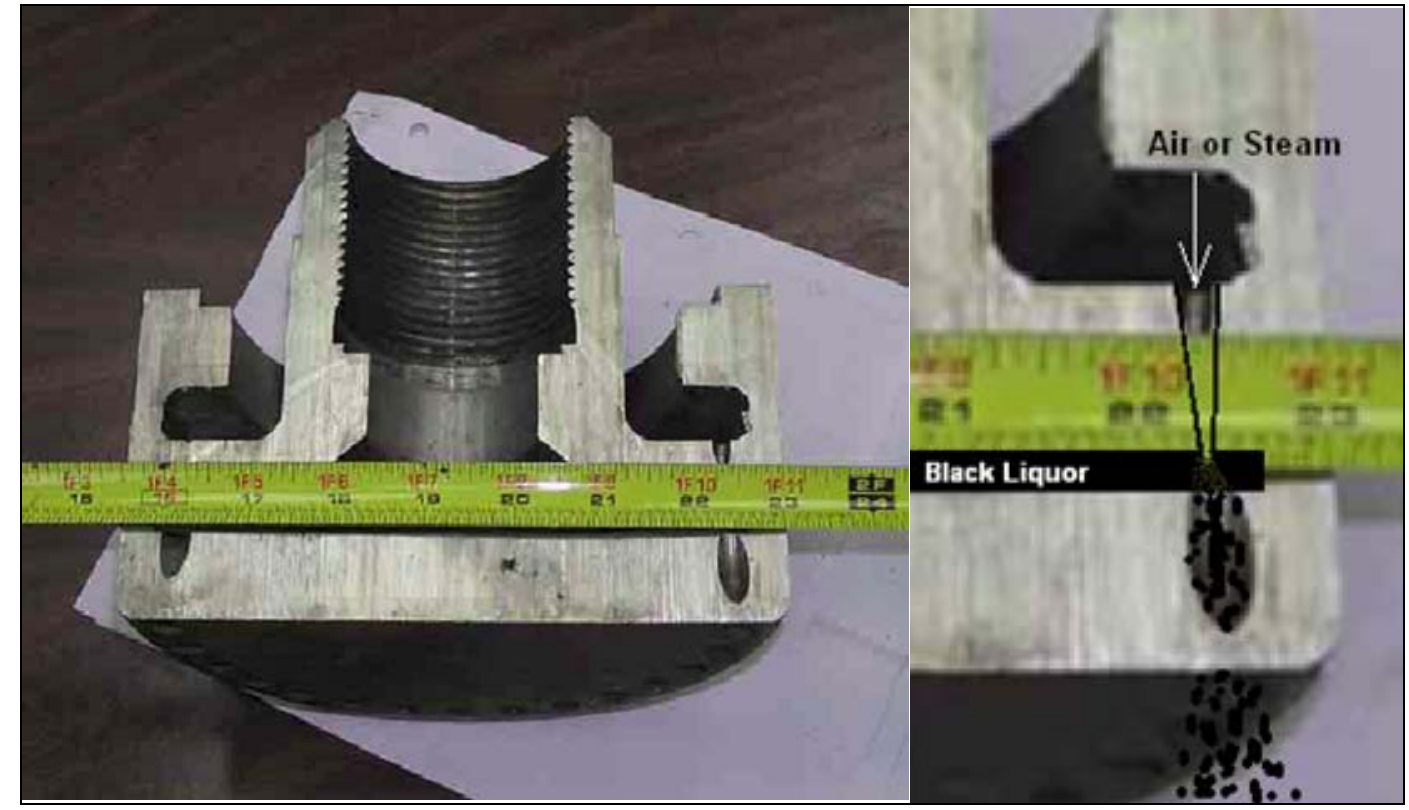

Figure 14. Cutaway view of the steam-atomized New Bern gasifier nozzle. (Source: Weyerhaeuser, fluid labels added) 


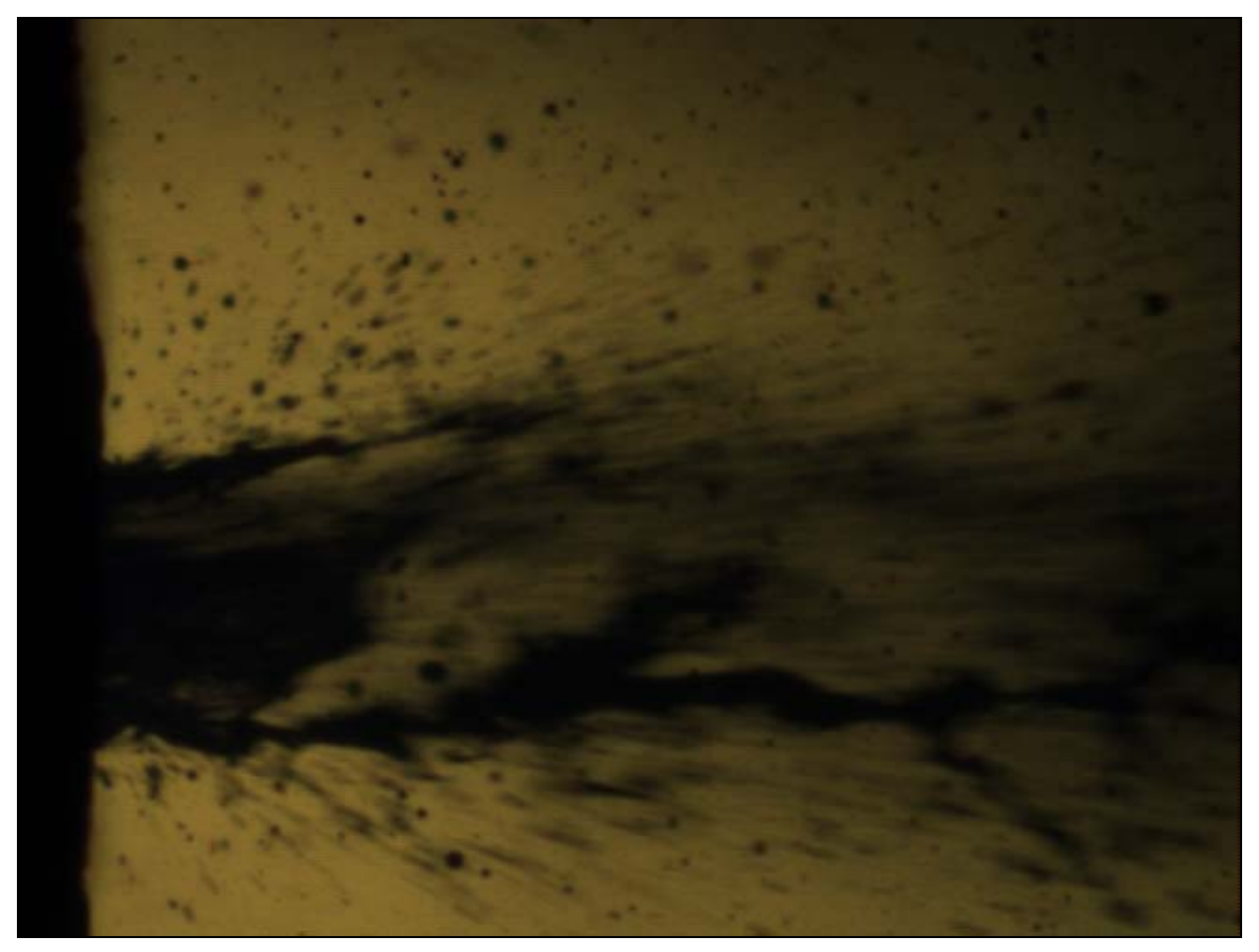

Figure 15. A sample image of a water spray taken at $16 \mu$ s exposure with the fluid and air connections reversed. Nozzle conditions: $5 \mathrm{~kg} / \mathrm{hr}$ water, $0.44 \mathrm{~kg} / \mathrm{hr}$ air at $40 \mathrm{psig}$.

\subsubsection{Spray Shape}

The backlit images were analyzed to determine light extinction produced by the spray in order to determine the spray cone angle and the distribution of liquid within the spray jet. The extinction profile of the images is approximately proportional to the mass distribution in the spray. The cone angle of the spray was observed to increase with increasing air flow rate (air pressure) until the air pressure reached approximately 22 psig after which the spray maintained the same shape. Figure 16 shows numerous extinction profiles over a wide range of atomizing air pressures (between 22 and 58 psig) at $2 \mathrm{~mm}$ downstream of the nozzle surface, as well as selected data for lower pressures, as labeled. The non-zero extinction on the outer edges of the jet is a result of water vapor surrounding the spray which builds up in the quiescent flow environment near the jet. It is anticipated that this extinction would be zero if carried away by the surrounding fluid motion. The data is not centered over the nozzle centerline because the camera and nozzle were misaligned by about $5^{\circ}$. The nozzle centerline is calculated from the edges of the spray at the nozzle exit in the image and as a result of the misalignment the data is offset from the nozzle axis by an amount that increases with distance from the nozzle. This was corrected for in an Abel inversion analysis. 


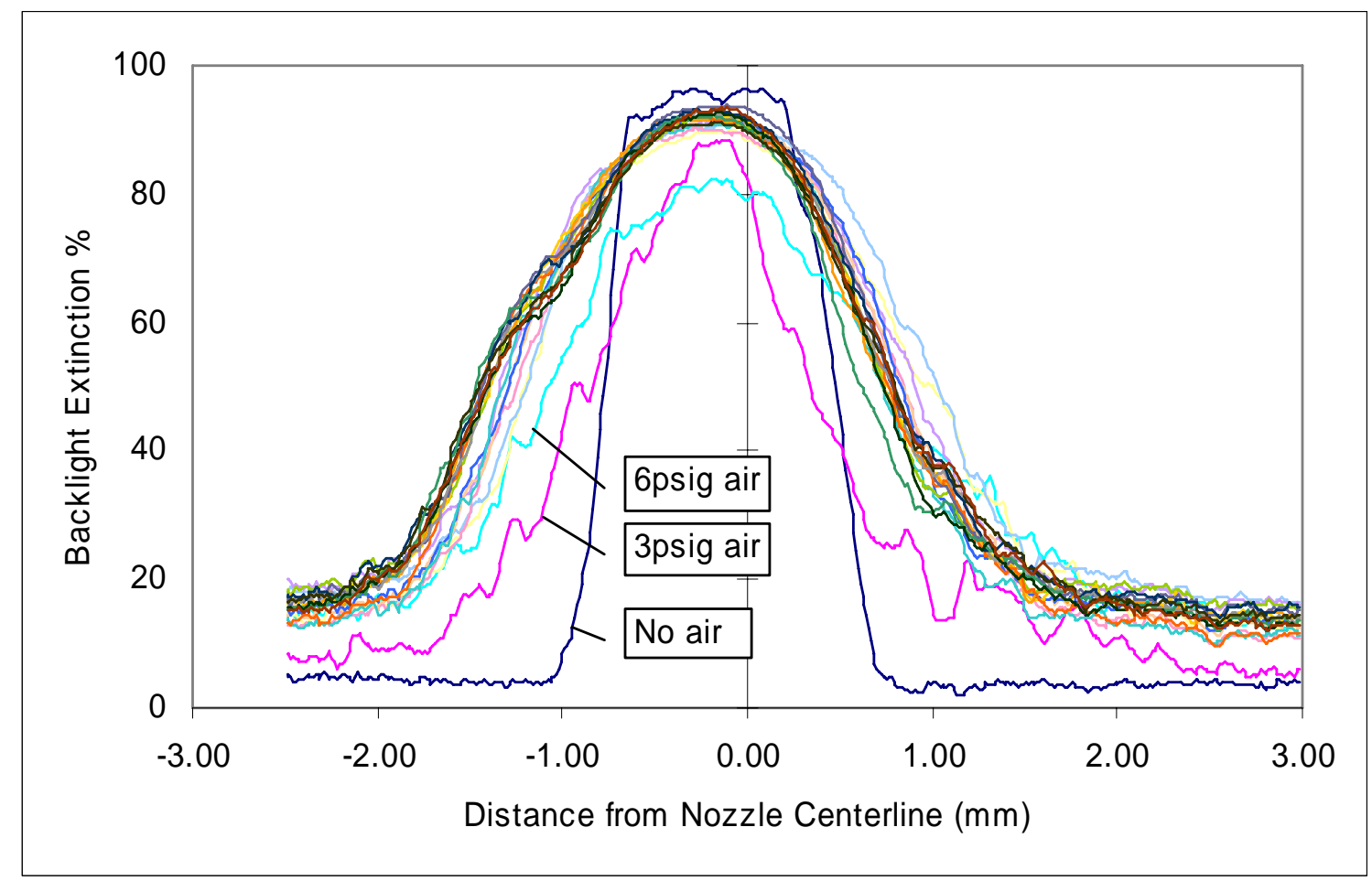

Figure 16. The independence of spray shape and mass distribution on atomizing air pressure is demonstrated by results of backlight extinction analysis of the water spray images. Data for a single liquid mass flow rate $(5 \mathrm{~kg} / \mathrm{hr})$ over a wide range of atomizing air pressures (22-58 psig and selected lower pressures) $2 \mathrm{~mm}$ downstream from nozzle is shown.

Using the extinction data, the cone angle of the spray can be determined. From the average, the approximate location of the spray edge can be see as the location where the slope of the extinction curve increases rapidly. This location can be found more precisely using the derivative of the extinction curve and locating the lowest slope before the slope increases.

This same procedure was followed at $4 \mathrm{~mm}$ downstream from the nozzle, and the resulting diameters were used to calculate the spray angle of 10.3 degrees. The nozzle is specified by the manufacturer to produce a cone angle between 13 to 15 degrees, which is relatively good agreement. It is possible that measurements further downstream would produce slightly larger spray angles as the jet loses momentum to the surrounding gas. 


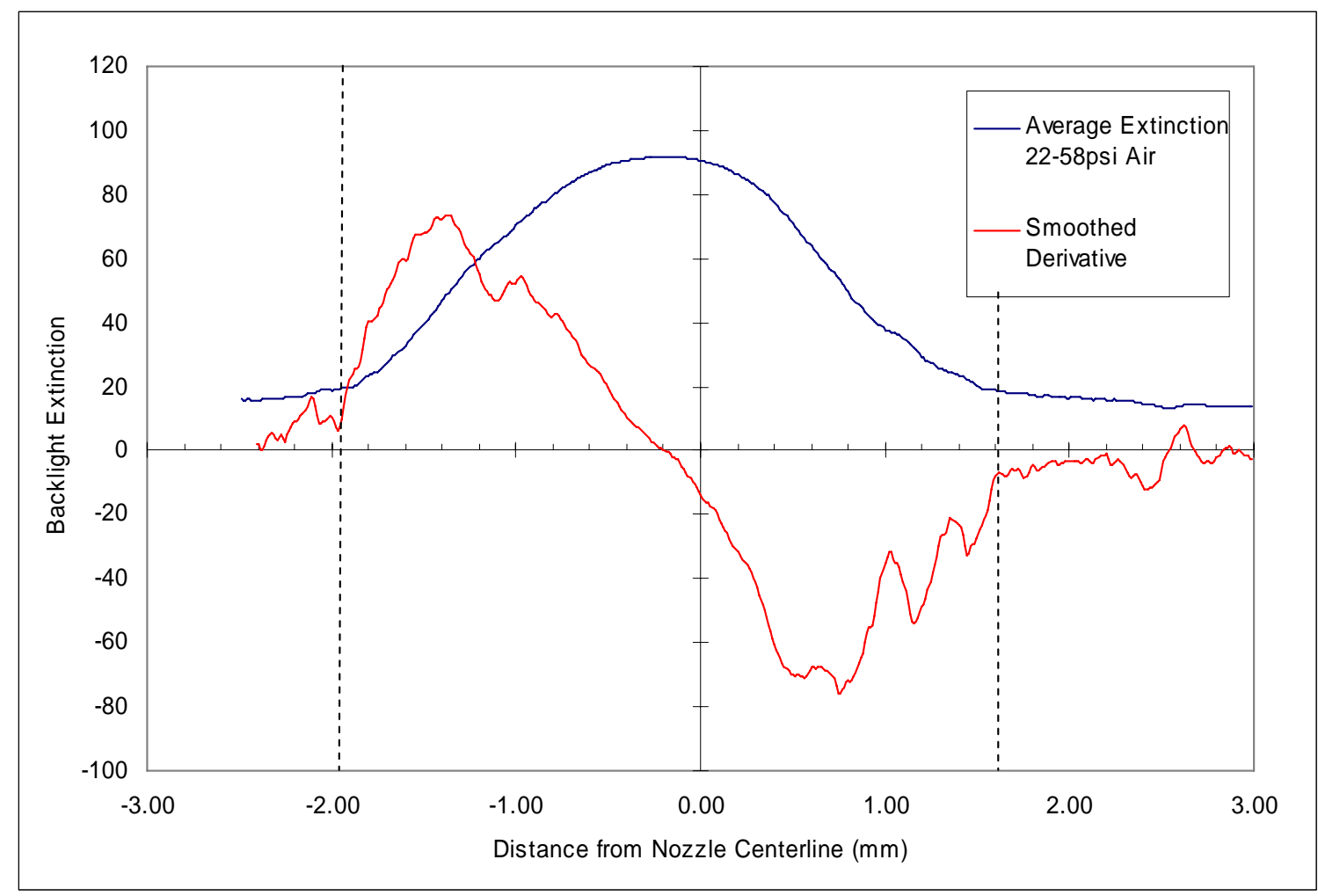

Figure 17. The edges of the spray (indicated by the dashed lines) are found by locating the departure of the smoothed derivative of extinction data from the neighborhood around zero.

\subsubsection{Approximate Radial Mass Distribution in the Spray}

With a value defining the edge of the spray, and the extinction data, an Abel inversion can be used to convert the extinction data from x-y to x-r coordinates. This is an approximate method, as the backlighting is not collimated light, but provides good qualitative insight into the spray’s mass distribution.

An example result at the maximum liquid flow rate over the range of atomizing air pressures where the spray shape and extinction data are independent of air pressure is shown in Figure 18. From the figure we can see that the liquid mass is concentrated in the core of the spray at $2 \mathrm{~mm}$ downstream, but that as we move further from the nozzle the spray diverges, and mass moves from the core towards the outside of the jet. Using these results with results from other liquid flow rates it would be possible to determine how the spray angle changes as liquid flow increases. 


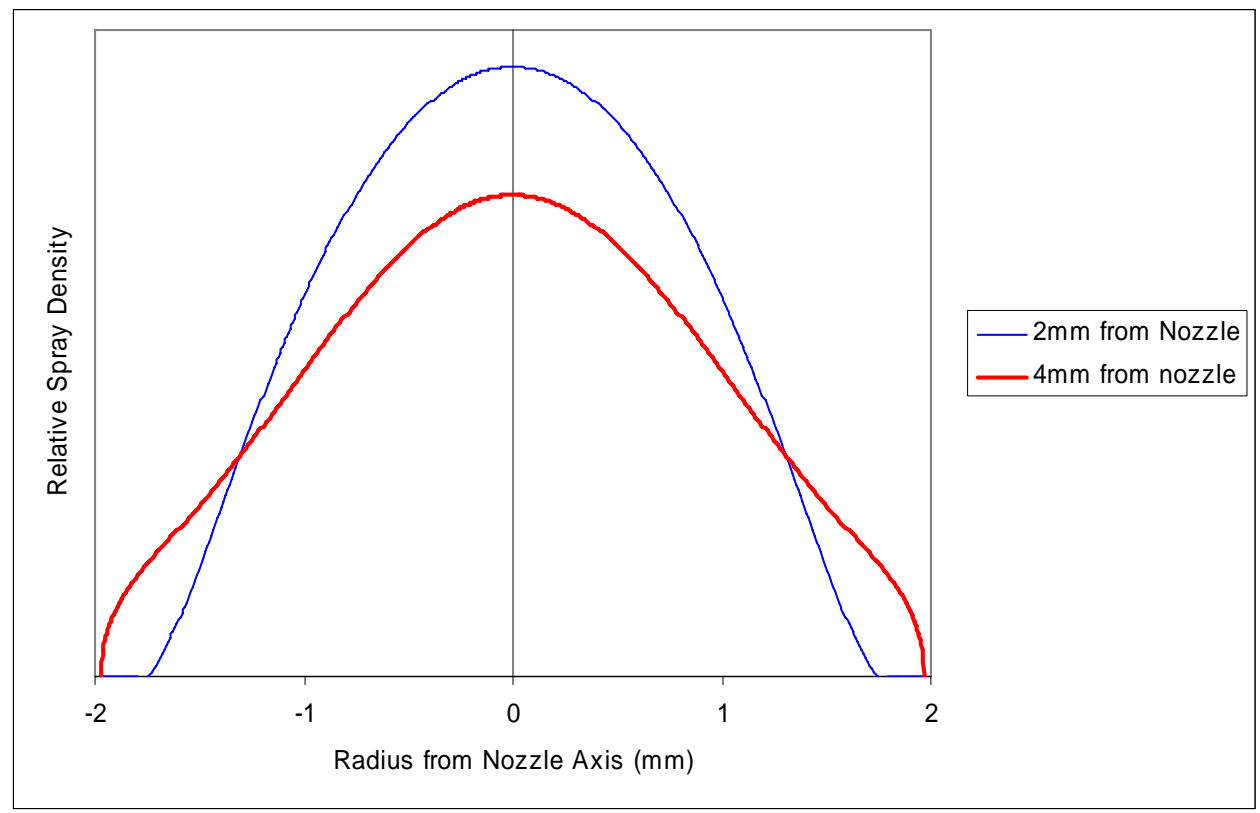

Figure 18. Relative spray density calculated from backlight extinction data for the maximum liquid flow rate $(5 \mathrm{~kg} / \mathrm{hr})$.

\subsubsection{Development of Ligaments into Droplets}

As already mentioned, large ligaments of fluid were observed to form on the nozzle perimeter. The development of these ligaments as they move downstream was studied using high speed video. Example frames taken 56 s apart are shown in Figure 19, with a single ligament labeled for discussion. Other ligaments may also be observed in this sequence.

In the first three frames the labeled ligament stretches and then breaks. It begins moving downstream and changes shape in frames 4-6 to a near spherical form, In observing many such broken ligaments it can be seen that they appear to shrink as they travel downstream. This indicates that their thickness out of the image plane is increasing, and thus we may conclude that the original ligaments are probably very thin sheets of fluid.

The final size of droplets formed this way is greater than that of droplets that do not originate from ligaments. Their velocities are also slower than the smaller droplets in the spray proper. It is anticipated that the large droplets will be a major concern in the goal of maintaining a tight distribution of droplet sizes, but they may allow a study of if and how this mechanism of spray atomization differs in black liquor from other fluids. 


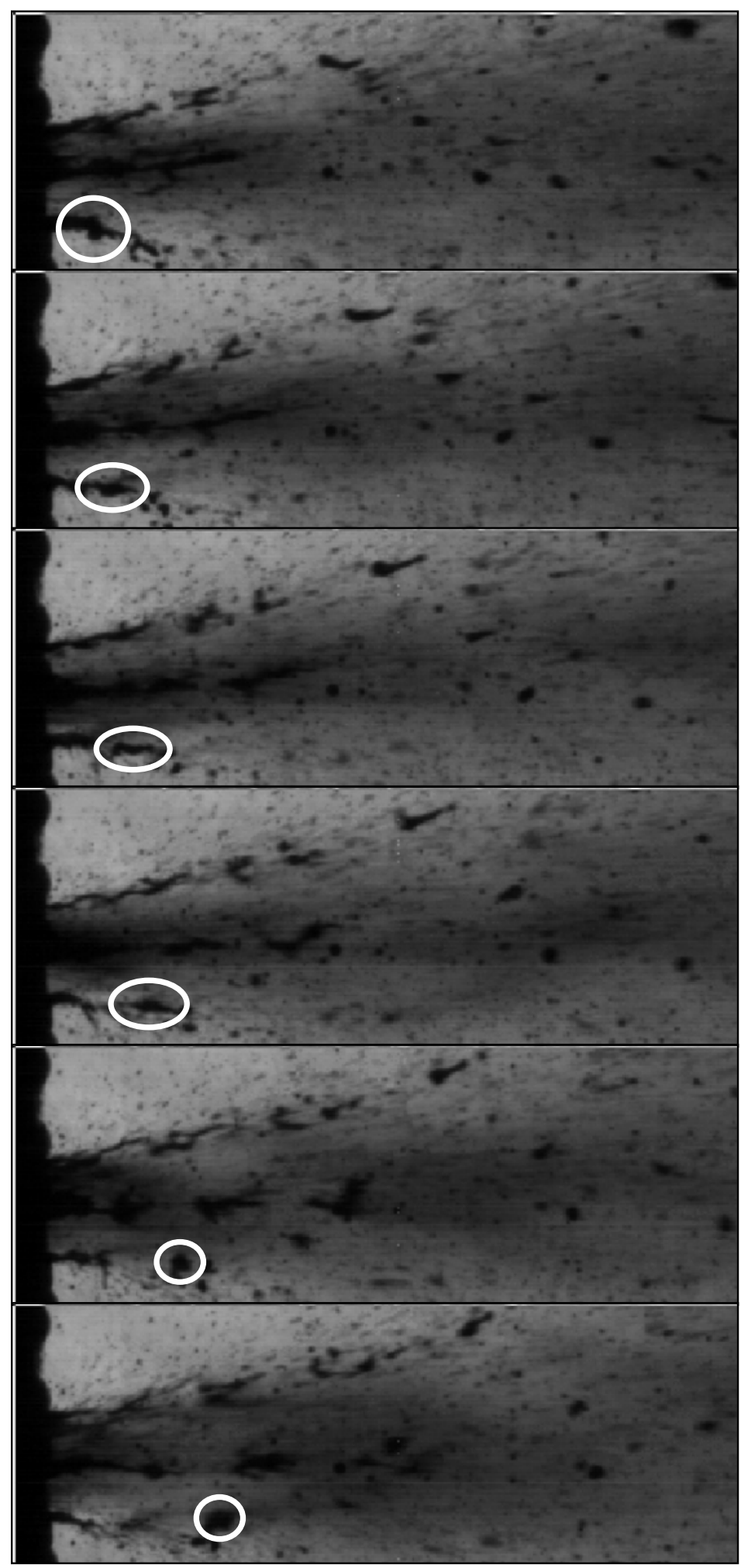

Figure 19. A sequence of images taken at $17900 \mathrm{fps}$ showing the development of ligaments into smaller structures. 


\subsubsection{Comparison of Black Liquor and Water Sprays}

For liquid sprays, there are different regimes of droplet breakup, determined by flow parameters such as the liquid Reynolds number. To make as fair a comparison as possible between water and liquor, the two sprays were compared in the same regime. The membrane regime was chosen because it offered the best atomization (droplets closest to the desired size) without exceeding the capability of the camera. The water was sprayed at room temperature, whereas the $70 \%$ solids liquor was sprayed at $110^{\circ} \mathrm{C}$. In both cases shown in this section, the surroundings and atomizing air were at or near room temperature. Black liquor injection into elevated temperatures is presented in a subsequent section.

An example of each spray is seen in Figure 20. While the droplet shapes are obviously different, both unbroken jets had a similar appearance near the nozzle. Both jets appeared to move or flap from side to side rapidly changing the trajectory of the fluid and shearing off fluid ligaments. The fluid parameters for both sprays are different, but close enough to place them both in the membrane regime, which is described in the literature [1]. The nature of the initial jet behavior is well characterized by literature descriptions of this membrane regime. Other dimensionless parameters such as the mass flux ratios $\left(\dot{m}_{\text {liquid }} / \dot{m}_{\text {air }}\right)$ are very similar (water, 13.4; black liquor, 11.6). The similarities in the jets end shortly after injection with the water producing thicker ligaments surrounded by nearly spherical droplets while the black liquor jet produces long narrow ligaments with no surrounding spherical droplets.

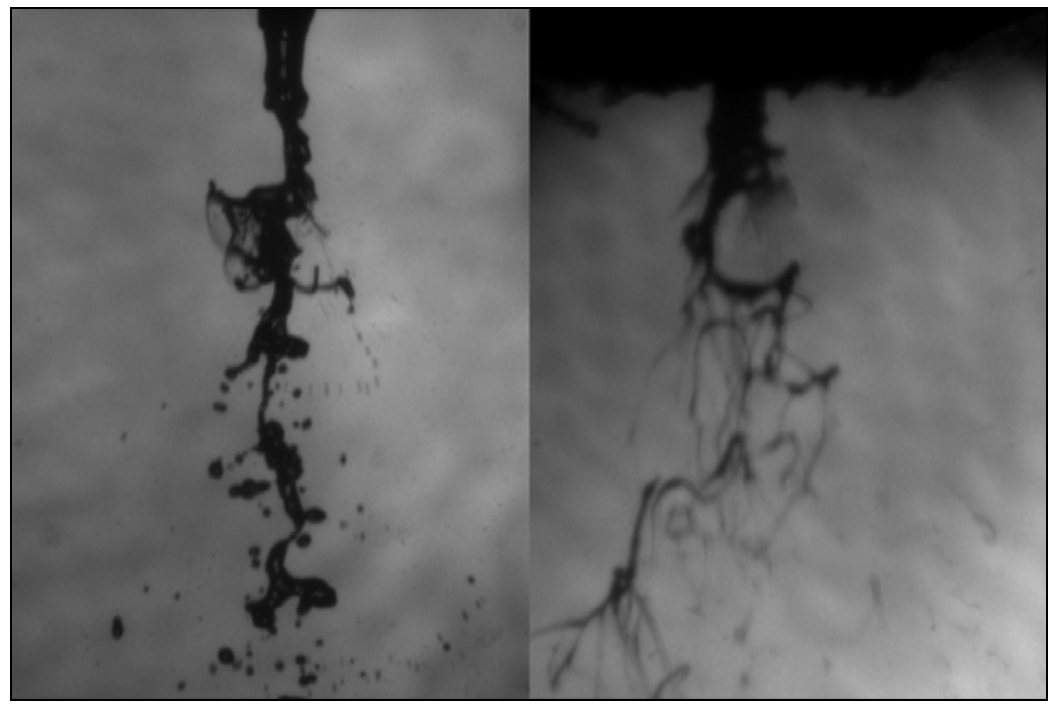

Figure 20. Comparison of water and black liquor sprays in the membrane breakup regime. Water (left): $\mathrm{Re}_{\mathrm{L}}=1982$, We=49; Black Liquor (right): $\operatorname{Re}_{\mathrm{L}}=17, \mathrm{We}=242$.

Figure 21 shows a comparison of the water and black liquor sprays $15 \mathrm{~mm}$ downstream from the nozzle. The water ligaments are more broken with an increased tendency towards spherical droplets, whereas the liquor jet has produced long thin structures. 


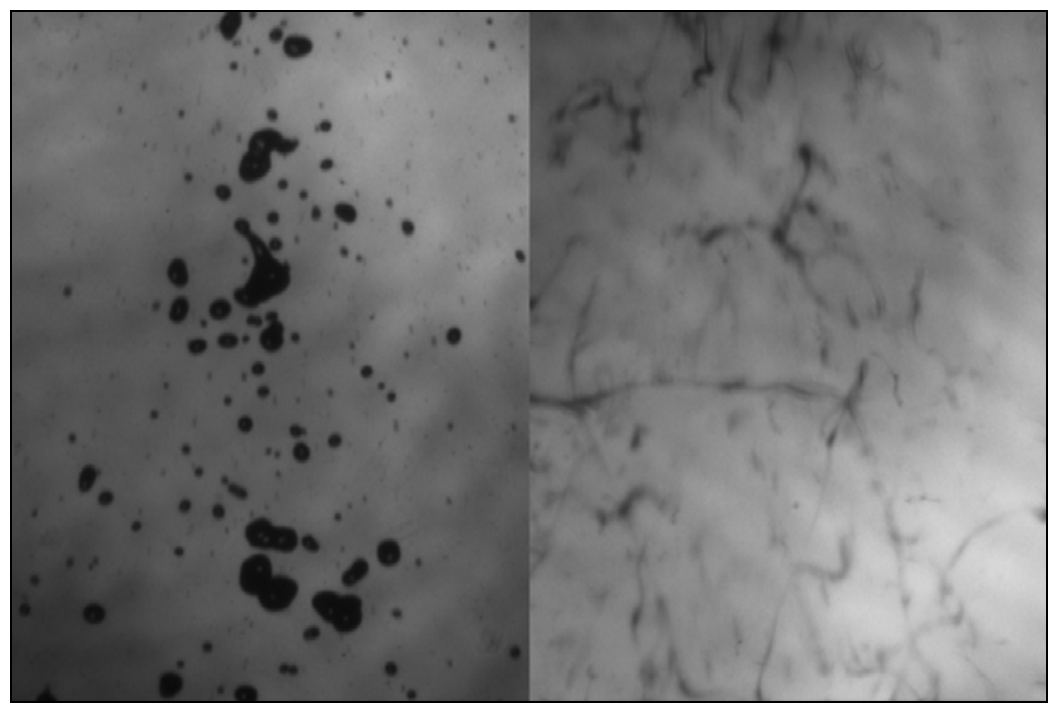

Figure 21. Comparison of water and black liquor sprays $15 \mathrm{~mm}$ downstream from nozzle. (Water: $\operatorname{Re}_{\mathrm{L}}=1982, \mathrm{We}=49$; Black Liquor: $\mathrm{Re}_{\mathrm{L}}=17$, $\mathrm{We}=242)$.

An image analysis program was written to quantify differences seen in the images between the sprays. Two important parameters calculated include the area equivalent diameter and the asphericity. The area equivalent diameter is determined by calculating the area or pixels below a certain intensity threshold which represent the liquid phase and then determining the diameter of a circle that would produce the same area. The asphericity is defined by the maximum straight line dimension of a liquid phase region divided by the area equivalent diameter. A perfectly spherical droplet would have an asphericity of one, and irregular shapes would have larger values.

Plots of the asphericity versus droplet size for the two sprays are shown in Figure 22. It can be seen that most water droplets have asphericity of less than 1.5, whereas the liquor droplets have a distribution of asphericity centered near 1.5. Maximum asphericity values are much higher for the liquor than the water and larger liquor droplets tend to be more non-spherical, whereas smaller water droplets have higher asphericity. It should be noted that many of the black liquor structures seen are not straight, leading to an underestimation of their asphericity. But, the comparison is still instructive. The two sprays used for this comparison of asphericity showed remarkable similarity in their droplet size distributions as analyzed by the program (which assumes spherical droplets as noted in Figure 23 and Figure 24). This suggests the ligaments that produce the fluid structures seen in the images are nearly the same projected area but have significantly different aspect ratios.

Figure 23 and Figure 24 show numerous statistical parameters calculated for the two sprays, including s*, the normalized standard deviation for the square-root Normal distribution. Several authors have fit this distribution to spray data and calculated this parameter, which is typically 0.24 [2]. In testing the fit of the square-root Normal and Rosin-Rammler distributions, neither was clearly a better fit in all cases, and therefore the square-root Normal was chosen to allow comparison of the data here with that reported elsewhere. For both sprays the value of $\mathrm{s}^{*}$ is close to that in the literature, and the distribution fits the data well, particularly for the smaller droplet sizes. Again, it should be noted that the calculation of $\mathrm{s}^{*}$ and other parameters relies on a spherical droplet assumption, which is clearly not the case for black liquor. 
The Sauter mean diameter, which was calculated as the sum of the area equivalent diameter cubed divided by the area equivalent diameter squared, is also reported for each spray. For spherical droplets, this would produce a droplet with the same volume to surface area ratio as the entire spray and is probably the most important diameter when combustion and gasification reactions are involved. Since the current method assumes the areas represent spheres, the Sauter mean diameter calculated for the black liquor is expected to be over predicted. Because the black liquor ligaments look long and thin, they may be more accurately represented by cylinders with a high aspect ratio. This would increase the surface area to volume ratio and decrease the Sauter mean diameter. If a distribution of sizes based on actual surface area to volume ratios were calculated it may actually be a narrower distribution than calculated above, meaning that with respect to reactivity, the very large structures seen in the black liquor spray may not be as problematic as would be expected.

Figure 23 and Figure 24 also show both the number distribution (top right) and mass distribution (bottom center). Analysis of the water spray in Figure 23 showed that less than $0.052 \%$ of the spray mass was contained in the 9,497 single pixel droplets. This is well described by the theoretical distributions, and was surprising when first seen only because most of the literature shows mass distributions rather than number distributions.
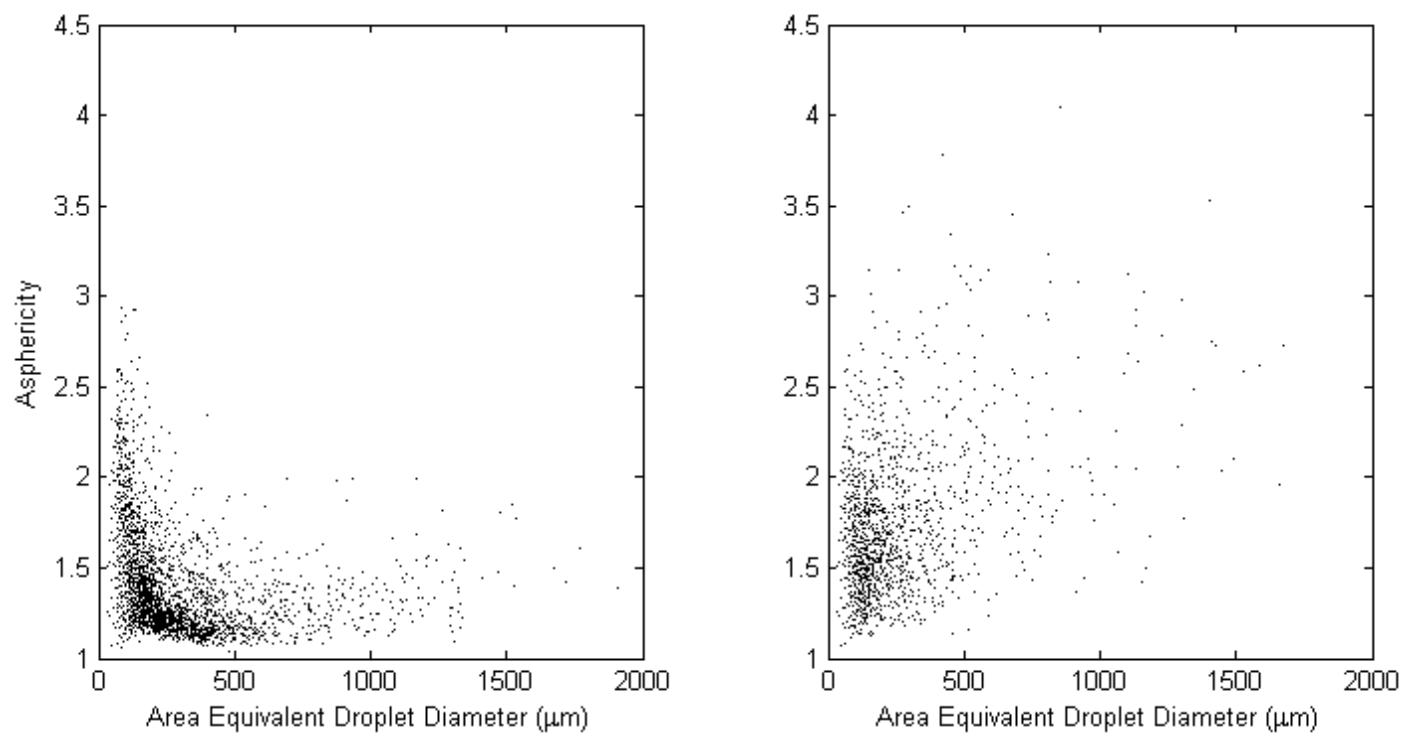

Figure 22. Comparison of water (left) and black liquor (right) droplet asphericity as a function of droplet size. 


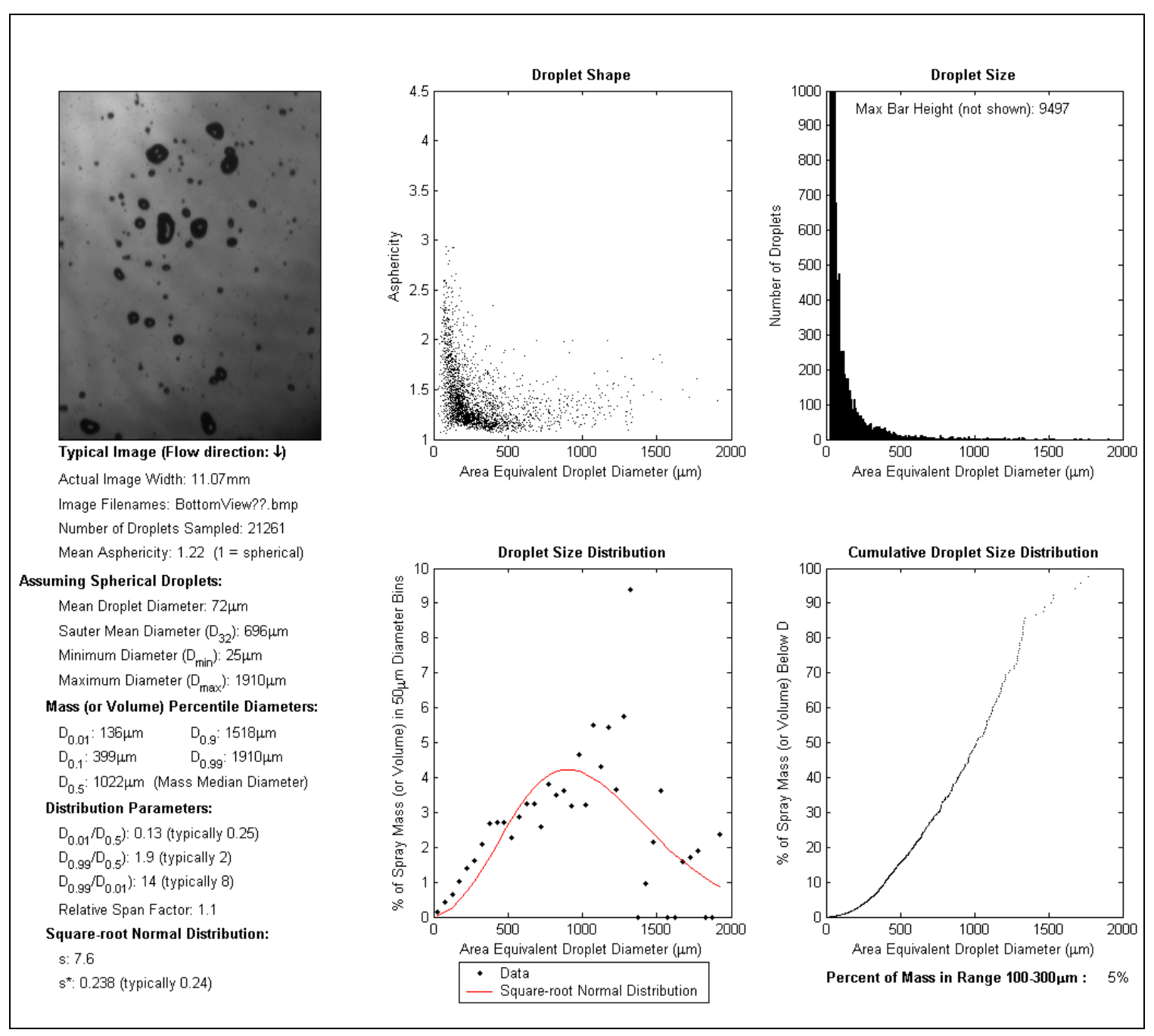

Figure 23. Image analysis results for a water spray.

Two possible reasons for the marked differences in the water and black liquor sprays are first, the difference in the liquid properties prior to injection, and second, the possibility that properties of the liquor on the surface change rapidly as a result of drying forming an outer layer or skin.

Surface tension is the liquid property that encourages droplets to become spherical while viscosity is the property that resists changes in shape. The Ohnesorge number $(\mathrm{Oh})$ is frequently used when studying droplet formation, and is a dimensionless ratio of viscous to surface tension forces. It is defined in Equation 1, and values of Oh for the sprays above are shown. Oh for the liquor was calculated to be 0.593 , and is more than three orders of magnitude greater than that calculated for water $(0.00487)$. So, it is likely that this is a significant factor in the final shape of the black liquor ligaments.

$$
\text { Oh }=\frac{\mu}{\sigma \rho_{\text {liquid }} d_{\text {nozzle }}}
$$




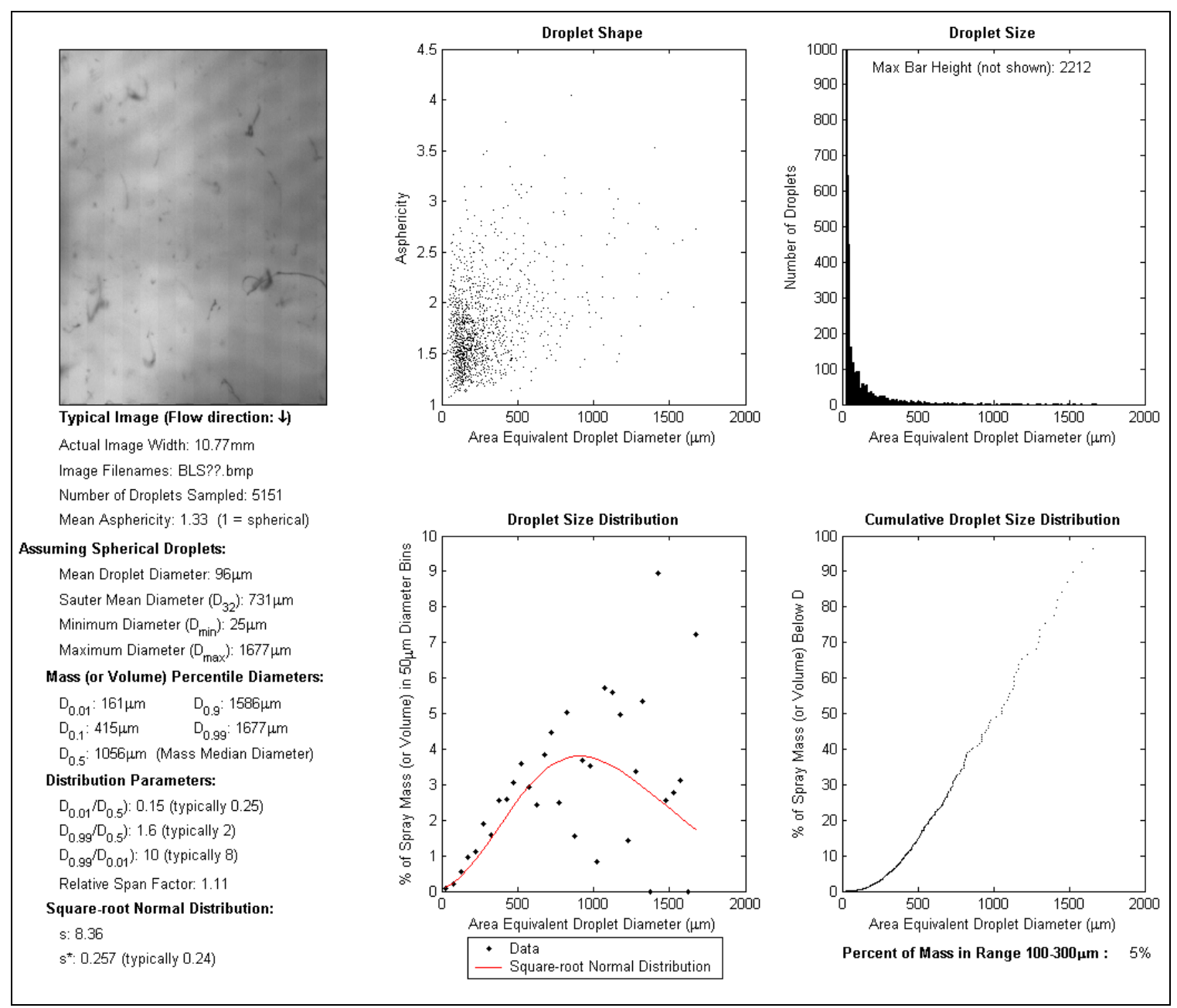

Figure 24. Image analysis results for a black liquor spray.

Bousfield [3] noted that evaporation of water from the surface of a black liquor structure can create a high viscosity skin capable of stopping droplet formation processes. This is also a possible explanation, as the liquor was pumped at $110^{\circ} \mathrm{C}$ (close to the elevated boiling point) and was atomized with dried compressed air.

\subsubsection{Comparison of Liquor Sprays in Hot and Cold Surroundings}

The $70 \%$ solids black liquor was sprayed into room temperature conditions and into the lower region of the electrically heated spray chamber (heated to $1000^{\circ} \mathrm{C}$ ). All other conditions were kept the same for these two tests, and the spray was imaged $50 \mathrm{~mm}$ downstream from the nozzle. Three image sets from each condition were taken and analyzed. Key parameters (shown in Figure 25) appeared to show a difference between the sprays in the two conditions. The Student's t-test is commonly used to test for statistically significant differences in small samples such as these and was used here to determine if the hot environment had an effect on the spray. The results of the t-tests are shown in Figure 25 as the probability that the hot and cold condition data came from the same population. As all of these values are less than $5 \%$ we can be at least $95 \%$ confident that the hot environment has an effect on the spray. As noted above, the parameter values are based on a spherical droplet assumption, which makes them 
somewhat meaningless as absolute values, but still useful as relative values to compare sprays such as these.

Larger droplets were produced in a high temperature environment in these tests. Since the fluid properties are initially the same for both black liquor sprays, the change in size must be attributed to the higher ambient gas temperature. This is consistent with the hypothesis that a skin is formed on the surface of the ligaments hampering the progress of droplet formation.

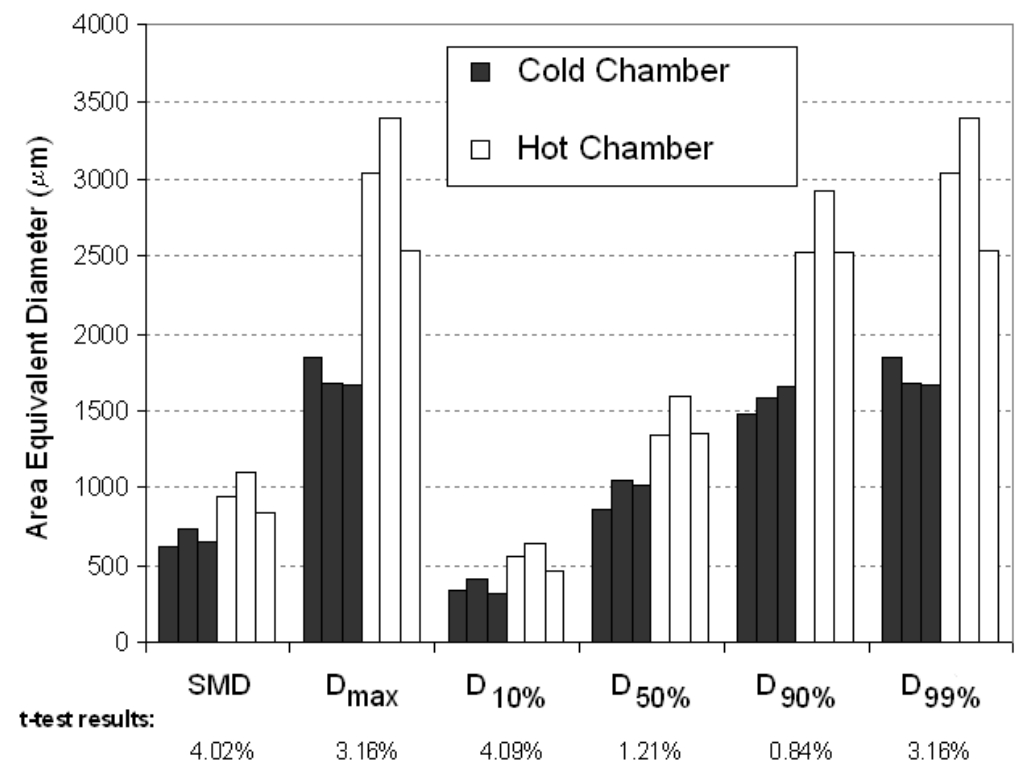

Figure 25. Summary of results of image analysis on black liquor sprays in hot and cold chambers. The Student's t-test results show that the claim that the hot environment produced larger droplets is statistically significant.

\subsection{Single Droplet Imaging}

Several different methods of producing a monodisperse stream of black liquor droplets were considered. Initially, a vibrating orifice approach was pursued. Such a system has been successfully used in the past to create a stream of monodisperse droplets of heavy fuel oil. A stream of water droplets was successfully produced. However, the design and electronics for the vibrating orifice system are rather complex, and practical considerations such as liquor heating and probe design ultimately led to the decision to pursue a simpler design, the shear stripping injector described in section 2.3.

In development of the final design, a prototype single droplet generator based on the shearing approach was constructed. This generator underwent a series of modifications during development, until the relative geometries of the liquor tube and air annulus and corresponding flow rates were considered acceptable. The final droplet generator, shown in Figure 9, was based on the best geometries from the prototype generator. 
A photo of the tip of the prototype generator and the resulting droplets is shown in Figure 26 . The droplets produced by this prototype were somewhat larger than desired, roughly 550 microns. The new generator was able to produce droplets less than 300 microns in diameter.

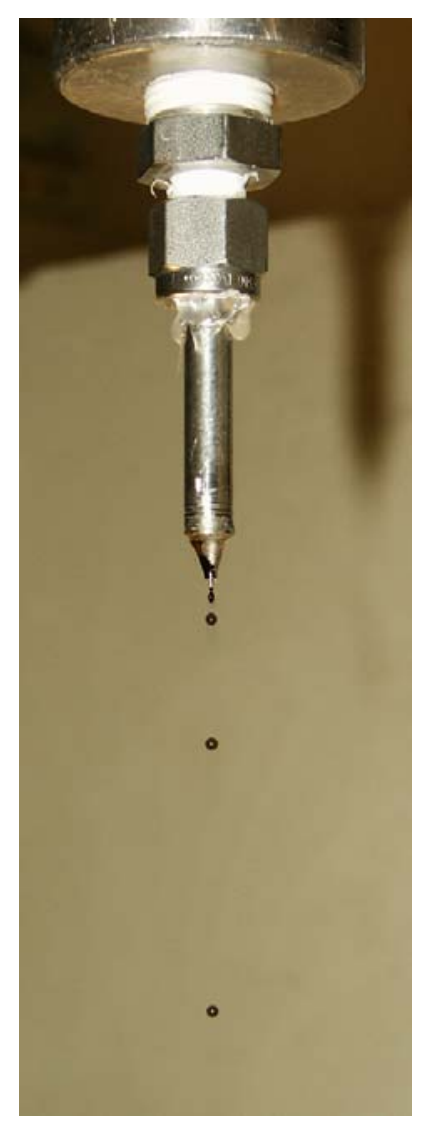

Figure 26. Tip of the prototype droplet injector and resulting droplet stream.

\subsection{Computational Modeling of Black Liquor Spray Formation}

Simulent, Inc. developed a simulation of black liquor injection specifically into small-scale gasifier that was conducted under this program. Details regarding the modeling approach, and results of the simulations, are presented in the sections below.

\subsubsection{Numerical modeling}

The nozzle that was given for simulation by University of Utah was an off-the-shelf full cone nozzle from a commercial supplier, with 0.061 inch orifice diameter. A picture of the nozzle is shown in Figure 27. This nozzle is made with internal removable vane design. To obtain the internal design of the nozzle, it was dismantled and after carefully measuring the dimensions of different parts, the nozzle geometry was regenerated using a CAD software. The resulting design is shown in Figure 28. 


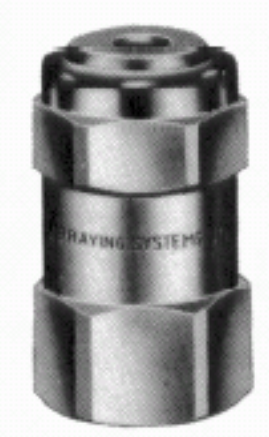

Figure 27. The Full Jet 1/8G3 nozzle. (Spraying System Co.)

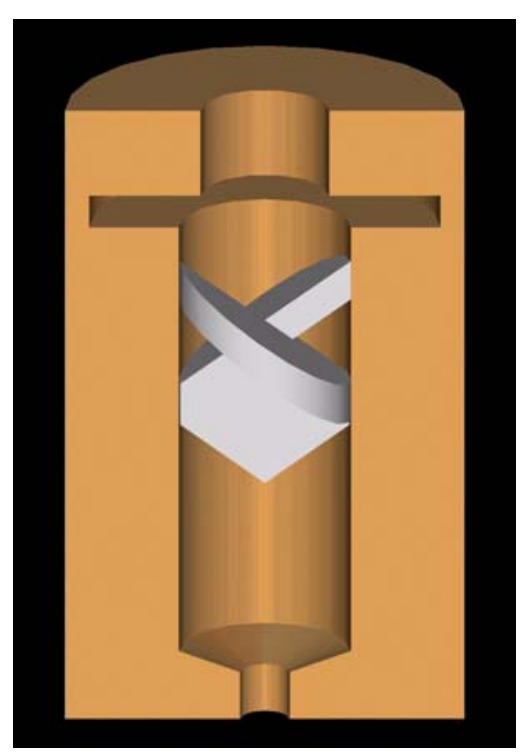

Figure 28. The CAD design of the nozzle, shown in Figure 27.

The design, shown in Figure 27, was used for numerical simulation of flow inside the nozzle.

In order to simulate the fluid flow inside the nozzle and to obtain the droplet size and velocity distribution outside the nozzle in a reasonable time and with required efficiency, it was decided that the simulation takes place in four stages, as shown in Figure 29:

1. Simulation of the liquid inside the nozzle under steady state conditions

2. Free surface flow simulation outside the nozzle at a short distance from the nozzle exit

3. Determination of the droplet size and velocity at the exit of the nozzle, using a linearized instability sheet atomization model

4. Simulation of the atomization and spray characteristic at a further distance from the nozzle (10 centimeter from the orifice). 


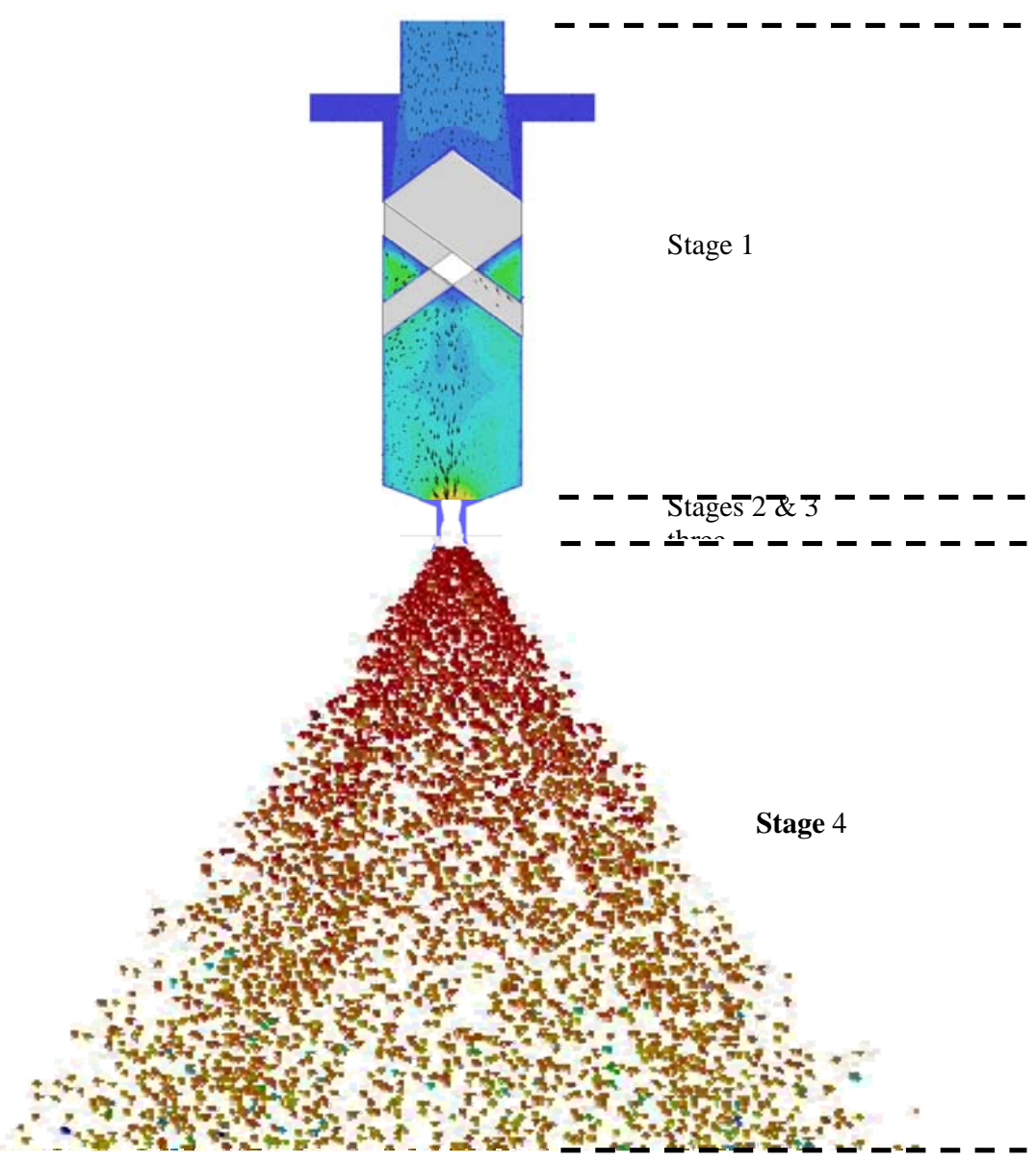

Figure 29. Schematic presentation of the simulations steps for modeling the atomization.

\subsubsection{Stage 1: Flow inside the nozzle}

For the internal flow simulation (inside the nozzle), a single phase, steady state, three dimensional algorithm was used that also included a turbulence model. The number of tetrahedral cells, generated for simulation, for inside the nozzle was 795,127 cells. Figure 30 shows the mesh generated for simulating the nozzle, as well as the locations of flow inlet and outlet boundary conditions. In Figure 31, the close up for the tetrahedral mesh is shown. 


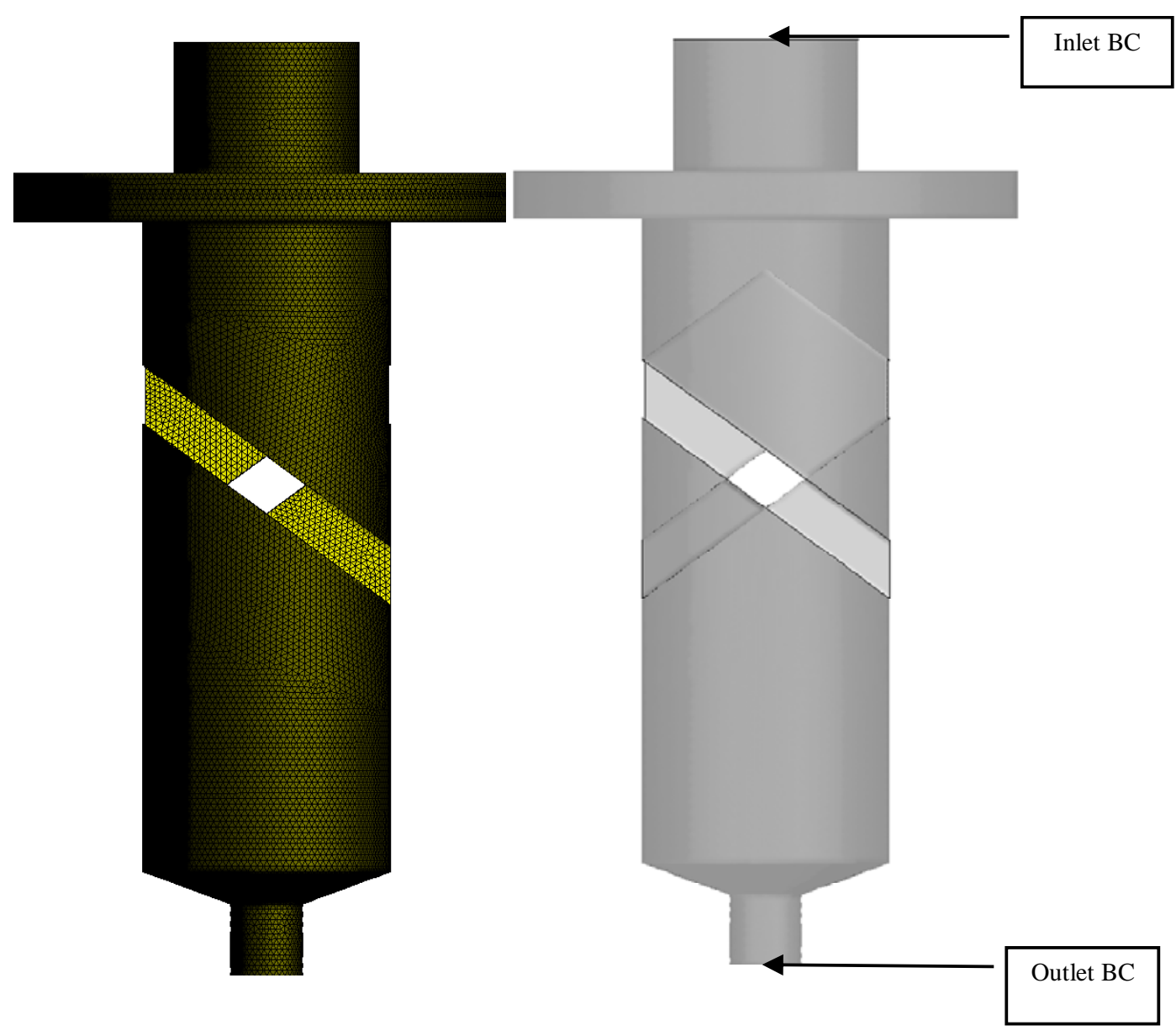

Figure 30. Simulation domain, flow boundary location, and mesh generated for simulating the flow inside the nozzle.

The simulations were performed for two different inlet flow rates of 2 liters $/ \mathrm{min}$ and 3 liters $/ \mathrm{min}$. To validate the model and to be able to compare with the experimental data, the properties of water, i.e., density and viscosity, at standard conditions were used for the first set of the simulations. In Figure 32, the steady state pressure contours inside the nozzle at two different flow rates are shown. The pressure contours are presented on a cross section plane, at the middle of the nozzle. The magnitudes of the pressure at the inlet to the nozzle is about 4 and 6.5 atmospheres for flow rates of 2 and 3 liters $/ \mathrm{min}$, respectively. These numbers are very close to the suggested values from the manufacturer.

Also in this figure it can be seen that at the orifice of the nozzle the liquid pressure is negative, indicating the vacuum generated by swirl velocity. This issue is very important during the modeling process, because as will be shown later, in the free surface flow modeling at the exit of the nozzle this negative pressure plays a significant role. 


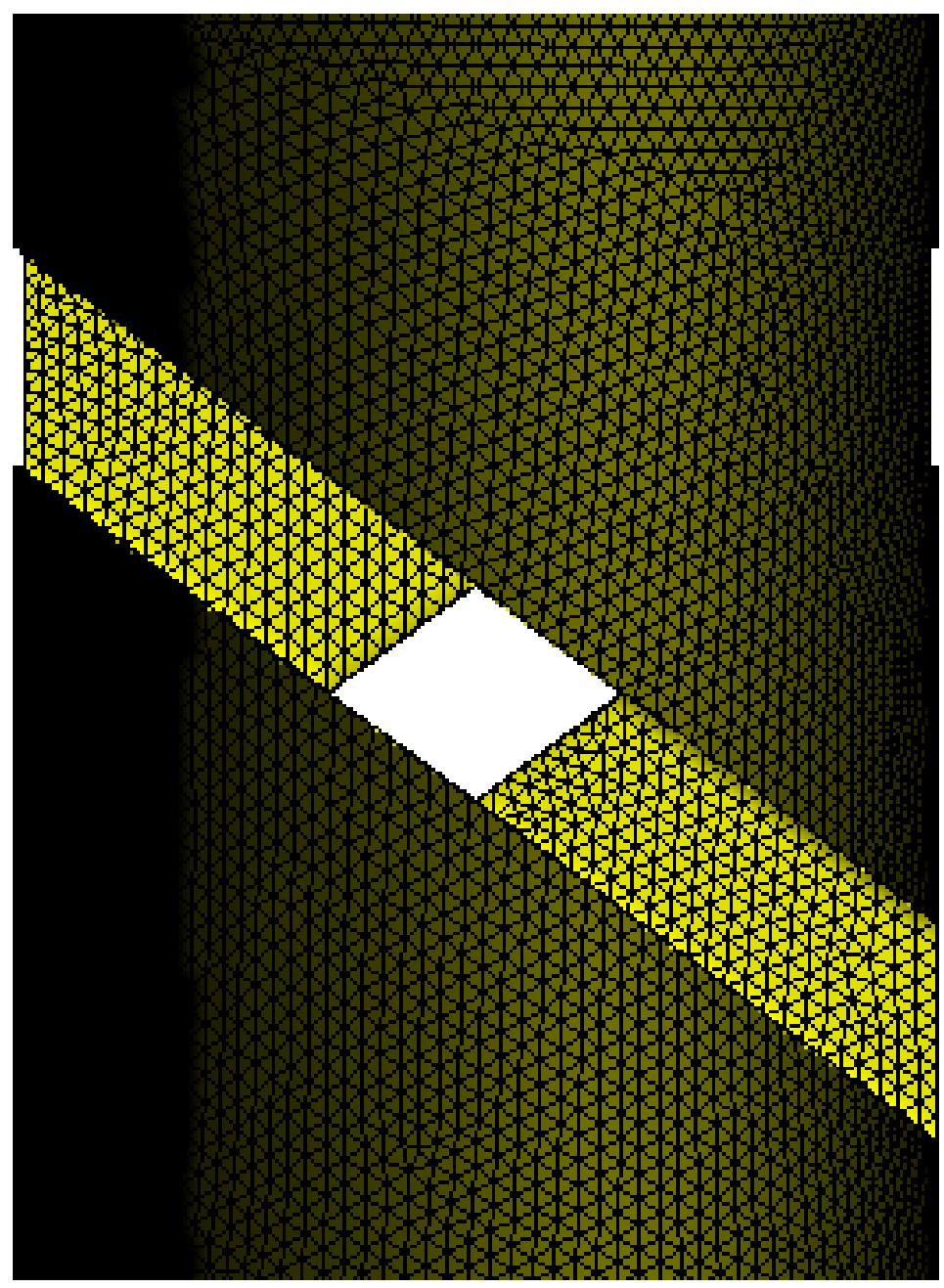

Figure 31. Close up of the tetrahedral cells, generated close to the vanes. 


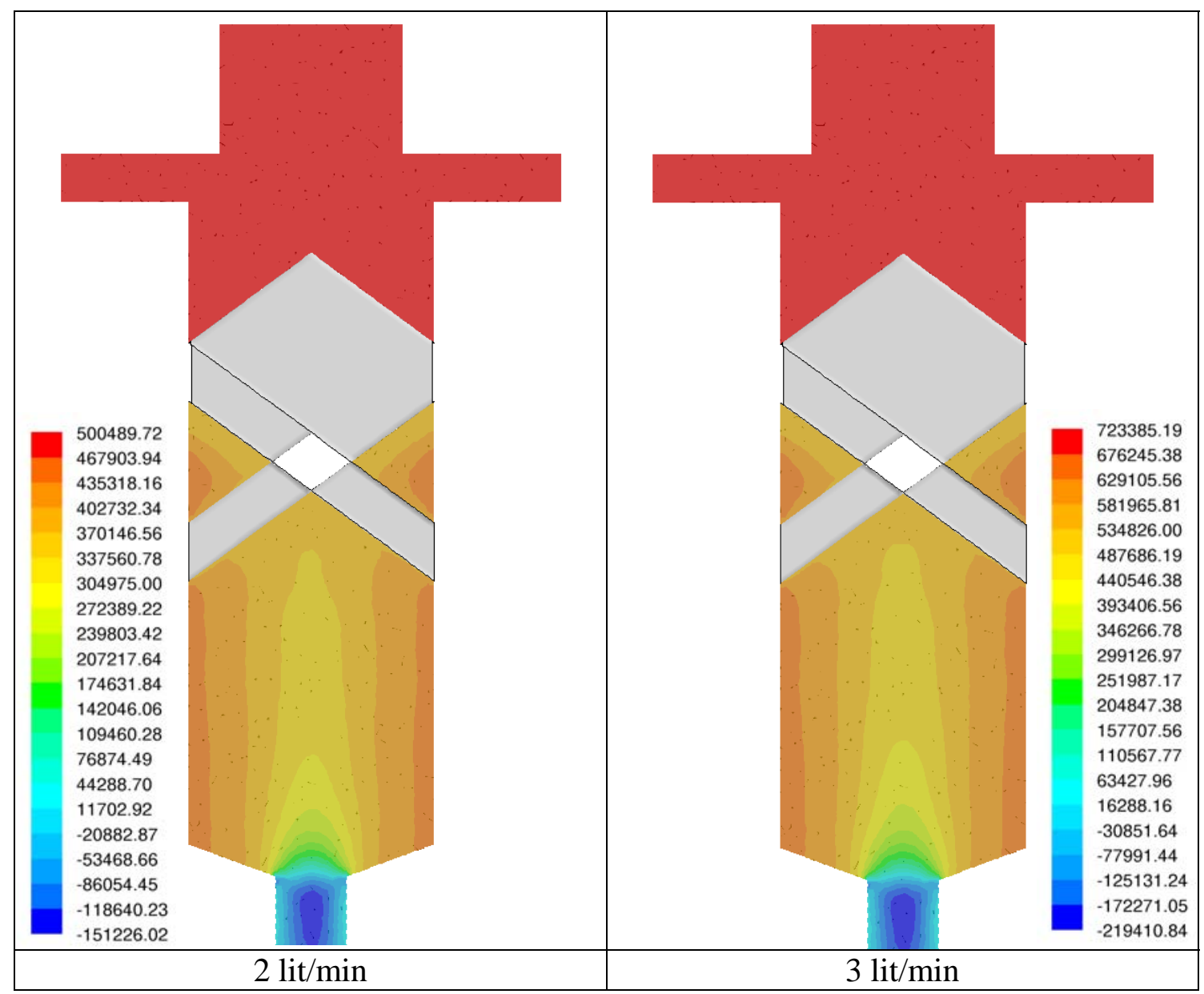

Figure 32. Pressure contours inside the nozzle at two different flow rates. The unit for pressure is Pascal.

Figure 33 shows the flow velocity contours and vectors at the same locations where the pressure contours are shown. The average outlet flow velocities are about 30 and $35 \mathrm{~m} / \mathrm{s}$, for inlet flow rates of 2 liters/min and 3 liters/min, respectively. 


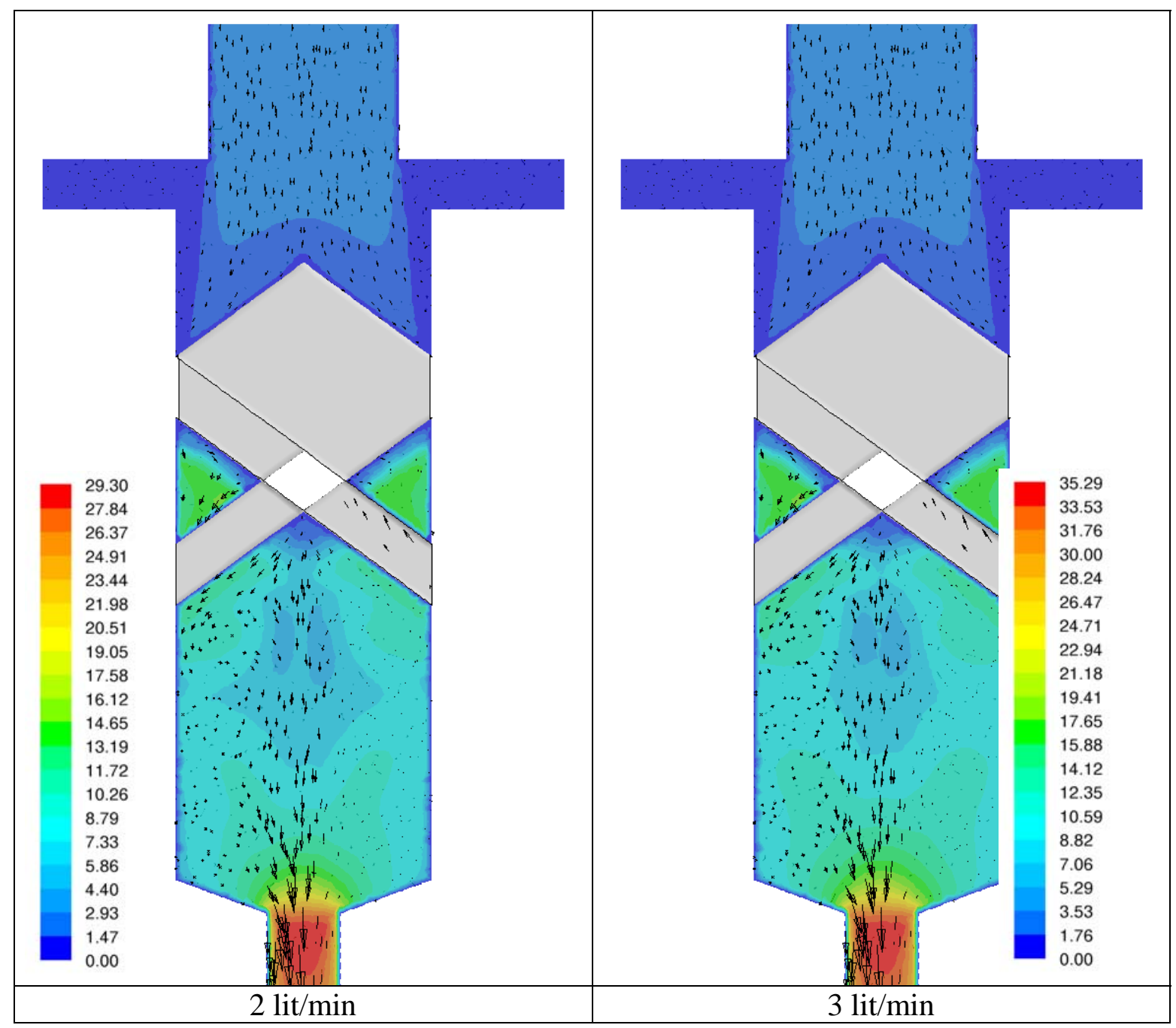

Figure 33. Velocity contours and velocity vectors of liquid at a cross section of nozzle, at the middle of the nozzle. The velocity unit is $\mathrm{m} / \mathrm{s}$.

In Figure 34, the flow stream lines inside the nozzle, corresponding to two different flow rates, are shown. As was expected, the two helical vanes inside the nozzle create flow swirl that lead to the increase of the velocity of the liquid. The colors of the stream lines correspond to the velocity magnitude of the liquid, shown in Figure 33. 


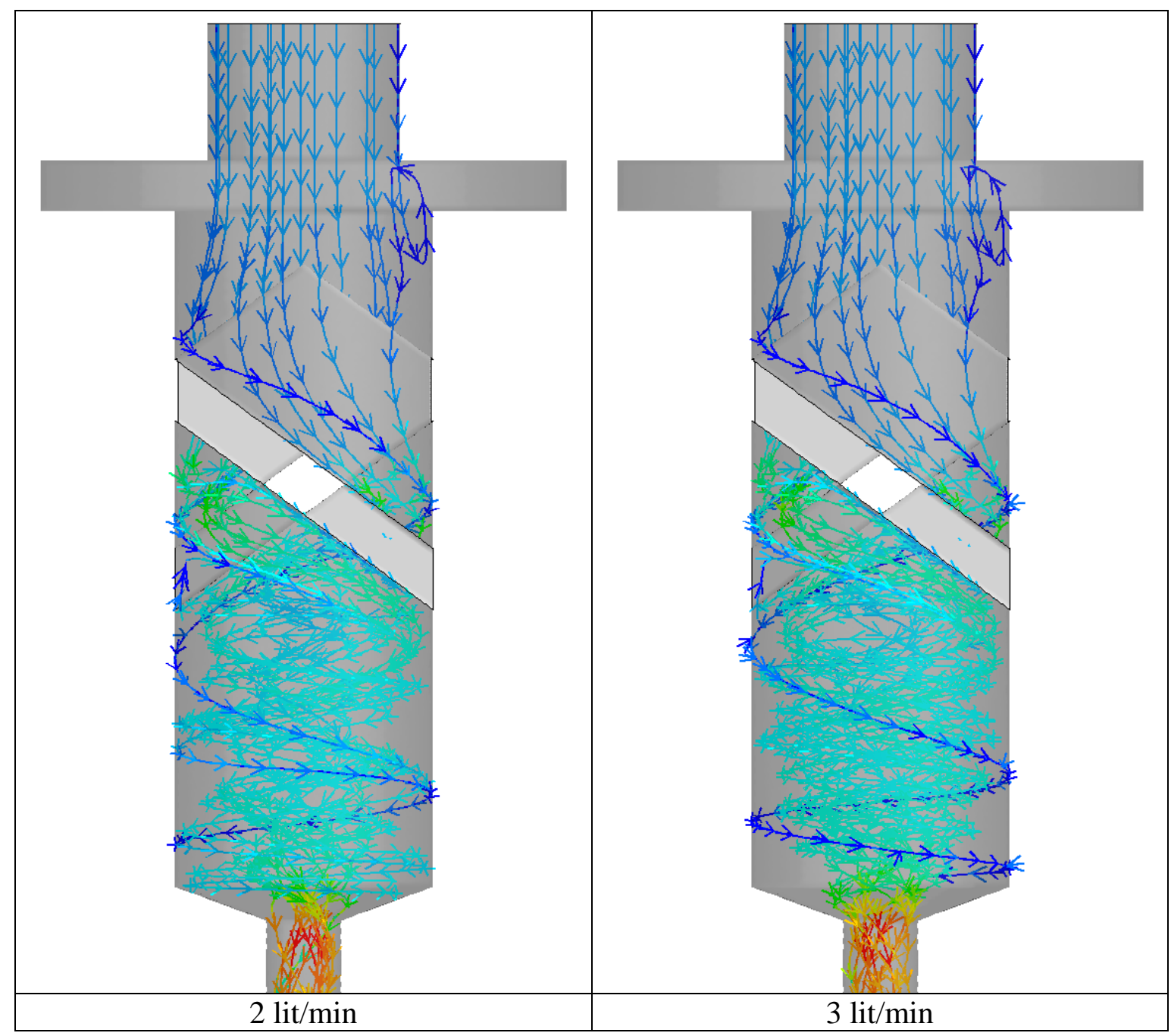

Figure 34. Flow stream lines inside the nozzle, colored based on the velocity magnitude

In Figure 35, the velocity vectors of liquid, at different cross section along the axis of the nozzle are shown. This figure also shows the configuration of the internal vanes. The generation of the swirl is clearly observed after liquid leaves the vanes.

Once the steady state solution was achieved, the velocity profile of the liquid at the exit of the nozzle is taken and used as the inlet condition for the next stage of the simulations. Due to the existence of the swirl at the exit of the nozzle and the resulting vacuum created at this location, see Figure 32, the second stage of simulation is not started just at the exit of the nozzle. Instead, as will be shown in the next section, the velocity profile at some position inside the main nozzle cylinder was selected. This position and the corresponding flow velocity are shown in Figure 36. 


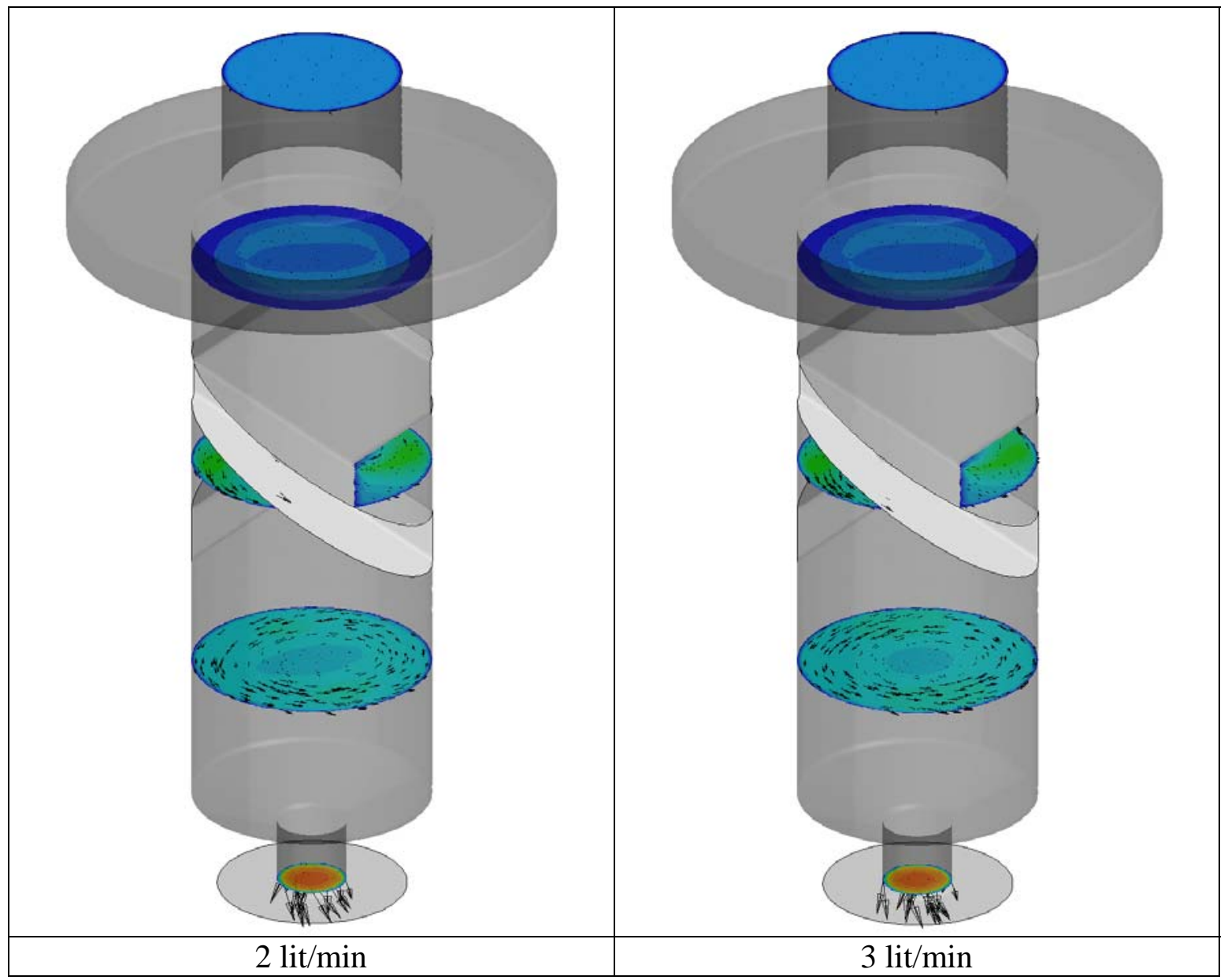

Figure 35. Velocity vectors at 4 different cross sections of the nozzle, along the axis. 


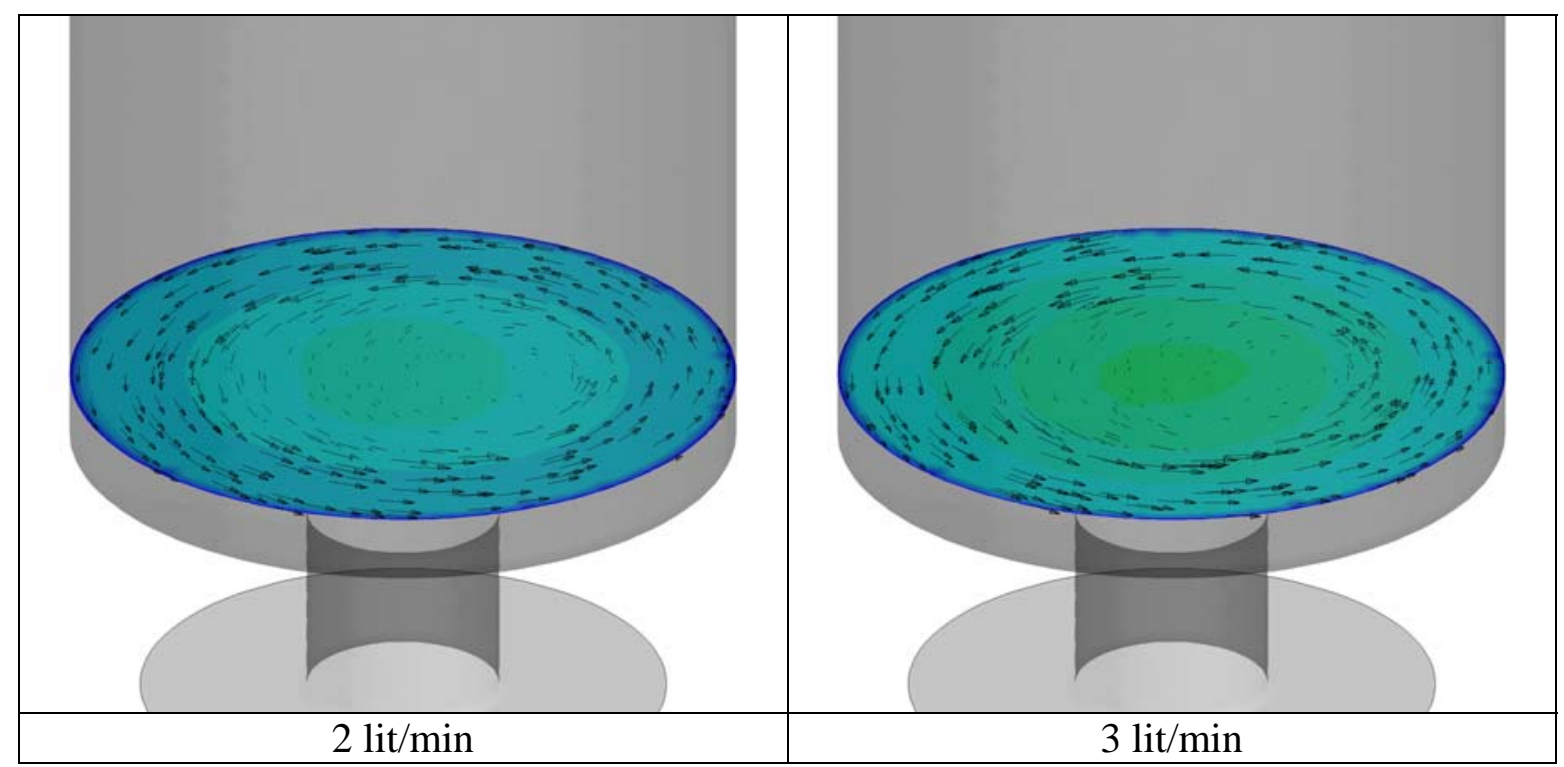

Figure 36. Velocity vectors at the cross section used as the inlet boundary for stage two of simulations.

Three components of the velocity vector at the exit of the nozzle, (location shown in Figure 36), i.e., axial, radial, and tangential components, were extracted from the results and their average values versus radius of the nozzle were plot in Figure 37. These values were then used as input liquid velocities for the next stage of the flow simulation.

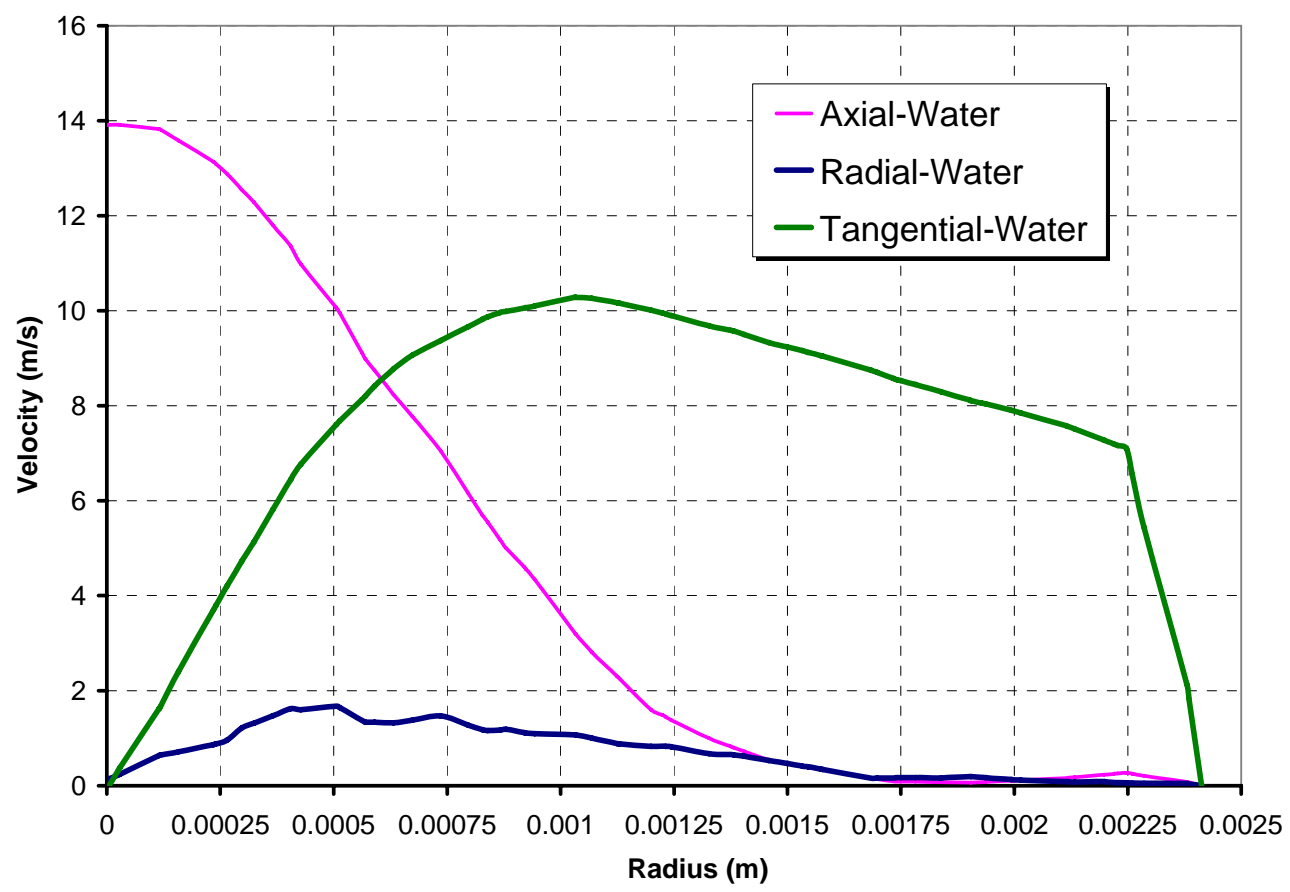

Figure 37. Average values of the axial, radial, and tangential components of the velocity at the exit of the nozzle 


\subsubsection{Stage 2: Spray modeling at the exit of nozzle}

In order to model free surface flow simulation outside the nozzle at a short distance from the nozzle exit, a two dimensional, two-phase, axi-symmetric model with swirl was used to reduce the calculation effort and to obtain results in a reasonable amount of time.

The two-dimensional axi-symmetric algorithm that simultaneously solves both liquid and gas phases separated by an arbitrary interface was developed. Some of the specific attributes of this code are:

- 2-D axi-symmetric

- Both liquid and gas phases are solved simultaneously

- Volume of Fluid (VOF) technique is used to model the interface separating gas and liquid

- Both flows are laminar, viscous and incompressible 


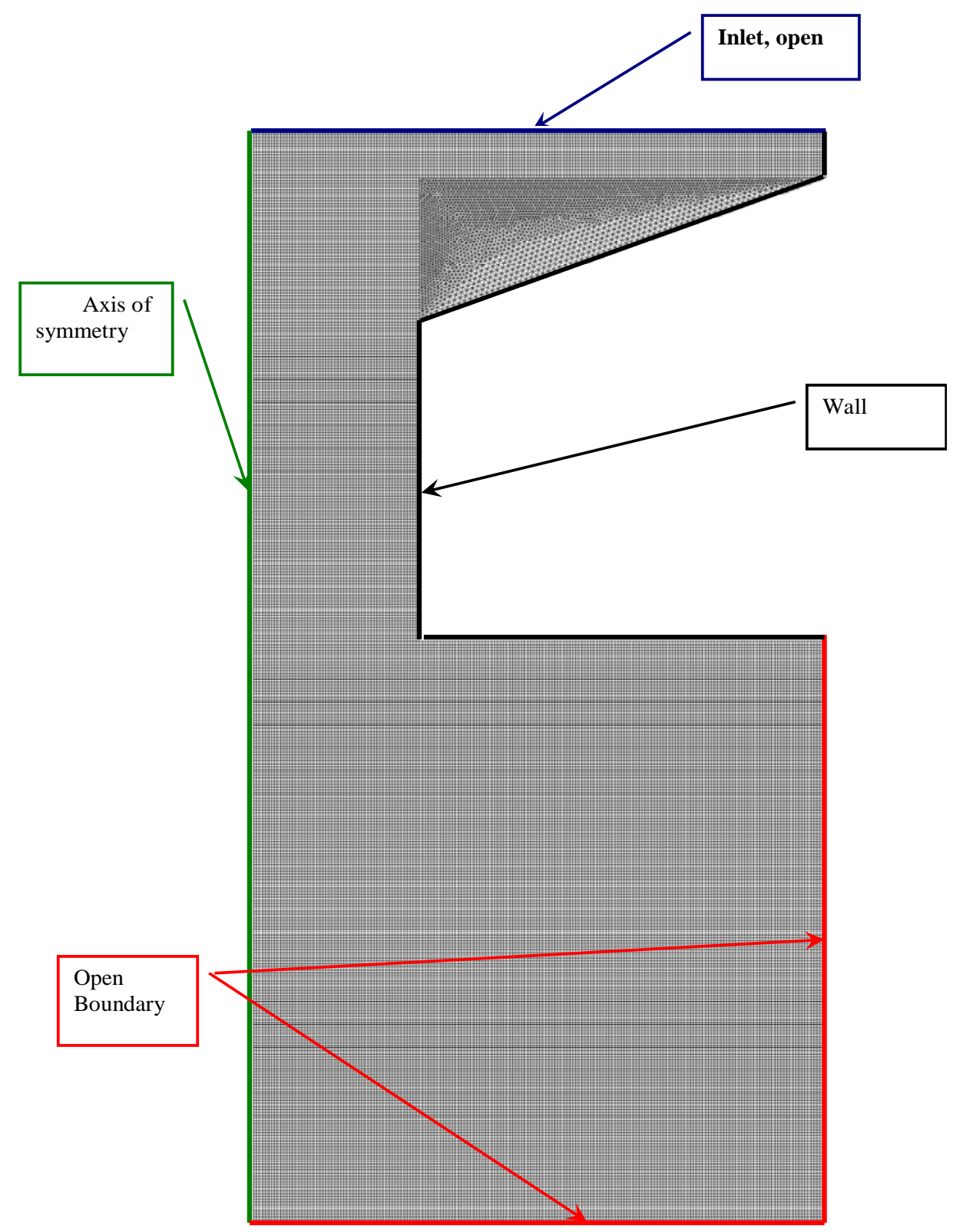

Figure 38. Schematic of the 2-D axi-symmetric simulation domain for stage two.

The calculation domain for the free surface simulation is shown in Figure 38 and corresponding boundary types are indicated in this figure as well. The total number of cells used in this simulation was 54,772, which is more refined at the conic part of the nozzle, (Figure 39). 


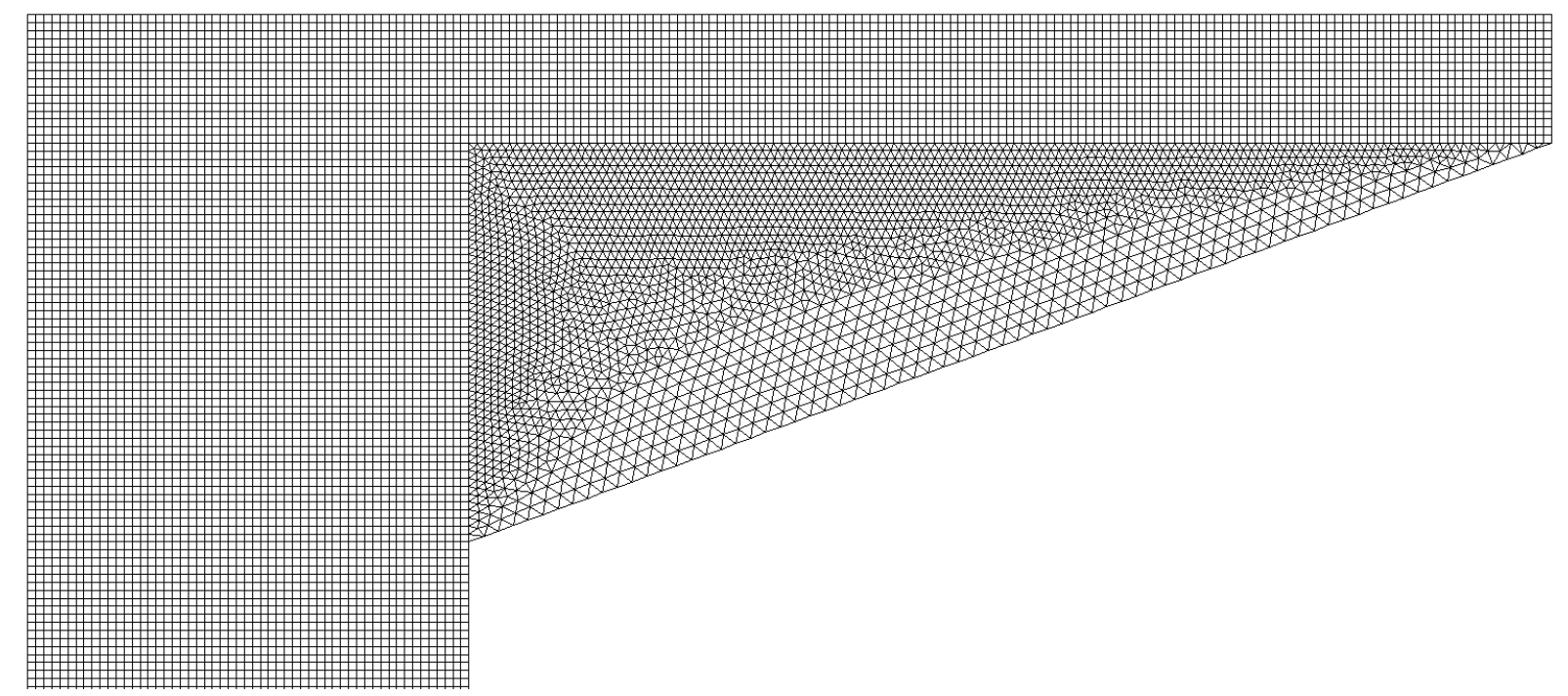

Figure 39. Mesh refinement at the conical part of the nozzle.

In Figure 40 and Figure 41, the snapshots of the results, for two flow rates of 2 and $3 \mathrm{lit} / \mathrm{min}$ are shown respectively. The Figure shows the liquid sheet exiting from the nozzle at a short distance of the nozzle tip. The snapshots are $10 \mathrm{~ms}$ apart.

The suction of the air into the nozzle orifice, which is due to the swirl, is clearly obvious from these pictures. That is the reason why the free surface simulations were started from the inside the nozzle. The surrounding air was assumed to be still (no air velocity).

As can be seen, due to the existence of the swirl, the thickness of the liquid sheet and the spray angle at this location varies slightly with time. The thickness of the liquid sheet at the exit of the nozzle was measured at different times at $1 \mathrm{~mm}$ below the nozzle exit. This thickness was used in the next stage of calculation to estimate the initial droplet size at the exit of the nozzle. Also at this stage the spray angle was measured at different time intervals and the average values were used as the spray angle. These values are shown in Table 1. 


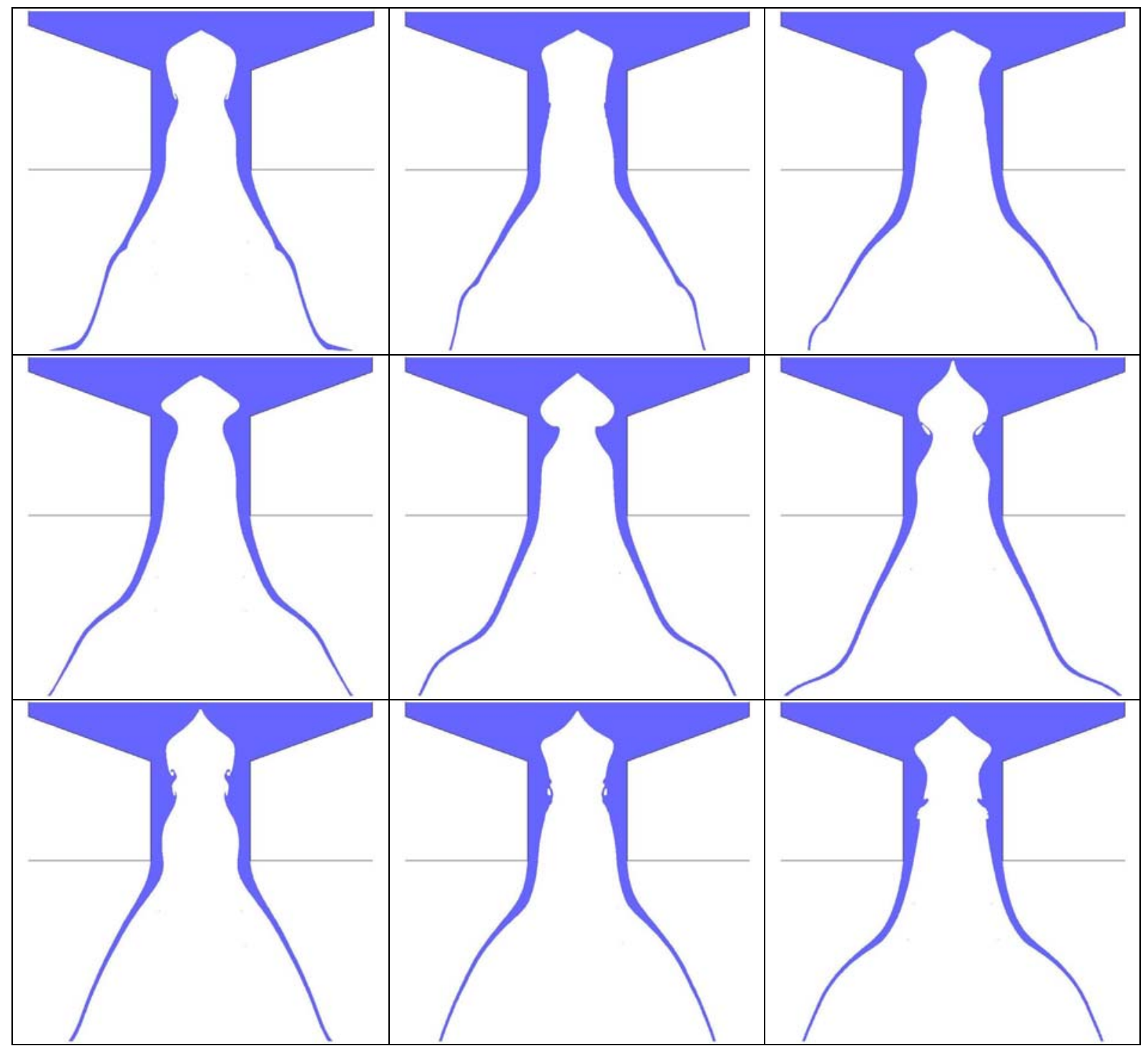

Figure 40. Snapshots of the 2D modeling of the flow at the exit of nozzle for flow rate of 2 liters/min. Time interval between snapshots is $10 \mathrm{~ms}$. The horizontal lines indicate the location of the nozzle tip. 


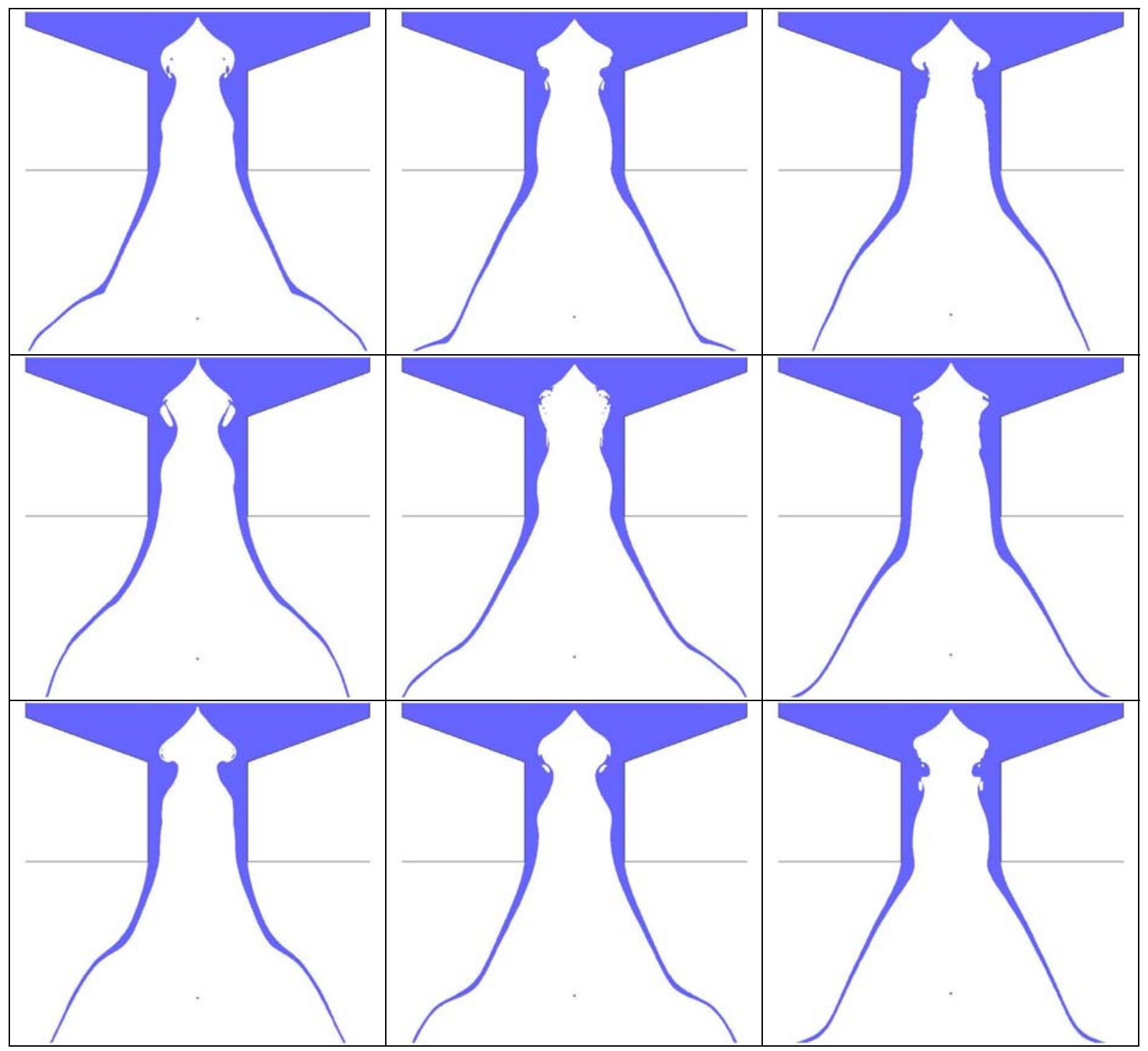

Figure 41. Snapshots of the 2D modeling of the flow at the exit of nozzle for flow rate of 3 liters/min. Time interval between snapshots is $10 \mathrm{~ms}$. The horizontal lines indicate the location of the nozzle tip.

\subsubsection{Stage 3: Estimating the Droplet size at the exit of nozzle}

To determine the initial droplet size at the nozzle exit, a statistical model was used. This model, also known as the Linearized Instability Sheet Atomization (LISA) model, utilizes a linearized instability analysis of the breakup of a viscous liquid sheet to estimate the initial droplet size.

In this analysis, first an expression for the most unstable disturbance of the wave growth rate is driven and next by using the average liquid sheet velocity and properties, nozzle geometry (nozzle exit diameter) and liquid (water or black liquor) properties, resulting droplet diameter is associated to the amplitude of the unstable wave. More details about this method can be found in paper by Senecal, et al. [4]. 
By using data obtained from the free surface simulations into the LISA model and using the existing nozzle geometry and air and water properties, the droplet size at different times were calculated and shown in Figure 42 and Figure 43, for flow rates of 2 and 3 lit/min, respectively. Because of the swirl in the flow, the droplet size and velocity at the exit of the nozzle are presented in a specific time period. The time span is 0.1 ms which is a good representation of the fluctuations in velocity and sheet thickness.

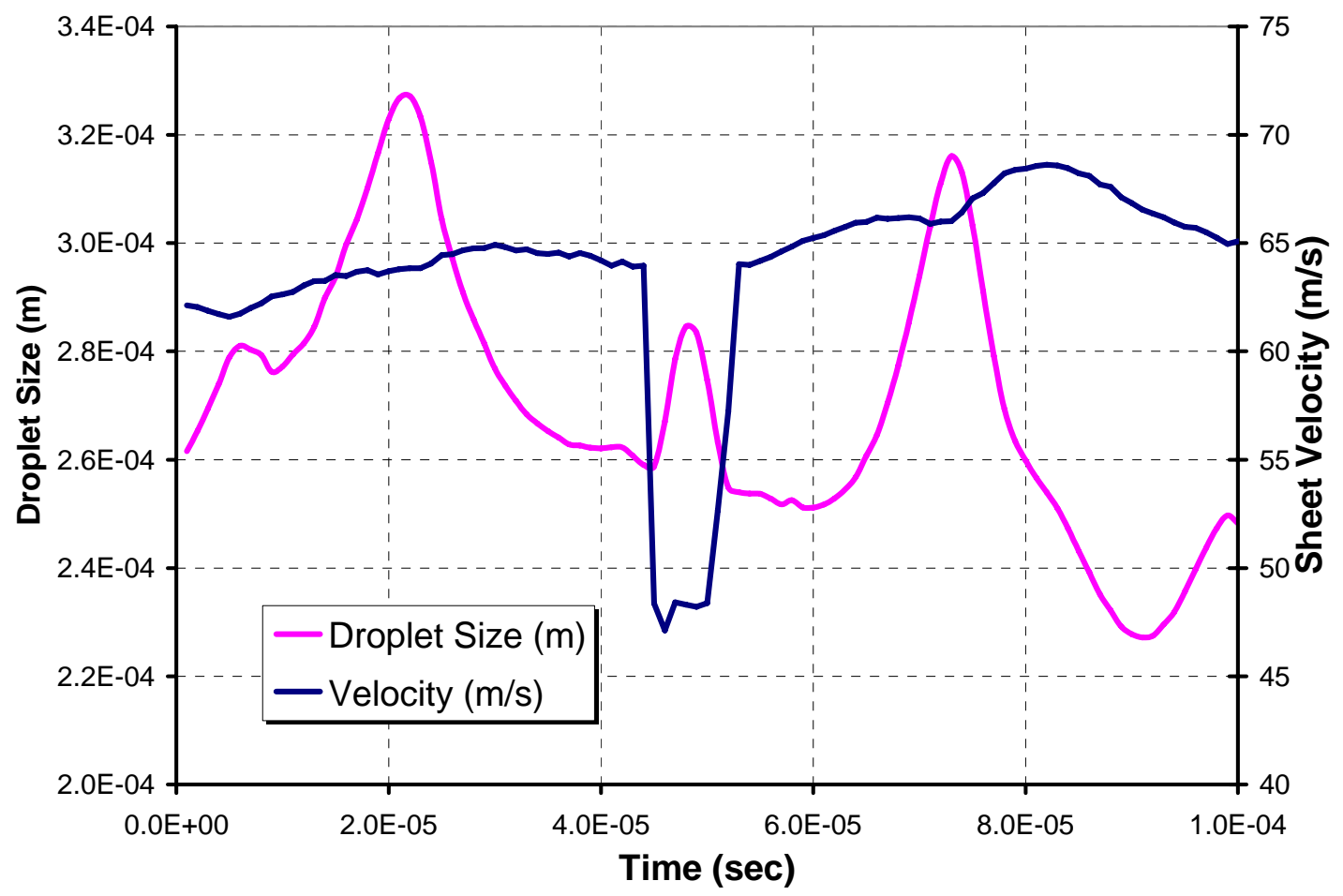

Figure 42. Droplet size and sheet velocity history at $\mathrm{Q}=2$ liters/min.

In Table 1, a summary of the minimum and maximum liquid sheet velocity and droplet sizes, at two different flow rates, as well as the average spray angle are shown. It must be mentioned that the average spray angles obtained from the simulation are very close to those reported by the nozzle manufacturer. 


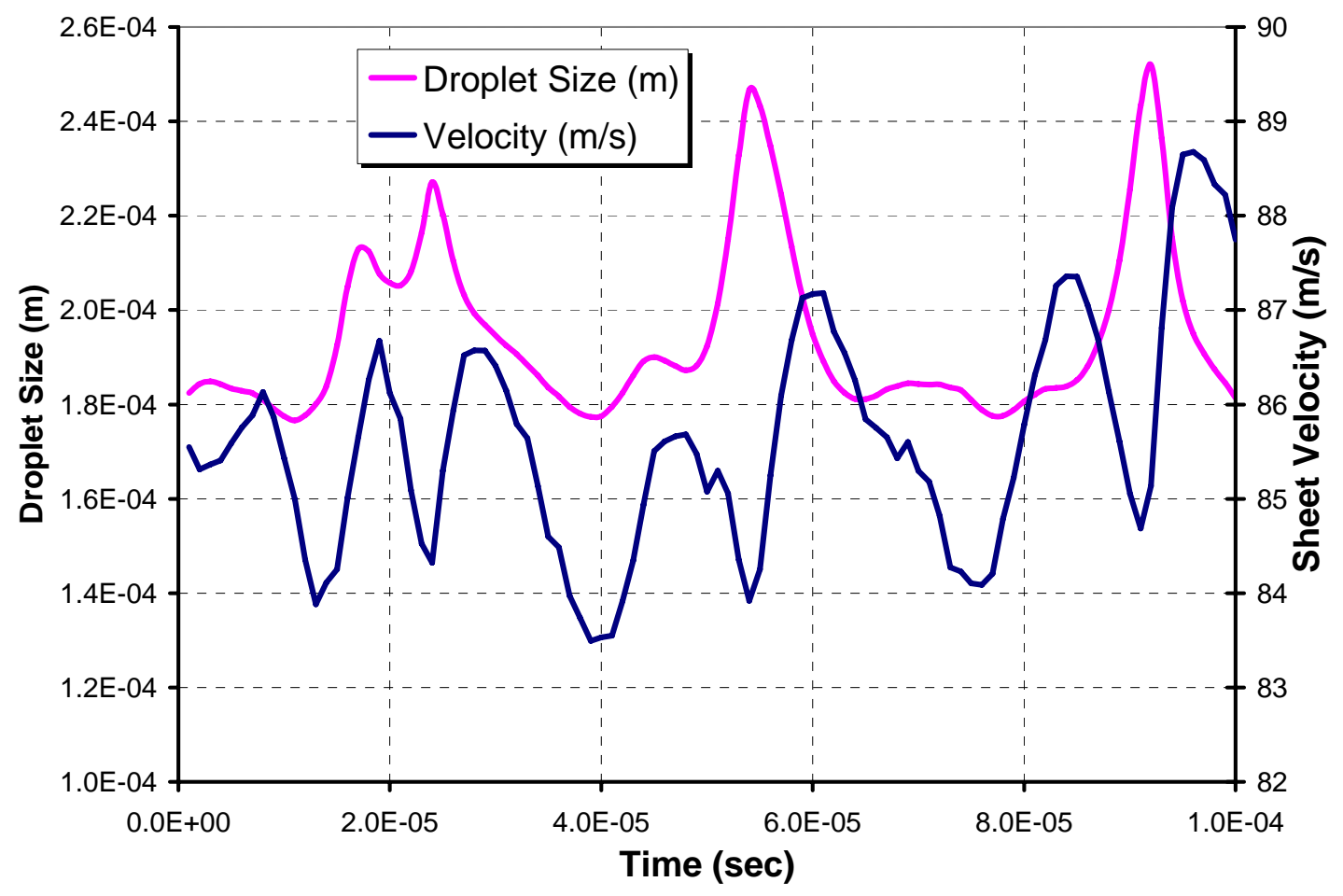

Figure 43. Droplet size and sheet velocity history at $\mathrm{Q}=3$ liters $/ \mathrm{min}$

TABLE 1. SUMMARY OF THE SHEET VELOCITY, DROPLET SIZE, AND SPRAY ANGLE AT THE NOZZLE EXIT

\begin{tabular}{lcc}
\hline & 2 liters/min & 3 liters/min \\
\hline Minimum velocity $(\mathrm{m} / \mathrm{s})$ & 47 & 84 \\
Maximum velocity $(\mathrm{m} / \mathrm{s})$ & 68 & 89 \\
Minimum drop size $(\mu \mathrm{m})$ & 230 & 180 \\
Maximum drop size $(\mu \mathrm{m})$ & 330 & 250 \\
Average spray angle & 52 & 58 \\
\hline
\end{tabular}

\subsubsection{Stage 4: Atomization Model}

A three-dimensional algorithm that models transient, turbulent, chemically reactive flows with sprays was developed. Some of the specific attributes of this code are: 
- Unsteady flow

- Turbulent flow

- Evaporation, collision and breakup of fuel particles

- Combustion

The algorithm simultaneously solves the continuity equation for all the species, the continuity equation for the total fluid flow, the momentum equation for the total fluid flow and the energy equation. It incorporates two turbulence models:

- Standard K- $\varepsilon$ turbulence model

- $\quad$ Sub-grid scale (SGS) model

The algorithm also solves the equation of state and considers the chemical reactions, if needed.

The 3D simulation was performed for water with the flow rate of 2 liters/min. In this simulation, the droplet sizes obtained from LISA model was used as the input (initial conditions) to the atomization model. The algorithm then provided the information about the droplet size distribution outside the nozzle. In Figure 44, the droplet size distribution for this case is shown. Figure 45 shows the velocity histogram calculated for the same flow rate.

In Table 2, the summary of the droplet size and velocity, for the flow rate of 2 liters/min is shown.

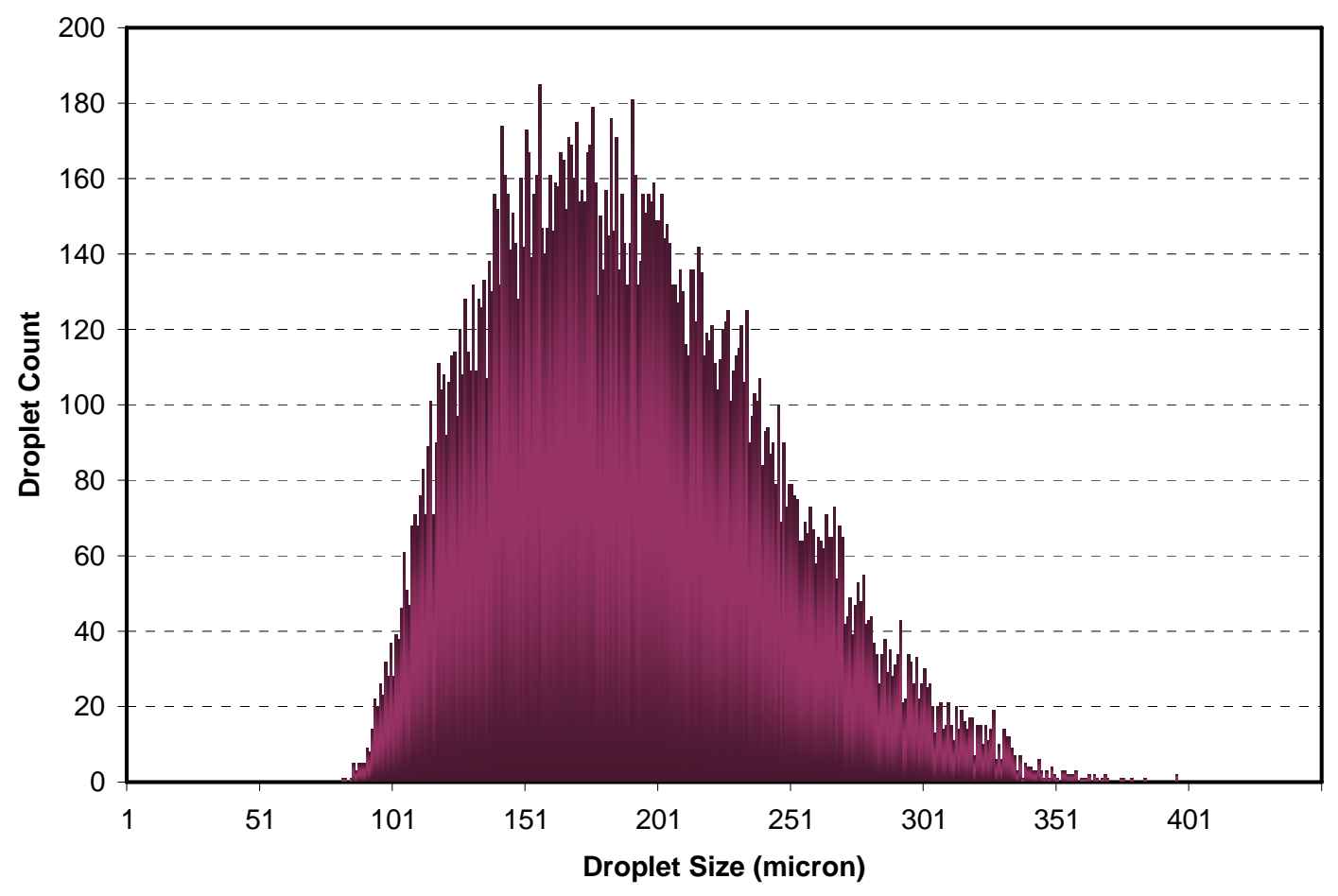

Figure 44. Droplet size distribution at $10 \mathrm{~cm}$ below the nozzle, simulation results. Flow rate is 2 liters/min. 


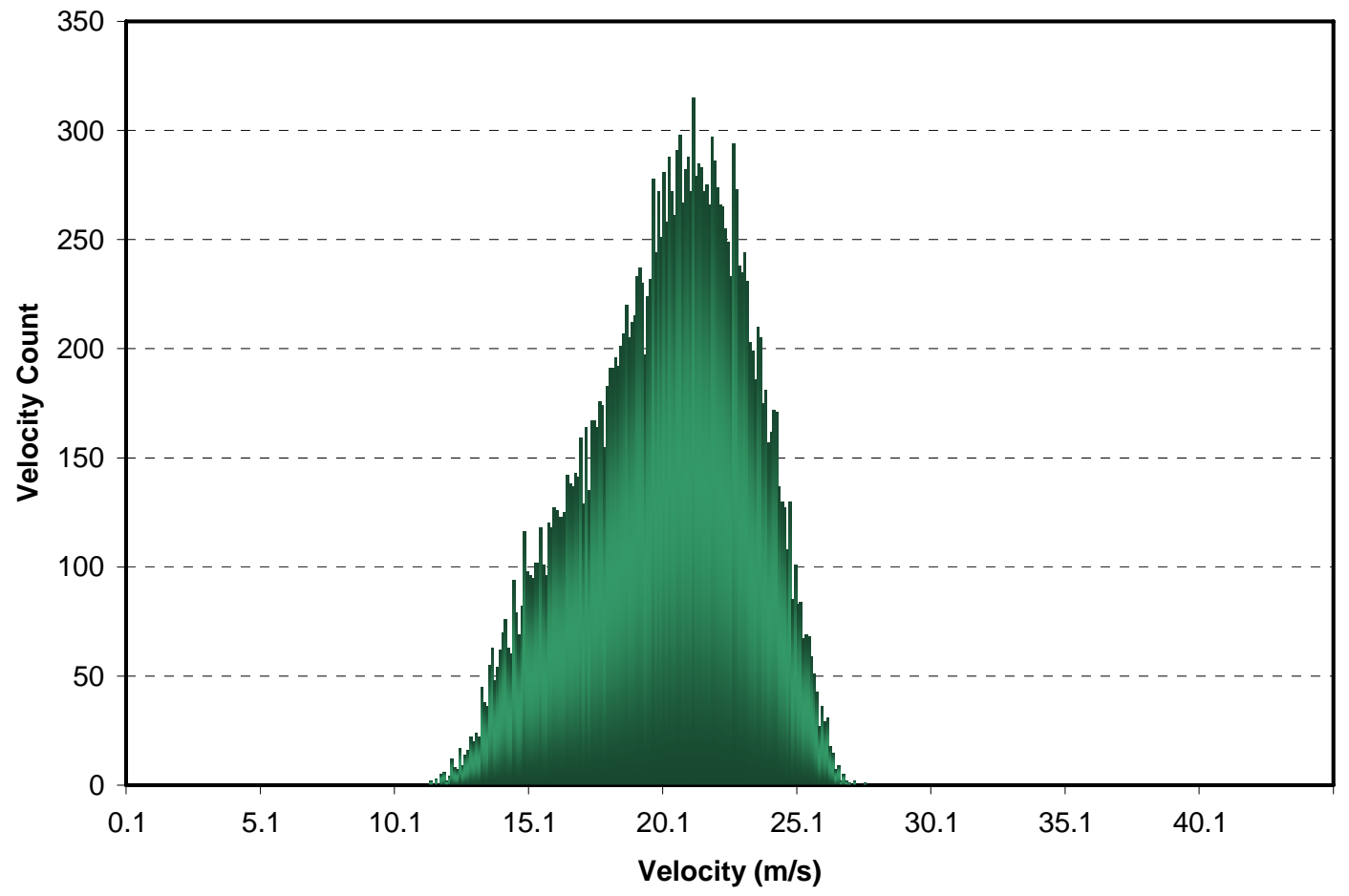

Figure 45. Velocity histogram at $10 \mathrm{Cm}$ below the nozzle, simulation results. Flow rate is 2 liters/min.

TABLE 2. SUMMARY OF NUMERICAL RESULTS FOR FLOW RATE OF 2 LITERS/MIN

\begin{tabular}{lc}
\hline $\mathrm{D} 10(\mu \mathrm{m})$ & 190 \\
$\mathrm{D} 20(\mu \mathrm{m})$ & 197 \\
$\mathrm{D} 30(\mu \mathrm{m})$ & 203 \\
$\mathrm{D} 32(\mu \mathrm{m})$ & 218 \\
Average velocity $(\mathrm{m} / \mathrm{s})$ & 20 \\
\hline
\end{tabular}

Figure 46 shows a snap shot of the atomization simulation outside the nozzle for water with flow rate of 2 liters/min. 


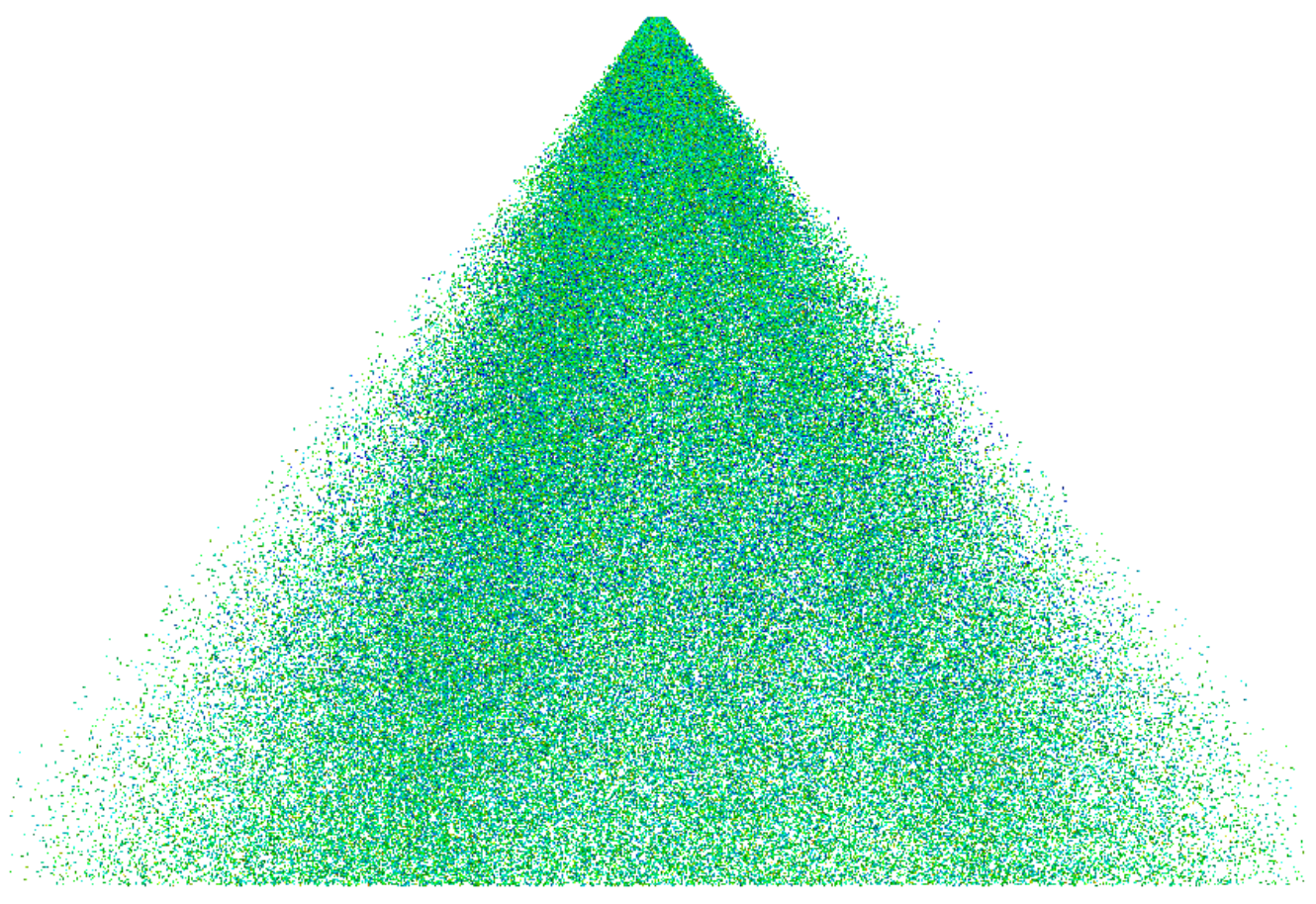

Figure 46. A snap shot of the simulation results for spray distribution and spray angle outside the nozzle. Colors represent the size of each particle, blue being smaller size and yellow larger sizes.

\subsubsection{Experimental study of Fulljet nozzle}

In order to validate the numerical modeling of droplet size and velocity for the full cone nozzle, and since such information was not already available, it was decided that the nozzle to be tested at the Multiphase Flow and Spray System Laboratory at the University of Toronto. The experiments were performed in the Spray Booth facility, shown in Figure 47 which is equipped with a three dimensional traverse system.

The droplet size and velocities were measured using the Phase Doppler Particle Analyzer (PDPA) which allows for the sizing of spherical particles. Along with size information, the velocity of the particle is also obtained, so in this sense the phase Doppler technique is an extension of LDV. The PDPA image and schematic of the measurement process are shown in Figure 48. 


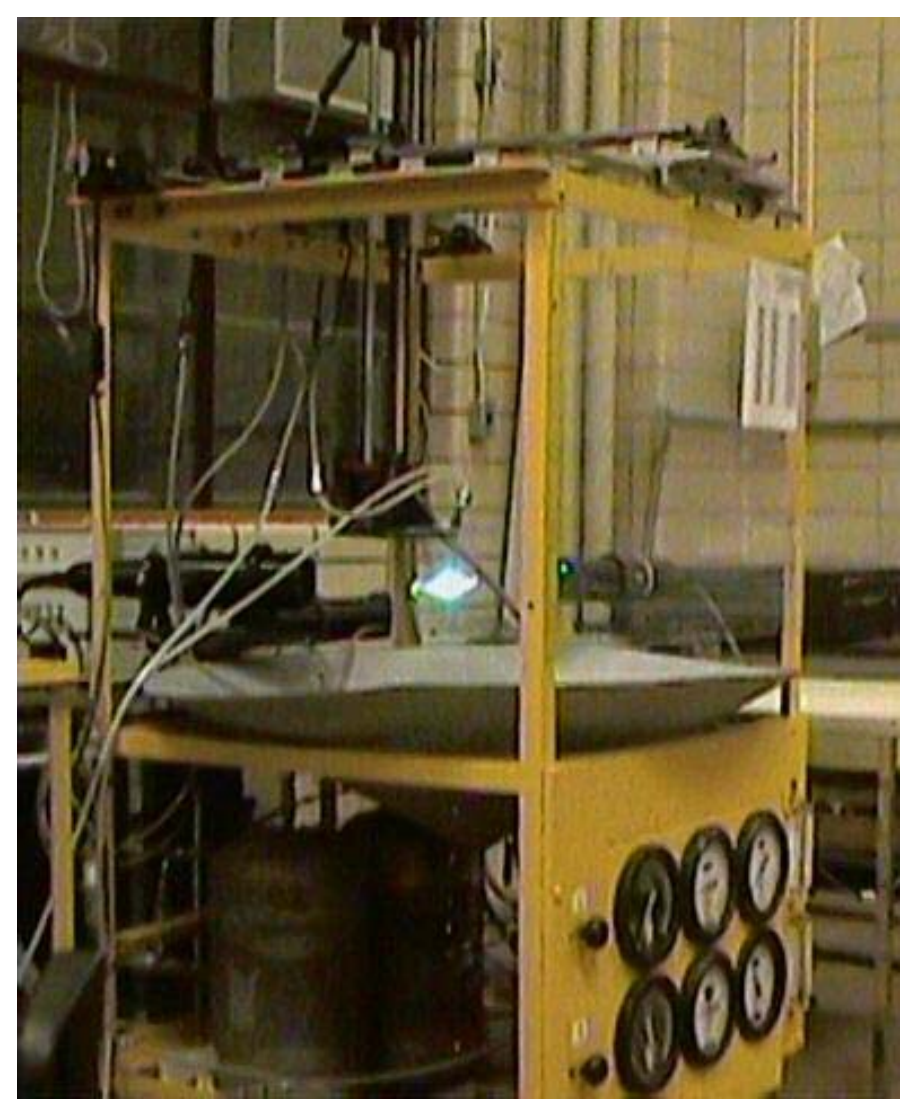

Figure 47. Spray Booth at MUSSL, University of Toronto
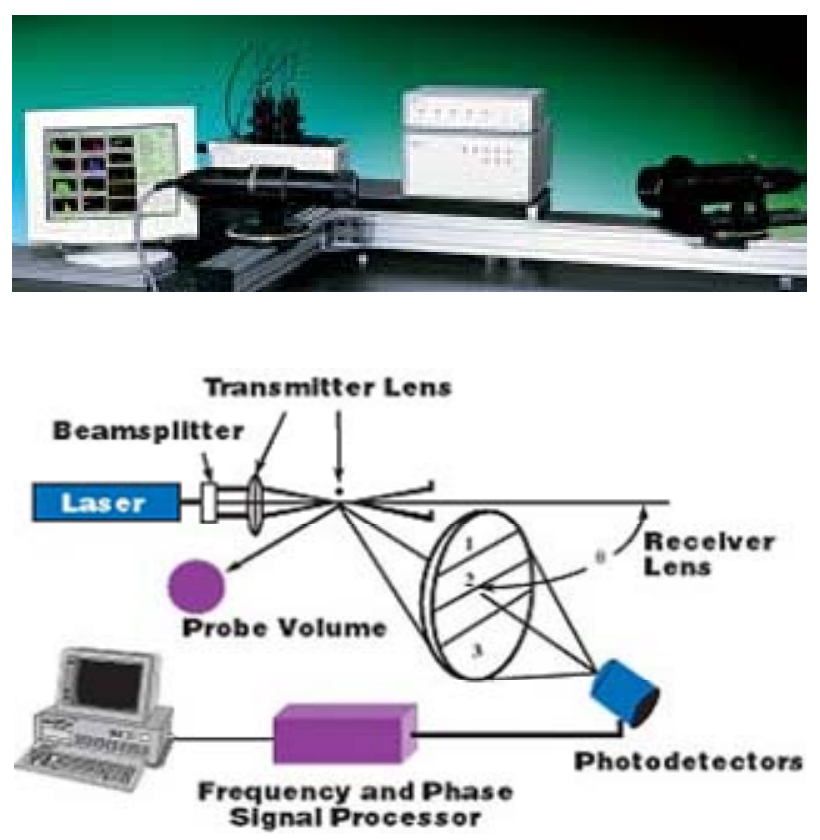

Figure 48. PDPA system (top) and measurement process (below) 
The experiments were performed using water as the spraying liquid and at two different flow rates of 2 liters/min and 3 liters/min. Typical images of the spray for these two flow rates are shown in Figure 49 and Figure 50.

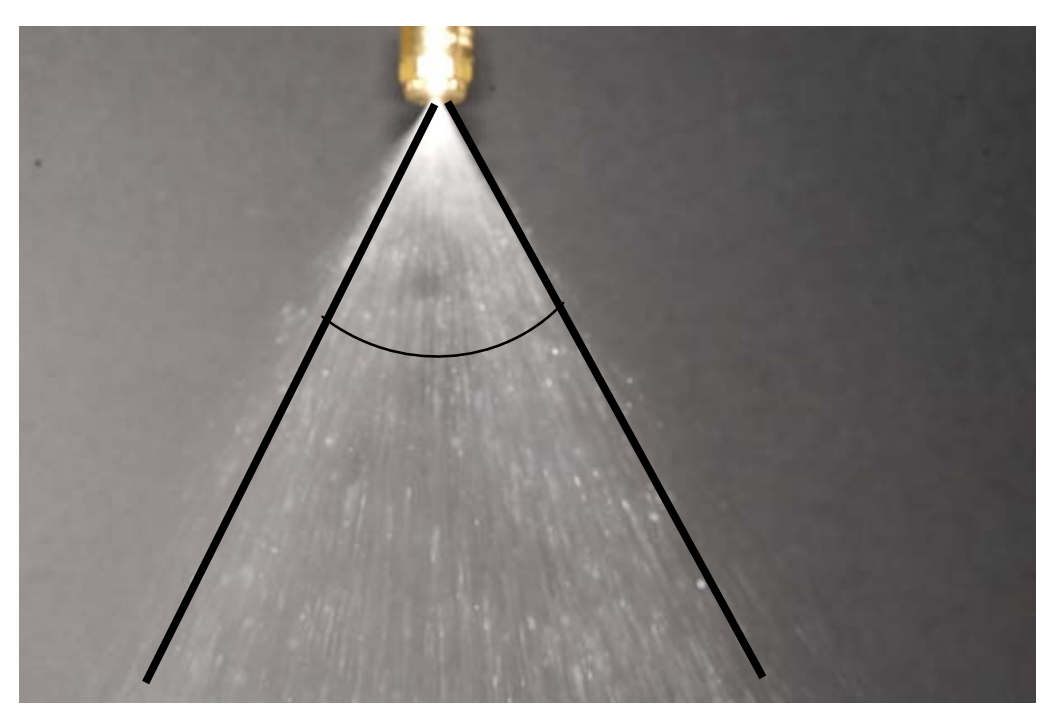

Figure 49. Spray from a full cone nozzle at 2 liters/min, Spray angle: $50^{\circ}$.

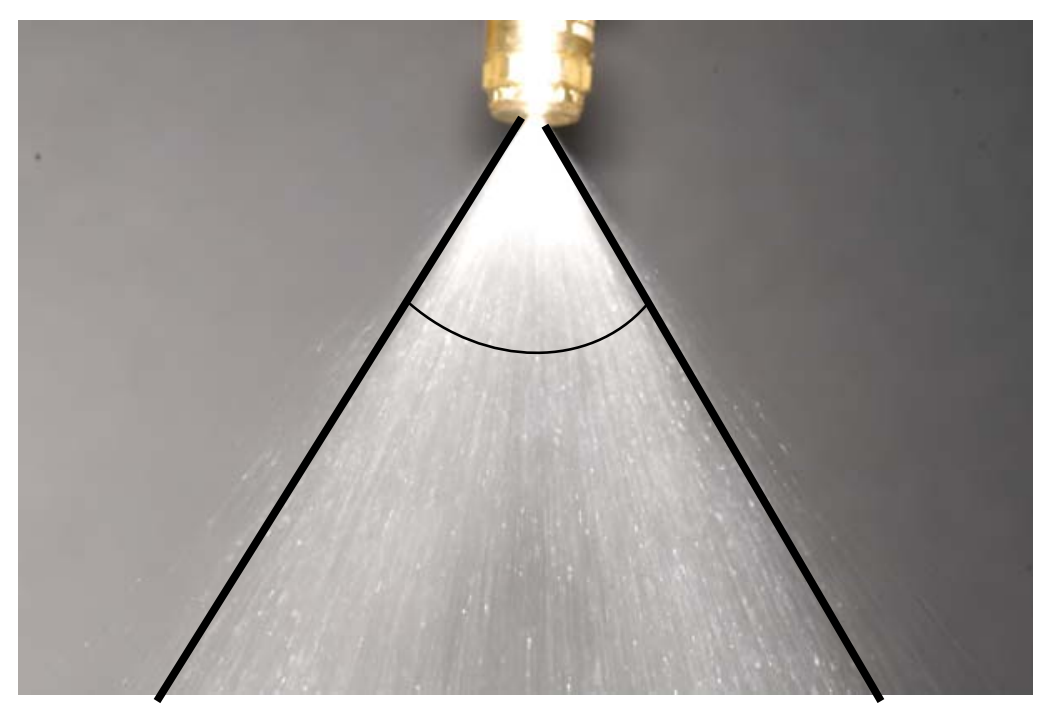

Figure 50. Spray from a full cone nozzle at 3 liters/min, spray angle $62^{\circ}$.

The statistical information obtained from these two sets of experiments is shown in Figure 51, Figure 52 and Figure 53. The following data are presented in these Figures:

- Diameter histogram

- Velocity histogram

- Frequency histogram 
- Diameter diff versus Diameter

- Statistical information about droplet diameter and velocity.

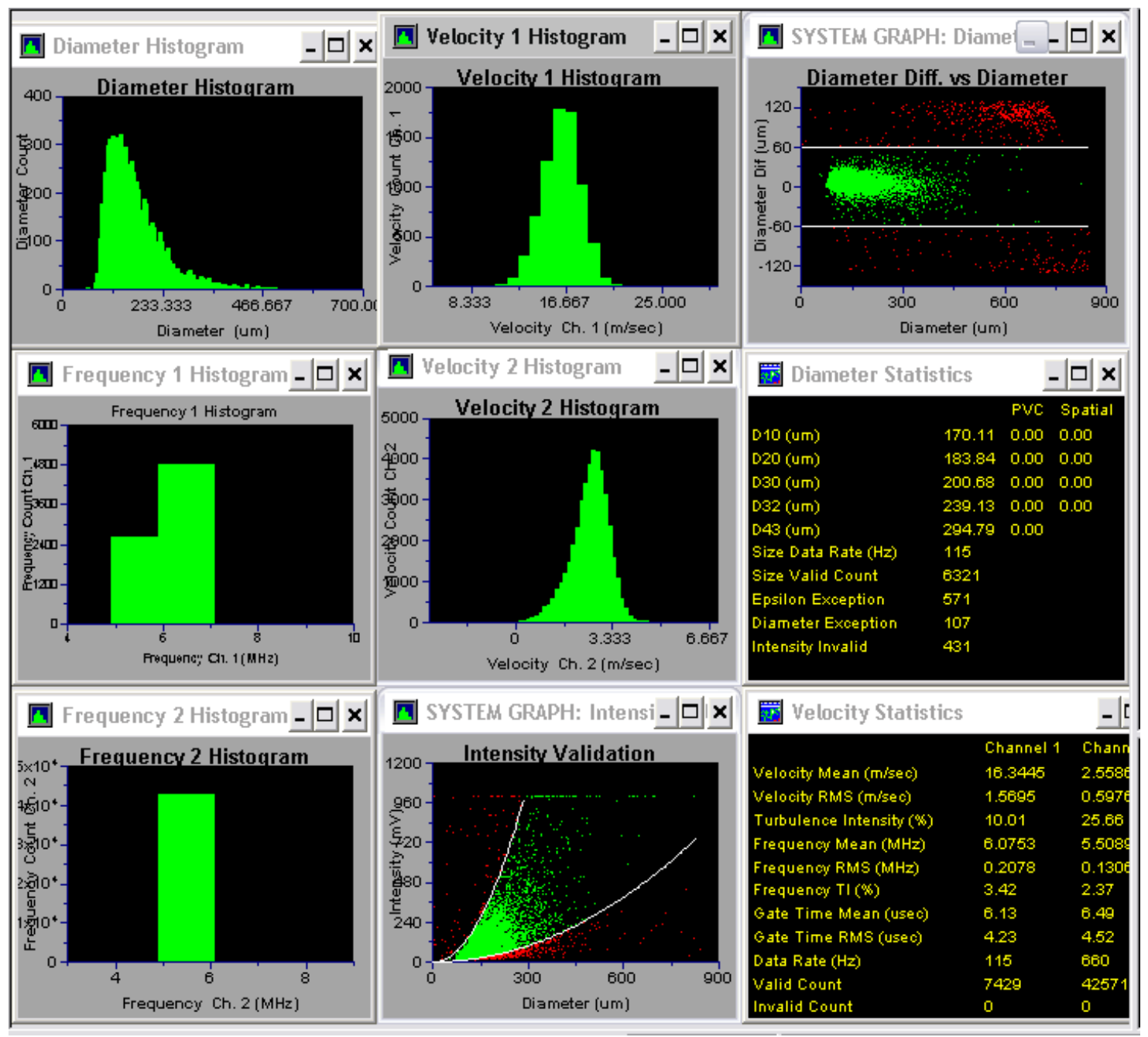

Figure 51. Typical measured information for spray, at 10 centimeter below the nozzle, for flow rate of 2 liters/min (center measurements) 


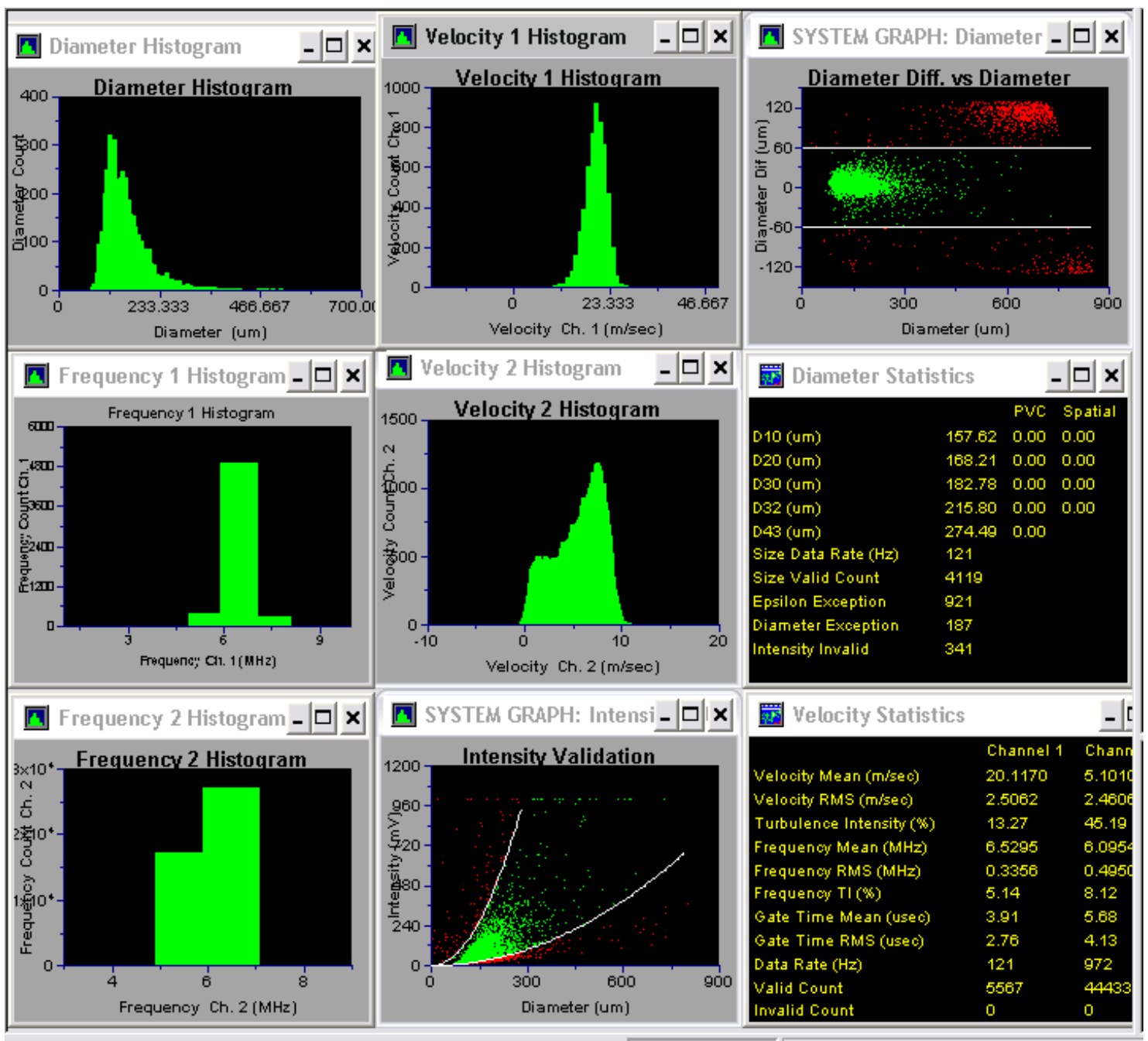

Figure 52. Typical measured information for spray, at 10 centimeter below the nozzle, for flow rate of 3 liters/min (center measurements). 


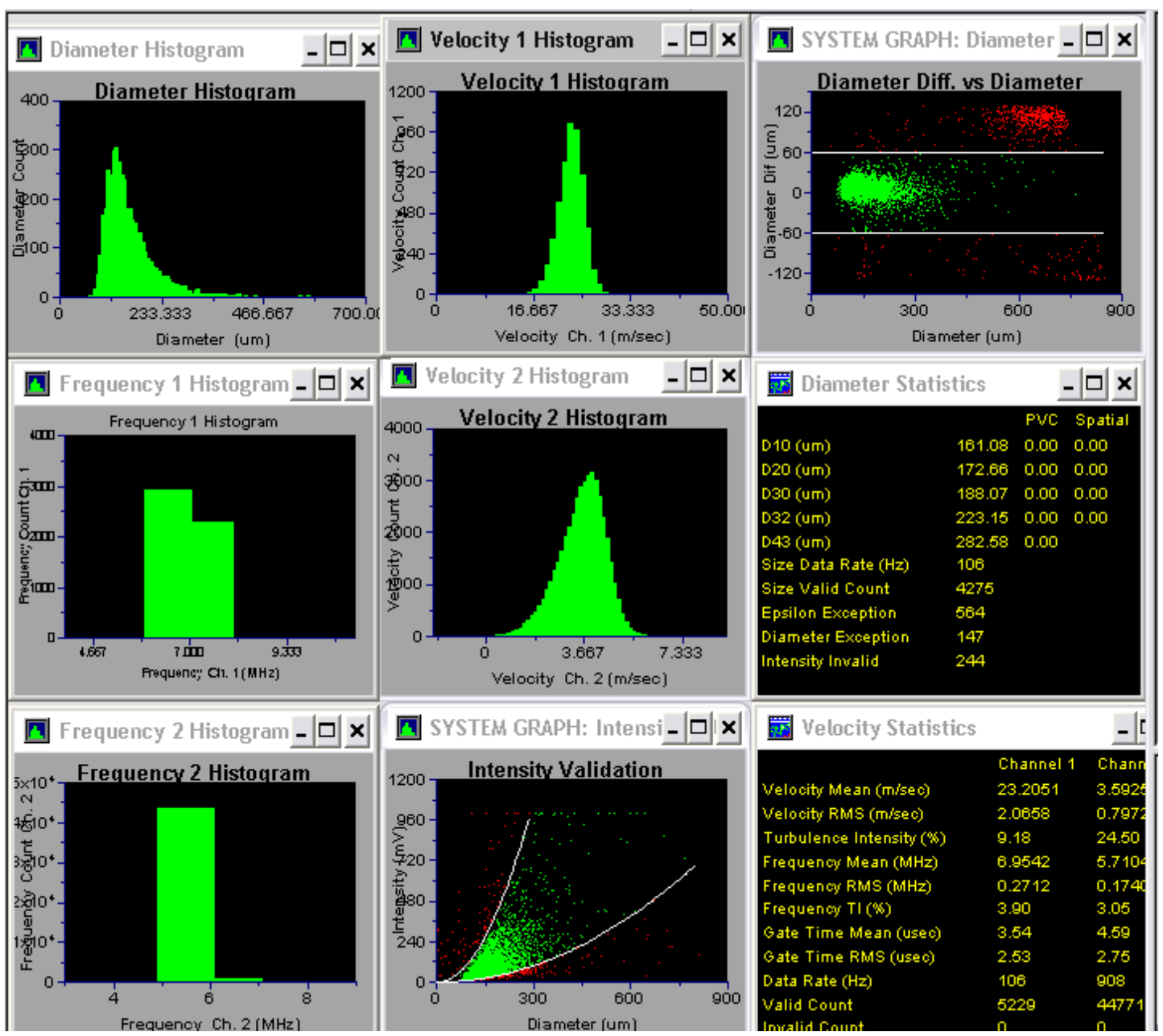

Figure 53. Typical measured information for spray, at 10 centimeter below the nozzle, for flow rate of 3 liters/min (edge measurements).

\subsubsection{Comparison of the developed code by Simulent with the experimental data}

A comparison between the simulation results and the experimental data was made and the results are shown in Table 3 and Table 4 for two flow rates of 2 liters/min and 3 liters/min, respectively. 
TABLE 3. COMPARISON BETWEEN THE EXPERIMENTAL AND SIMULATION RESULTS FOR FLOW RATE OF 2 LITERS/MIN

\begin{tabular}{lcc}
\hline & Numerical simulation & Experimental results \\
\hline Drop size $(\mu \mathrm{m})$, D10 & 190 & 170 \\
Drop size $(\mu \mathrm{m})$, D20 & 197 & 184 \\
Drop size $(\mu \mathrm{m})$, D30 & 203 & 201 \\
Drop size $(\mu \mathrm{m})$, D32 & 218 & 239 \\
Axial drop velocity $(\mathrm{m} / \mathrm{s})$ & 20 & 16.35 \\
Average spray angle & 52 & 50 \\
\hline
\end{tabular}

TABLE 4. COMPARISON BETWEEN THE EXPERIMENTAL AND SIMULATION RESULTS FOR FLOW RATE OF 3 LITERS/MIN

\begin{tabular}{ccc}
\hline & Numerical simulation & Experimental results \\
\hline Average spray angle & 58 & 62 \\
\hline
\end{tabular}

The results of the simulation for droplet size are all within $10 \%$ of the results from experimental measurements. Also note that for the case of 2 liters/min flow rate, the measurements are done for the center of the spray, in which the droplet diameters are smaller than the edge of the spray. While numerical simulation results contain all droplet information within the spray.

For the same reason the difference in droplet average velocities can be contributed to the fact that measurements were performed at the center of spray which has smaller droplet velocities. By comparing Figure 52 and Figure 53 for the flow rate of 3 liters/min, it can be seen that the average droplet velocity at the edge of the spray is higher than the velocity at the center. The simulation results cover the whole spray and not only edge or center of the spray.

The spray angles from spray measurements and from numerical simulations, nevertheless, match very well for both flow rates. 


\section{CONCLUSIONS}

During the first year, efforts within the University of Utah's project "Investigation of Pressurized Entrained-Flow Kraft Black Liquor Gasification in an Industrially Relevant Environment" focused on design and construction of a small-scale, pressurized entrained-flow gasifier for black liquor, construction of experimental devices for study of black liquor droplet development and char and smelt physical properties, and measurement of black liquor spray characteristics.

\subsection{Research Tools}

A small pilot-scale pressurized, oxygen-blown entrained-flow gasification system for black liquor was designed and built. The system was specifically designed to research the progression of black liquor during high temperature gasification. It therefore has a higher height-to-diameter ratio than a commercial gasifier, and has many ports for sampling gas and condensed phase material from the reactor. The reactor shell is designed to withstand 32 atmospheres (450 psig), and the refractory was selected to allow operation at temperatures as high as $1500^{\circ} \mathrm{C}\left(2730^{\circ} \mathrm{F}\right)$. The quench system downstream of the gasifier reactor is rudimentary, and was designed to be effective and functional, but not suitable for research on system quench design, which is outside the scope of the current program.

A system for researching the characteristics of the spray resulting from injection of black liquor and the corresponding development of liquor droplets under hot conditions was designed and constructed. The system has two main components, the liquor feed and spray system, and the heated reactor and spray characterization system. The liquor feed system comprises a liquor feed reservoir, feed pump and injection nozzle, all of which are heat-traced to allow feeding of concentrated liquor. The spray characterization system comprises a heated reactor and associated optics for characterization. A simpler system for characterizing liquor spray under cold conditions, which involves imaging the silhouette of the spray against a strong backlight, has also been constructed and testing has been performed with this system.

A system to create a monodisperse stream of very small black liquor droplets has been designed to allow detailed study of particle size and shape development and char and pyrolysis gas properties in a hot environment. A prototype single droplet injector based on droplet formation by high velocity sharing was designed, built and optimized. A smaller injector, suitable for insertion into a high temperature drop tube with optical access, was designed.

A novel system for investigating physical properties of molten black liquor smelt was designed. The system comprises a small muffle furnace with a 1.25-inch hole drilled through the top. A crucible of black liquor smelt is placed inside the furnace and heated until it is molten. The viscosity of the molten smelt can be measured using a modified viscometer shielded from the heat of the furnace. Emissivity of the smelt can be measured using a radiometer for total emissivity or an FTIR for spectral emissivity.

\subsection{Liquor Spray Characteristics}

Black liquor can successfully be fed through a twin-fluid atomizing nozzle. Higher atomizing air pressures correspond to smaller droplets. Atomization is more effective when the liquor is fed through the central channel, with atomizing air being supplied annularly around the liquor stream, than when atomizing air is fed through the central channel and liquor is introduced through the annular channel 
surrounding this. The spray angle increases with increasing atomizing air pressure up to a point ( 22 psig), after which additional atomizing air pressure has little effect.

The liquor spray appears to have two distinct types of droplets. One is a very fine, well dispersed "mist" of very small droplets that exist already at the exit from the injector tip. The other is much larger strands, or ligaments, of liquor. These ligaments are observed to either break apart into smaller, though still large, droplets, or to re-shape themselves into more spherical-shaped droplets having the same volume as the original ligament. This ligament formation and resulting formation of very large droplets is one of the significant challenges to obtaining a monodisperse distribution of particle sizes.

\subsection{Liquor Spray Modeling}

A four-stage computational model was developed by Simulent, Inc. to simulate liquor injection through a pressure-atomized, full-cone nozzle into the small-scale entrained-flow reactor built under this program. The model considered flow within the nozzle, including the influence of swirl on flow and pressure at the nozzle exit. The transition zone between the nozzle outlet and the bulk reactor environment was modeled, and finally this model was integrated with a model of droplet development Two flow rates of liquor were considered, 2 and 3 liters per minute. The simulations considered both the geometry of the system and rheological properties of the liquor. Results based on simulation with water were very similar to specifications provided by the nozzle manufacturer, which provided a level of confidence in the model. Droplet size was centered near 280 microns for the lower liquid flow rate, and around 215 microns for the higher flow rate. Spray angle was larger for the higher flow rate. These results indicate that higher flow rates, or alternately smaller nozzles, increase pressure drop across the nozzle and provide a more consistent and generally smaller droplet size distribution that will cover the reactor volume more effectively due to the wider spray angle.

\section{ACKNOWLEDGEMENTS}

This project is funded through a cooperative agreement from the United States Department of Energy's Office of Biomass Programs. The support of OBP and the managing group at the National Energy Technology Laboratory is greatly appreciated. Weyerhaeuser Company and Chemrec AB are acknowledged for their collaborative input and assistance with design of the entrained-flow system. Jim Keiser at Oak Ridge National Laboratories, Doug Singbeil at Paprican and Bill Headrick at University of Missouri - Rolla are thanked for their assistance with selection of materials to use in the system. Plibrico Company provided the refractory for the gasifier, and their generous contribution is appreciated.

\section{REFERENCES}

1. Lasheras, J. C., E. J. Hopfinger 2000, Liquid Jet Instability and Atomization on a Coaxial Gas Stream, Annu. Rev. Fluid Mech. 2000. 32:275-308.

2. Kankkunen, A., P. Miikkulainen 2003, Particle Size Distribution of Black Liquor Sprays with a High Solids Content in Recovery Boilers, IFRF Combustion Journal, Article Number 200308.

3. Bousfield, D.W. 1990, Research on Droplet Formation for Application to Kraft Black Liquors, Tech. Rept. \#5, U.S. DOE Contract AC02-83CE40626, The University of Maine, Orono, Maine.

4. P.K. Senecal, D.P. Schmidt, I. Nouar, C.J. Rutland, R.D. Reitz, M.L. Corradini; "Modeling High Speed Viscous Liquid Sheet Atomization"; International Journal of Multiphase Flow 25 (1999) 1073-1097. 